\title{
Dual Targeting of the Mesenchymal and Amoeboid Pathways: A Viable Therapy against Metastatic Breast Cancer
}

Brandon C. Jones

Follow this and additional works at: https://researchrepository.wvu.edu/etd

\section{Recommended Citation}

Jones, Brandon C., "Dual Targeting of the Mesenchymal and Amoeboid Pathways: A Viable Therapy against Metastatic Breast Cancer" (2017). Graduate Theses, Dissertations, and Problem Reports. 5905. https://researchrepository.wvu.edu/etd/5905

This Dissertation is protected by copyright and/or related rights. It has been brought to you by the The Research Repository @ WVU with permission from the rights-holder(s). You are free to use this Dissertation in any way that is permitted by the copyright and related rights legislation that applies to your use. For other uses you must obtain permission from the rights-holder(s) directly, unless additional rights are indicated by a Creative Commons license in the record and/ or on the work itself. This Dissertation has been accepted for inclusion in WVU Graduate Theses, Dissertations, and Problem Reports collection by an authorized administrator of The Research Repository @ WVU. For more information, please contact researchrepository@mail.wvu.edu. 
Dual Targeting of the Mesenchymal and Amoeboid Pathways:

A Viable Therapy against Metastatic Breast Cancer

Brandon C. Jones

Dissertation submitted to the

School of Medicine

at West Virginia University

in partial fulfillment of the requirements

for the degree of

Doctor of Philosophy

in

Biochemistry \& Molecular Biology

Elena Pugacheva, Ph.D., Chair

J. Michael Ruppert, M.D., Ph.D.

Maxim Sokolov, Ph.D.

Michael Schaller, Ph.D.

Scott Weed, Ph.D.

Graduate Program in Biochemistry

West Virginia University School of Medicine

Morgantown, West Virginia

2017

Keywords: NEDD9, mesenchymal, amoeboid, breast cancer, metastasis

(c) 2017 Brandon C. Jones 


\section{ABSTRACT \\ Dual Targeting of the Mesenchymal and Amoeboid Pathways: A Viable Therapy against Metastatic Breast Cancer}

\section{Brandon C. Jones}

Metastasis from the primary tumor site is the major cause of death in breast cancer, and acquisition of migration capacity is a key element for successful metastasis. Recently, it was found that expression of NEDD9, a focal adhesion associated scaffolding protein, could be used to switch between two types of single cell movement known as mesenchymal and amoeboid. Control of this "switch" can potentially open up new avenues of treatment against cancer metastasis. Simultaneous inhibition of both types of single cell movement may prevent cancer migration, thus decreasing cancer spreading and increasing survival of cancer patients. For example, forcibly pushing the switch toward amoeboid migration in combination with treatment against the kinase ROCK, a key component of amoeboid movement, might prove to be a vital strategy against metastasis. Currently, such strategies are not available in clinical practice. This project seeks to fill this gap in knowledge and provide new migration-based strategies to treat breast cancer metastases by 1) defining the impact of NEDD9 expression on regulation of mesenchymal invasion in breast cancer cells, 2) deciphering the mechanism and characterizing the key downstream effectors of NEDD9-dependent signaling that contribute to breast cancer mesenchymal migration, and 3) determining the anti-metastatic therapeutic benefit of inhibiting both mesenchymal and amoeboid breast cancer cell movement in vitro and in vivo. 


\section{ACKNOWLEDGMENTS}

I would like to thank everyone who has supported and encouraged me throughout my time at West Virginia University. I want to acknowledge my research graduate committee for their consultation and insight, including most notably my mentor, Dr. Elena Pugacheva, whose guidance, leadership, and motivation has allowed me to become a successful scientist. I would also like to thank my lab colleagues for their invaluable assistance and discussions, both scientific and informal, as well as my family and friends for their confidence and encouragement. Finally, I would like to thank all of the brave mice who helped to make this work possible - you're the real heroes. 


\section{TABLE OF CONTENTS}

ABSTRACT ii

ACKNOWLEDGMENTS iii

LIST OF FIGURES vi

GLOSSARY vii

CHAPTER 1: LITERATURE REVIEW.

I. Breast Cancer.

1.1. Importance of Breast Cancer Research ......................

1.2. Triple Negative Breast Cancer.................................

II. Metastasis and Types of Invasion

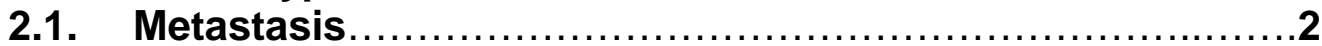

2.2. Overview of Mesenchymal Invasion............................

2.3. Overview of Amoeboid Invasion .............................

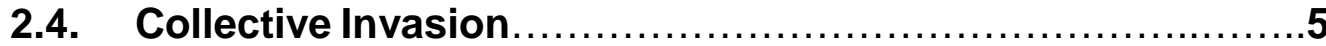

III. Molecular Machinery of Mesenchymal and Amoeboid Invasion

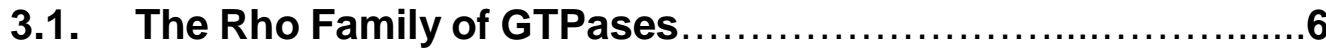

3.2. Proteins of the Mesenchymal Pathway........................

3.3. NEDD9 Promotes Mesenchymal Movement through an Additional AURKA-Driven Signaling Pathway................11

3.4. Proteins of the Amoeboid Pathway.........................12

3.5. Regulation between Mesenchymal and Amoeboid Pathways 14

IV. Treatment of Breast Cancer Invasion and Metastasis

4.1. Targeting the Mesenchymal Pathway......................15

4.2. Targeting the Amoeboid Pathway.........................16

4.3. Dual Pathway Targeting ......................................

4.4. Comparisons of Mouse Models ...........................18

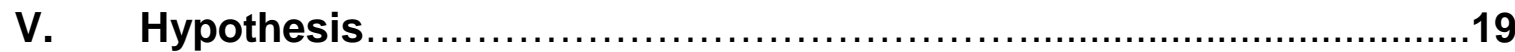

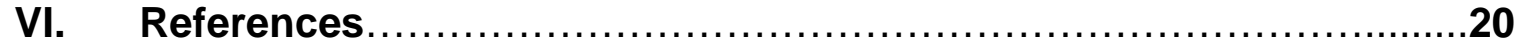

CHAPTER 2: PAPER PUBLISHED IN MOLECULAR CANCER RESEARCH, $2017 \ldots \ldots$

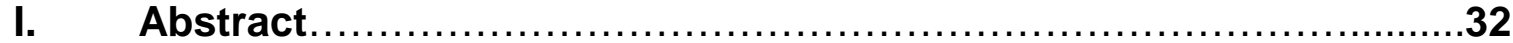

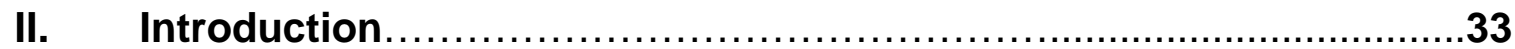

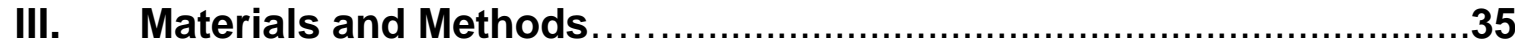




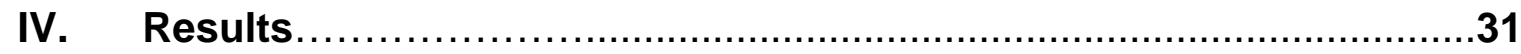

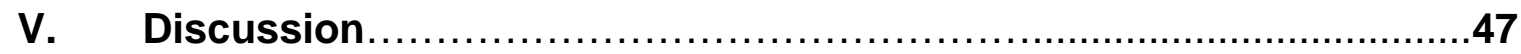

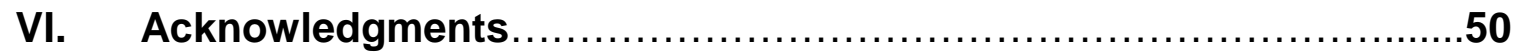

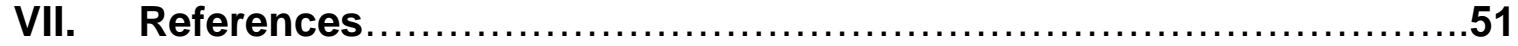

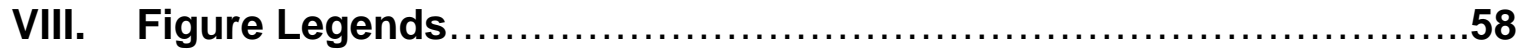

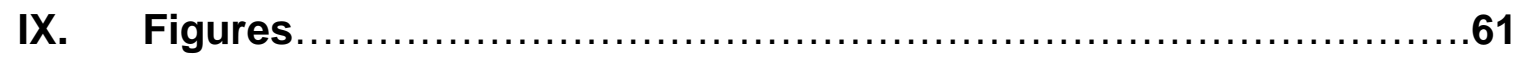

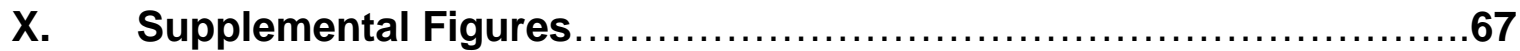

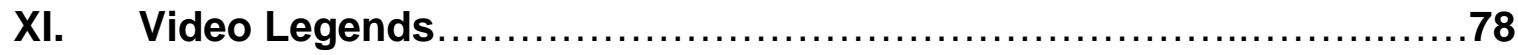

XII. Supplemental Materials and Methods ..............................8

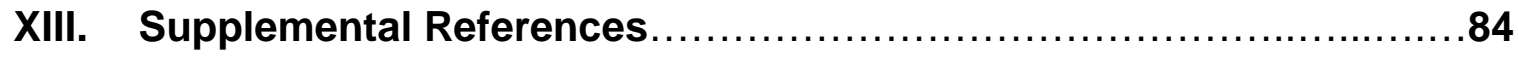

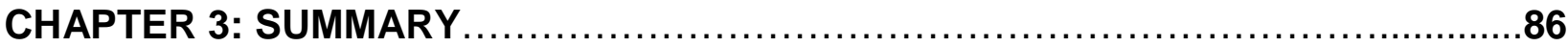




\section{LIST OF FIGURES}

\section{CHAPTER 2:}

Figure 1: TNBC cell morphology changes upon NEDD9 and ROCK inhibition.....

61

Figure 2: NEDD9 depletion increases phosphorylation of MLC2 and decreases

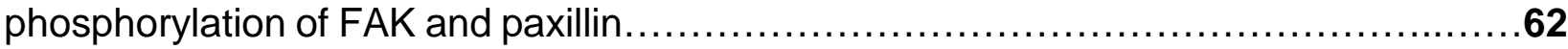

Figure 3: NEDD9 regulates AURKA-driven phosphorylation of CTTN and stability of actin

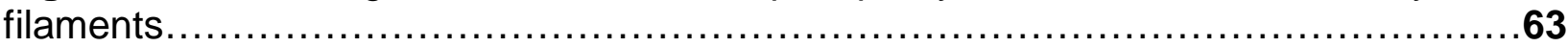

Figure 4: NEDD9 drives Rac1 activity through interaction with GEF VAV2 $\ldots \ldots \ldots \ldots \ldots . \ldots 4$

Figure 5: Simultaneous targeting of NEDD9 and ROCK/RhoA hinders breast cancer cell motility/invasion in vitro.

Figure 6: Simultaneous targeting of NEDD9 and ROCK hinders breast cancer cell

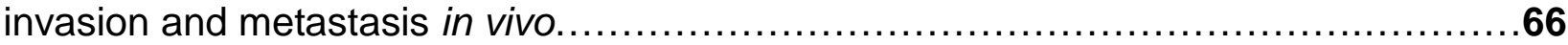

Figure S1: NEDD9 depletion causes a switch to amoeboid morphology ...................67

Figure S2: NEDD9 depletion decreases phosphorylation of focal adhesion proteins in

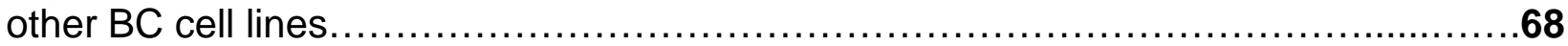

Figure S3: NEDD9 depletion affects vinculin-containing focal adhesion dynamics.......69

Figure S4: NEDD9 depletion affects talin-containing focal adhesion dynamics ............70

Figure S5: AURKA phosphorylates CTTN in breast cancer cells......................71

Figure S6: NEDD9 depletion decreases Rac1 activity in other breast cancer cell

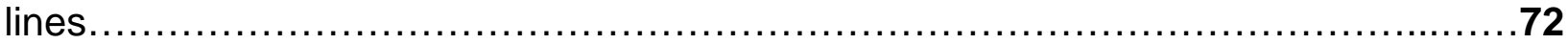

Figure S7: Depletion of NEDD9 via CRISPR-Cas9 system and overexpression of CARhoA decreases cell invasion and increases round amoeboid phenotype ................73

Figure S8: Simultaneous inhibition of mesenchymal and amoeboid pathways through NEDD9 and RhoA knockdown hinders cell invasion in vitro....

Figure S9: Depletion of NEDD9 hinders invasion of other breast cancer cell lines in vitro. 75

Figure S10: AURKA inhibition hinders breast cancer cell invasion......................76

Table S1: Co-immunoprecipitation results of NEDD9 with multiple GEF proteins.........77 


\section{GLOSSARY}

aa

a-tub

ACTN4

AGC family

AMT

ANOVA

Arp2/3

ATP

AURKA

BC

BLI

BM

BMI1

BRCA

BSA

CA

Cas-L

Cas9

CB

CD

CITED1

CRISPR

CTCs

CTTN

CXCL12

CXCR4

DEF6

DIC

DIP
Amino acids

Alpha-tubulin

Alpha-actinin 4

Protein kinase A, G, C (PKA, PKG, PKC)-related family

Amoeboid-mesenchymal transition

Analysis of variance

Actin-related proteins 2/3

Adenosine triphosphate

Aurora kinase A

Breast cancer

Bioluminescent imaging

Basement membrane

B cell-specific Moloney murine leukemia virus integration site 1

Breast cancer

Bovine serum albumin

Constitutively-active

Crk-associated substrate-like protein

CRISPR-associated protein 9

Cell body

Cluster of differentiation

Cbp/p300 interacting transactivator with Glu/Asp rich carboxy-terminal domain 1

Clustered regularly interspaced short palindromic repeats Circulating tumor cells

Cortactin

C-X-C motif chemokine ligand 12

C-X-C motif chemokine receptor 4

Differentially expressed in FDCP (mouse homolog) 6

Differential interference contrast

Diaphanous interacting protein 


\begin{tabular}{|c|c|}
\hline DN & Dominant-negative \\
\hline DOCK & Dedicator of cytokinesis \\
\hline ECM & Extracellular matrix \\
\hline ECT2 & Epithelial cell transforming 2 \\
\hline EDTA & Ethylenediaminetetraacetic acid \\
\hline EGFR & Epidermal growth factor receptor \\
\hline EMT & Epithelial-mesenchymal transition \\
\hline Endo180 & Endocytosis receptor, $180 \mathrm{kDa}$ \\
\hline Endog & Endogenous \\
\hline EphA2 & Ephrin type A receptor 2 \\
\hline ER & Estrogen receptor \\
\hline ERK & Extracellular signal-regulated kinase \\
\hline Exog & Exogenous \\
\hline F-actin & Filamentous actin \\
\hline FA & Focal adhesion \\
\hline FACS & Fluorescence-activated cell sorting \\
\hline FAK & Focal adhesion kinase \\
\hline fbFA & Fibrillar adhesion \\
\hline FBS & Fetal bovine serum \\
\hline FHOD1 & Formin homology 2 domain containing 1 \\
\hline FilGAP & Filamin A -binding RhoGTPase-activating protein \\
\hline FMNL2 & Formin-like protein 2 \\
\hline GAP & GTPase-activating protein \\
\hline GAPDH & Glyceraldehyde 3-phosphate dehydrogenase \\
\hline GDP & Guanosine diphosphate \\
\hline GEF & Guanine nucleotide exchange factor \\
\hline GEM & Genetically engineered model \\
\hline GFP & Green fluorescent protein \\
\hline G-actin & Globular actin \\
\hline G-LISA & G-protein linked immunosorbent assay \\
\hline GST & Glutathione S-transferase \\
\hline GTP & Guanosine-5'-triphosphate \\
\hline H\&E & Hematoxylin and eosin \\
\hline
\end{tabular}




\begin{tabular}{|c|c|}
\hline HA tag & Hemagglutinin tag \\
\hline HDAC6 & Histone deacetylase 6 \\
\hline HEF1 & Human enhancer of filamentation 1 \\
\hline Hem-1 & Hematopoietic protein 1 \\
\hline HER2 & Human epidermal growth factor receptor 2 \\
\hline HIF-1-alpha & Hypoxia-inducible factor 1 alpha \\
\hline HNSCC & Head and neck squamous cell carcinoma \\
\hline HRP & Horseradish peroxidase \\
\hline IF & Immunofluorescence \\
\hline IgG & Immunoglobulin G \\
\hline IP & Immunoprecipitation \\
\hline IVIS & In vivo imaging system \\
\hline kDa & Kilodalton \\
\hline KO & Knockout \\
\hline LE & Leading edge \\
\hline LIMK1 & LIM domain (Lin11, IsI-1 \& Mec-3) kinase 1 \\
\hline MARCKS & Myristoylated alanine rich protein kinase $\mathrm{C}$ substrate \\
\hline MAT & Mesenchymal-amoeboid transition \\
\hline MLC2 & Myosin regulatory light chain 2 \\
\hline MMP & Matrix metalloproteinase \\
\hline MMPI & Matrix metalloproteinase inhibitor \\
\hline NA & Nascent adhesion \\
\hline NEDD9 & $\begin{array}{l}\text { Neural precursor cell expressed developmentally down- } \\
\text { regulated protein } 9\end{array}$ \\
\hline Net1 & Neuroepithelial cell-transforming gene 1 protein \\
\hline NG2 & Neuron-glial antigen 2 \\
\hline NSG & NOD scid gamma (NOD.Cg-Prkdc ${ }^{\text {scid }} \| 2 \mathrm{rg}^{t m 1 W_{j} /} / \mathrm{SzJ}$ ) \\
\hline Oct-4 & Octamer-binding transcription factor 4 \\
\hline p130cas & 130 kilodalton Crk-associated substrate \\
\hline PAK & p21-activated kinase \\
\hline PBD & p21-binding domain \\
\hline PBS & Phosphate-buffered saline \\
\hline PD & Pulldown \\
\hline
\end{tabular}




\begin{tabular}{ll} 
PDX & Patient-derived xenograft \\
PKC-alpha & Protein kinase C alpha \\
PPM1F & Protein phosphatase, Mg2+/Mn2+ dependent 1F \\
PR & Progesterone receptor \\
PVDF & Polyvinylidene difluoride \\
RAC1 & Ras-related C3 botulinum toxin substrate 1 \\
RASAL2 & Ras protein activator like 2 \\
RBC & Red blood cell \\
RFI & Relative fluorescence intensity \\
RFP & Red fluorescent protein \\
RHOA & Ras homolog gene family, member A \\
ROCK & Rho associated coiled-coil containing protein kinase \\
SEM & Standard error of mean \\
SgRNA & Single guide RNA \\
SH3 domain & Src-homology 3 domain \\
shRNA & Short hairpin RNA \\
SiRNA & Small interfering RNA \\
TBS & Tris buffered saline \\
TGF-beta & Transforming growth factor beta \\
Tiam1 & T-cell lymphoma invasion and metastasis 1 \\
TNBC & Triple negative breast cancer \\
uPAR & Urokinase plasminogen activator receptor \\
VCA & Verprolin, central, acidic \\
VEGF & Vascular endothelial growth factor \\
WASP & Wiskott-Aldrich Syndrome protein \\
WAVE & WASP-family verprolin homologous protein \\
WB & Western blot \\
WCL & Whole cell lysate \\
WT & Wild type \\
XG & Xenograft \\
\hline
\end{tabular}




\section{CHAPTER 1: LITERATURE REVIEW}

\section{l. Breast Cancer}

\section{1: Importance of Breast Cancer Research}

Despite all advances in the field of breast cancer research, breast cancer remains the most commonly diagnosed cancer for women in the United States, as well as the second highest cause of cancer death in women behind lung cancer (1). It is estimated that 1 in 8 women (12.3\%) in the United States will be diagnosed with breast cancer in their lifetime (2). This risk increases with age - the median age for women diagnosed with BC was 61 years old in 2015 (2). The American Cancer Society projects that in 2017 there will be over 250,000 newly diagnosed cases and over 40,000 new deaths as a result of invasive breast cancer (cancer.org). These startling statistics showcase a critical need for rapid advancements in therapeutic strategies against the invasive potential of this disease.

\section{2: Triple Negative Breast Cancer}

The search for targetable biomarkers of breast cancer has yielded a few favorable targets with encouraging therapies. Around $60-70 \%$ of breast cancers have been found to have high expression of hormone receptors for estrogen or progesterone (3). Much success has been had against such cancers using hormone-targeting therapies like tamoxifen, which binds and inhibits estrogen receptor signaling, or aromatase inhibitors which suppress estrogen production $(4,5)$. Another $15 \%$ of breast cancers are positive for amplification of the oncogene HER2 (also referred to as HER2/neu or erbB2) (3). This gene codes for a receptor tyrosine kinase that complexes with other members of its family (EGFR/erbB1, erbB3, and erbB4) on the cell surface. Treatment against HER2-positive cancers has had much success using monoclonal antibody trastuzumab therapy $(6,7)$. 
Breast cancers that are negative for expression of ER, PR, and HER2 are referred to as triple negative breast cancer (TNBC). TNBC comprises about $15-20 \%$ of all BC and is associated with increased tumor cell proliferation, substantial invasion and metastasis, and much poorer patient survival in comparison to other BCs $(8,9)$. TNBC is also associated with a higher incidence in mutation of the breast cancer tumor suppressor genes BRCA1 and BRCA2, which help maintain DNA integrity and control proper cell division/apoptosis $(10,11)$.

The diminished survival rate of TNBC is not only due to the rampant aggressiveness of the disease, but also because of a decrease in the extent of applicable therapies. The lack of ER/PR/HER2 diminishes the number of available proven targeted treatment options, with cytotoxic chemotherapy being the main approved regimen (8). Circumstances of chemoresistance restrict potential remedies even further, unfortunately leaving very limited options. While breast cancer death rates have been on the decline in older women, they have remained fairly steady for women younger than 50 (cancer.org). This may be linked to TNBC being more commonly diagnosed in younger women ( $<50$ years), who do not have as many treatment options as other BCs $(8,10)$.

\section{Metastasis and Types of Invasion}

\section{1: Metastasis}

Metastasis of cancer cells from the primary tumor site is the most life-threatening aspect in the majority of diagnosed cancer cases. This involves a phenomenon known as epithelial-tomesenchymal transition or EMT, where normal epithelial cells lose their polarity and cell-cell adhesions to become invasive mesenchymal cells (12). These cells can then invade neighboring tissues or break through the basement membrane into the blood stream by intravasation and be carried to a distant site in the body for further colonization. Once cancerous cells are able to enter the blood stream, survival rate of the patient is likely to decrease at an accelerated rate. 
Cancer cells are capable of migrating either collectively or individually (13-16). Individual invasive cells lose all cell-cell adhesions and are known to be able to invade via two different methods of migration known as mesenchymal and amoeboid (17-19). Depending upon conditions such as extracellular matrix (ECM) composition, pore size, and rigidity of the cell microenvironment, these two methods can be used interchangeably by the same cell population in order to invade into different areas $(14,18)$. For example, since the interstitial matrices of the human body are heterogeneous - ranging from loose fibrillary regions to dense connective tissue

- macrophages have been shown to utilize both mesenchymal and amoeboid migration to navigate such environments and reach different tissue sites (20-22). The switching between these two modes is referred to as mesenchymal-to-amoeboid transition (MAT) and amoeboidto-mesenchymal transition (AMT).

\section{2: Overview of Mesenchymal Invasion}

Mesenchymal migration is characterized by an elongated cell phenotype and the construction of lamellipodia actin structures at the mobile leading edge of the cell (17). Fibroblasts are commonly associated with this type of cell movement (23). The lamellipodium at the leading edge beneath the membrane is a typically broad treadmilling branched-actin meshwork, and helps to propel the cell across the microenvironment (24). Cell-matrix adhesion interactions, consisting of integrins and signaling protein clusters at the membrane that act as hubs between the extracellular matrix outside and the actin cytoskeleton inside, are quite strong in mesenchymal movement (17). This allows the leading edge of the cell to reach out, get a firm "grip" with the focal adhesions, and then follow up by pulling in the cell rear (23). In addition to this, mesenchymal movement is also characterized by the formation of invadopodia (25). These long actin basal ventral membrane protrusions extend from the cell membrane for the purpose of matrix degradation. Through the activation of enzymes called matrix metalloproteinases or 
MMPs at invadopodia membrane sites, the cell can cut holes through the ECM in order to clear a viable path for cell movement $(17,23)$. This ability to degrade matrix makes mesenchymal movement less restricted by the pore size of any given substratum, even allowing it to dig into bones (26).

MMPs are especially useful for invasion of the basement membrane (BM), which is a dense matrix that lines the epithelium and endothelium layers and can act as a physical barrier to metastatic cells invading and entering the circulatory system. A dense reconstituted protein mixture that is prepared from mouse sarcoma is often used to experimentally test the ability of mesenchymal cells to invade basement membrane. This protein mixture, most commonly marketed under the name Matrigel, contains many ECM proteins including laminin, collagen IV, entactin, fibronectin, and vitronectin, thus making it a good representation of BM (27). The density and rigidity of this matrix makes mesenchymal movement ideal for invasion in such applications.

\section{3: Overview of Amoeboid Invasion}

Amoeboid migration is characterized by a more rounded cell phenotype and the contractility of cortical actomyosin fibers $(17,28)$. These tense contractile forces aid in the movement of the cell across matrices and can also result in representative blebbing of the cell membrane. This method of movement does not usually utilize matrix metalloproteinases, and instead deforms cell shape to squeeze through preexisting gaps or uses its contractile forces to slightly widen holes in the ECM (29). Due to its lack of use of MMPs, amoeboid movement is restricted in tissue with rigid highly crosslinked matrices like BM or bone, instead being most suited for invasion through less dense and more flexible microenvironments such as collagen I (20). Collagen $I$ is the most abundant protein in human connective tissue and breast microenvironment, making it an excellent physiological representation of tumor 
microenvironment when used in experimental studies (30). Common cells to use this type of movement are leukocytes such as neutrophils or monocytes, which do not require MMP enzymes to freely navigate through the flowing blood stream (23).

Another point of difference is that cell-matrix adhesion interactions are diffuse and thus overall weaker in amoeboid cells in comparison to mesenchymal cells (17). This may provide an explanation for why amoeboid movement has been shown to be faster than mesenchymal in some reports, as the cells could quickly rearrange focal adhesions while rolling through existing holes in the ECM. The speed at which amoeboid cells can move is heavily linked to their microenvironment and the pore size of the extracellular matrix. The smaller the pore, the more difficult it is for the cell to deform its shape and squeeze through. The greatest limiting factor for the cell is the deformation of its nucleus, which must deform enough to squeeze through tight spaces but also be resilient enough to not rupture $(28,31)$. Complete arrest of amoeboid cell migration has been shown to occur when the pore size reaches about $10 \%$ of the nuclear cross section - for tumor cells, this is typically about $7 \mu \mathrm{m}^{2}(28)$. Nuclear lamin concentrations have been shown to play a large role in nuclear deformability regulation during amoeboid movement (31). Lamin proteins make up the main structural component of the nucleus, where they line the inside of the nuclear membrane to provide mechanical stability and scaffolding functions for protein and chromatin binding (32). Loss of lamin has no effect on migration ability through large pores, but severely hinders invasion through small pores due to compromise of the nuclear envelope. Likewise, too high of a lamin concentration makes it more difficult for the nucleus to deform, which can also hinder amoeboid invasion.

\section{4: Collective Invasion}

In collective migration, cells actually retain much of their epithelial characteristics such as cell-cell adhesions and invade in bonded layers. The cells at the leading edge of the sheet 
typically have mesenchymal and proteolytic characteristics that allow for degradation of the matrix and pulling along of the sheet. Common physiological uses for this type of cell migration in the body are in embryonic development and wound healing. This type of invasion is prominent in melanoma, large cell lung cancer, epithelial prostate cancer, and most commonly in squamous cell carcinoma (33).

\section{Molecular Machinery of Mesenchymal and Amoeboid Invasion}

\section{1: The Rho Family of GTPases}

The Rho family of GTPases, which is a subfamily of the Ras superfamily, is a class of small signaling G proteins ( $21 \mathrm{kDa})$ known to heavily regulate intracellular actin dynamics and have roles in multiple functions including cell motility, cytoskeletal management, wound healing, cytokinesis, and organelle development (23). In mammals, over 20 members of this family have been identified, but the most common and extensively characterized are Rac1, RhoA, and cdc42 (34). These proteins have been found to affect formation of lamellipodia/membrane ruffling, stress fibers, and filopodia, respectively (23).

GTPases act as signaling switches by first binding guanosine triphosphate (GTP) and then binding various downstream effectors (24). To deactivate the signal, GTP is hydrolyzed by the protein into guanosine diphosphate (GDP), and the GTPase dissociates from the effector. These GTP- and GDP-bound states of GTPases are regulated by two different protein families: guanine nucleotide exchange factors (GEFs) which prime GTPases through facilitating the switching out of GDP for GTP, and GTPase-activating proteins (GAPs) which turn off GTPases through stimulation of their GTPase enzyme activity and subsequent hydrolysis of GTP to GDP (34).

The mesenchymal and amoeboid pathways exhibit a competing relationship between the activities of Rac1 and RhoA GTPases $(35,36)$. Mesenchymal phenotype has been classified as 
having high activity of Rac1, while amoeboid phenotype has high activity of RhoA (36). Both Rac1 and RhoA have their own subfamilies within the greater Rho family of GTPases, but Rac1 and RhoA have been identified as the most important and main contributors to the mesenchymal/amoeboid motilities. The Rac-related subfamily includes Rac1, Rac2, and Rac3, which all share $80 \%$ sequence identity (23). While Rac1 is ubiquitously expressed throughout the body, Rac2 is only expressed in hematopoietic cells, where it has a role in NADPH oxidase activation and formation of reactive oxygen species (ROS) (23). Rac3 is expressed highly in brain, where it is thought to have a role in neuronal differentiation (37). The Rho-related subfamily, sharing $85 \%$ identity, consists of RhoA, RhoB, and RhoC $(23,38)$. All 3 members have been found to be ubiquitously expressed, but their subcellular localization varies (34). RhoA and RhoC localize to the plasma membrane, while RhoB localizes to endosomal membranes (39). This is thought to be due to their differences in 15 amino acids at the Cterminal, where they exhibit the highest contrast $(23,34)$. RhoA and RhoC are both activated at the cell edge, playing roles in actomyosin contractility and cell movement (23). RhoC has also been implicated in promoting directional polarized migration, and appears to become activated slightly before RhoA $(39,40)$ In contrast, the localization of RhoB to endosomes has shown it to have a role in intracellular trafficking, receptor-mediated angiogenesis, and cell survival (41).

\section{2: Proteins of the Mesenchymal Pathway}

Rac1 GTPase has been proven vital to the function of the mesenchymal pathway. Rac1 binds and activates the WAVE regulatory complex (Wiskott-Aldrich syndrome protein family verprolin-homologous protein) (42). This activation by Rac1 causes a conformational change that releases inhibition on the VCA (verprolin, cofilin, acidic) domain of WASP family proteins like WAVE, allowing their VCA domain to bind and stabilize a small protein called Arp2/3 (actinrelated protein 2/3). Arp2/3, which physically resembles a cluster of monomeric globular actin, 
acts as a seed for the polymerization of new actin filaments (42). This polymerization aids in the formation of actin-rich lamellipodia and invadopodia structures. Lamellipodia are broad sheetlike membrane protrusions at the leading edge of the cell membrane, given structure by a dense and dynamic network of actin filaments, which assist in cell motility and mechanosensing of ECM rigidity (43). Invadopodia are more specialized actin-based protrusion structures necessary for the degradation of ECM components and the basement membrane, subsequently promoting invasion and metastasis (44).

Invadopodia formation localizes the activation and secretion of matrix metalloproteinases (MMPs), which are very important for the mesenchymal phenotype. This family of zincdependent proteolytic enzymes modify and degrade components of the ECM to create tunnels and pathways for cells to invade $(45,46)$. The cleavage of ECM proteins by MMPs can also contribute to invasion through the uncovering and release of new binding sites in the ECM that can stimulate multiple signaling pathways such as proliferation, migration, or angiogenesis (47, 48). In addition to their path-clearing capacity, MMPs can also dissociate cell-ECM and cell-cell junction connections, leading to the release of individual cells from epithelial sheets and promoting invasion $(46,49,50)$. Over 20 members of the MMP family exist in humans, which can be further classified into subgroups based on their main substrates or their structure. These include collagenases (MMP-1, MMP-8, MMP-13, MMP-18), which cleave collagens, gelatinases (MMP-2, MMP-9), which degrade gelatin/denatured collagens, stromelysins (MMP-3, MMP-10, MMP-11) and matrilysins (MMP-7), which target a wide variety of other non-collagen ECM proteins, and membrane-type MMPs (MT1-MMP/MMP-14, MMP-15, MMP-16, MMP-17, MMP24, MMP-25), which are transmembrane MMPs that express on the cell surface instead of being secreted $(45,46)$. Multiple specific MMPs have been found to have important roles and influence in the progression of breast cancer. For example, MMP-3 and MMP-7 both target E-cadherin, a transmembrane protein important for cell-cell junctions, causing disruption of cell aggregation, 
releasing an active cleaved signaling molecule that stimulates invasion itself, and promoting EMT in mammary epithelial cells $(51,52)$. Furthermore, targeting of proteins such as protease activated receptor 1 (PAR-1) and P-cadherin by MMP-1 or MMP-2 has been shown to enhance invasion of breast cancer cells $(53,54)$. Additionally, the membrane-bound MT1-MMP has been linked to breast cancer invasion, seemingly through its processing of alpha- $V$ integrin $(55,56)$. The importance of this link between MMP activity and the mesenchymal phenotype cannot be understated.

In order for Rac1 to carry out its role in regulating lamellipodia and invadopodia formation and subsequent MMP activation, it must first be activated itself by a GEF protein. Multiple GEFs for Rac1 GTPase such as VAV2, DOCK180, DEF6, ECT2, and DOCK8 have been identified in various tissues (57-61). In melanoma cell lines, it has been shown that Rac1 is activated by the Rac1 GEF DOCK3 (dedicator of cytokinesis 3), which is recruited to cell membranes through interaction with a scaffold protein called NEDD9 (neural precursor cell expressed developmentally down-regulated 9), also commonly referred to as Cas-L or HEF1 (human enhancer of filamentation 1) $(35,36)$. NEDD9 is a member of the Crk-associated substrate (Cas) family of proteins, which also includes p130cas/BCAR1, EfS/Sin1, and CASS4/HEPL (62). NEDD9 is known to participate in migration and proliferation pathways $(12,25,63)$ and is commonly overexpressed in many human cancers, including both melanoma (64) and breast (12). Scaffold proteins like NEDD9 do not possess enzymatic activity of their own, but instead act as binding partners to bring multiple proteins together in a complex. It was shown in melanoma that large focal adhesion signaling complexes form in mesenchymal cells consisting of multiple proteins including integrin $\beta 3$, Src, FAK (focal adhesion kinase), NEDD9, and DOCK3 (35). These focal adhesion complexes act as signaling hubs mediating mechanical crosstalk between the extracellular matrix and the inside of the cell. Mesenchymal cells are known to possess larger, more mature focal adhesions which recruit multiple adaptor proteins such as 
talin, paxillin, and vinculin. FA maturation leads to increased activation/phosphorylation of FAK and paxillin, and can occasionally culminate in the formation of very long fibrillary adhesions (65).

Other proteins have been linked to the success of mesenchymal movement as well. Vascular endothelial growth factor (VEGF), a signaling protein which regulates vasculogenesis and angiogenesis, has been found to play a role in tumor growth and metastasis (66). Expression of the VEGF189 isoform, which binds at the cell membrane and interacts with the ECM, promotes mesenchymal phenotype and invasion (67). Secretion of the soluble isoform VEGF165 has been linked to amoeboid phenotype and has been found to support blood stream extravasation and metastasis to a greater degree than VEGF189 $(67,68)$. Activity of VEGF189 is enhanced through cleavage by proteases such as MMPs and urokinase plasminogen activator (69). Subsequently, expression of the urokinase plasminogen activator receptor (UPAR) has also been implicated in supporting mesenchymal invasion (70).

Additionally, the cyclin-dependent kinase inhibitor 1B (p27 Kip1) has been found to support mesenchymal motility and suppression of amoeboid signaling in multiple cells including macrophages (21), breast cancer (71), hepatocellular carcinoma (72), and melanoma (73). This role is dependent upon the transfer of p27 from the nucleus to the cytoplasm, where it colocalizes with F-actin to help mediate Rac-driven migration (71-73). The exact substrates and mechanism by which p27 promotes Rac activation are not fully understood, however it has been shown that the C-terminal of p27 can bind RhoA and inhibit its activation through physical blockage of Rho-GEF interactions (74). This is an important example of how these pathways can exhibit control upon each other in order to downregulate the opposite pathway - this will be further detailed in Chapter 3.5. 


\section{3: NEDD9 Promotes Mesenchymal Movement through an Additional AURKA-Driven}

\section{Signaling Pathway}

It has been previously shown that NEDD9 contributes to activation and stabilization of the enzyme AURKA $(75,76)$, a serine/threonine kinase that is also overexpressed in a majority of human cancers including melanoma and breast (77-80). AURKA has been shown to phosphorylate the consensus sequence $[R / K / N]-R-X-[S / T]-B$, where $B$ represents a hydrophobic amino acid (81). It is known that AURKA has a role in cell cycle and mitosis as a crucial enzyme in the formation of the mitotic spindle at the centrosome, linking it to cell proliferation processes (82). The common overexpression of this kinase in breast cancer correlates with poor survival in breast cancer patients (83). Nevertheless, the mechanisms of AURKA action on different stages of metastasis and particularly on invasion are currently unknown.

AURKA has been previously shown to phosphorylate and activate the histone deacetylase HDAC6 (76). This activation of HDAC6 leads to deacetylation and increased activity of cortactin, an actin-binding scaffolding protein that contributes to actin branching and polymerization (84). Cortactin binds and stimulates Arp2/3 with its $\mathrm{N}$-terminal region while simultaneously binding the sides of filamentous actin with its actin-binding repeat region (42). Interaction of Arp2/3 with Wiscott-Aldrich syndrome proteins like WASP or WAVE, which bind the SH3 domain of cortactin, can bring further stimulation to the activity and stability of Arp2/3 (85). Additionally, Arpc1b, a component of Arp $2 / 3$, has been recently reported to be a direct substrate of AURKA, which may also help to trigger its activity (86). Once Arp2/3 is active, polymerization of branched actin from the sides of filaments can be formed, constructing a branched actin meshwork. This polymerization of monomeric actin as a result of cortactin, Arp2/3, and WASP family members is vital to the formation of lamellipodia and invadopodia structures in promoting mesenchymal movement.

These additional signaling relationships as a result of NEDD9 expression suggest that in 
addition to its role in activating the Rac1 signaling cascade, NEDD9 can also promote mesenchymal motility through a second cascade of interactions involving NEDD9, AURKA, and CTTN - potentially making NEDD9 a critical hub of invasive stimulation that may mark it as a prime therapeutic target.

\section{4: Proteins of the Amoeboid Pathway}

Similar to Rac1's role in driving mesenchymal movement, the GTPase RhoA acts in a comparative manner to support the amoeboid signaling cascade. Multiple GEF proteins such as p114RhoGEF or Net1 have been found to activate RhoA (87-90). In breast cancer cells, it was shown that the cytokine CXCL12 helps support RhoA activation through its receptor CXCR4 and the GEF Net1 (90). Once active, RhoA binds and stimulates the Rho kinase ROCK (rhoassociated, coiled-coil containing protein kinase) (91). ROCK belongs to the AGC family of serine-threonine kinases and mainly functions in regulation of cytoskeletal proteins $(92,93)$. Amino acid consensus sequences for ROCK-targeted phosphorylation are $[\mathrm{R} / \mathrm{K}]-\mathrm{X}-[\mathrm{S} / \mathrm{T}]$ and $[R / K]-X-X-[S / T]$, where the $X$ amino acids can vary (94). The main target of ROCK in driving amoeboid migration is phosphorylation of MLC (myosin II light chain), thereby increasing actomyosin contractility of the cell membrane (92). ROCK can also phosphorylate and activate LIMK1, another protein kinase that functions to inactivate cofilin, an actin severing and depolymerization factor (95). LIMK1 was found to be critical for MAT in fibrosarcoma cells (96). Additional targets of RhoA include the formin Dia2 - interaction and colocalization between Dia2 and its partner DIP (diaphanous interacting protein) have been found to be necessary for the formation of membrane blebbing areas in breast cancer cells, supporting amoeboid migration $(90,97)$. Another formin-related protein, FMNL2, has also been found to support amoeboid movement in breast cancer cells, however interestingly is more specific for RhoC GTPase interaction than RhoA (98). RhoC has also been shown to interact with FMNL3 (39). 
In contrast to mesenchymal cells, amoeboid cells possess less mature focal adhesions and instead have many smaller, weaker nascent adhesions. These adhesions contain some of the same adaptor proteins as mature focal adhesions such as talin and paxillin, however the activation/phosphorylation of paxillin is decreased. Vinculin, a more mature FA marker, is less present in nascent adhesions. Loss of ERalpha, one of the hallmarks of TNBC, has been associated with a decrease in vinculin expression and an increase in amoeboid invasion and breast cancer metastasis (99).

The protein ezrin, a crosslinker between the plasma membrane and the actin cytoskeleton, has been hypothesized to have an important role in focusing the directionality of amoeboid movement. In amoeboid-moving melanoma cells, ezrin was found to localize to the cell rear, where it tightly binds the plasma membrane and seems to locally hinder bleb formation (100). This model suggests that a tiny hydrostatic pressure released by bleb formations in the front of the cell is able to create a small polarized motile force, thus pulling the cell forward in the direction of bleb growth.

Several other proteins have been implicated in supporting the amoeboid pathway or MAT in different cancer cell lines. In melanoma, TGF-beta stimulation was found to promote amoeboid phenotype along with increased expression of associated signaling transducers SMAD2, SMAD3, and CITED1 (101). Hypoxic conditions and expression of HIF-1alpha have been found to transition the collective movement of breast carcinoma and head and neck squamous cell carcinoma (HNSCC) cells to amoeboid migration (102). Other proteins whose expression has been reported to strengthen amoeboid phenotype include PKC-alpha (103), ACTN4 (104), EphA2 receptor tyrosine kinase (105), CD99 (106), NG2 (107), annexin II (108), transcription factors NANOG and Oct-4 (109), and collagen receptor Endo180 (110). The exact mechanisms for how many of these proteins help contribute to amoeboid phenotype are still unclear. 


\section{5: Regulation between Mesenchymal and Amoeboid Pathways}

To balance the competing relationship between mesenchymal and amoeboid phenotypes, various regulators have been shown to be utilized by each pathway to inhibit the competing signaling processes $(35,36)$. Upregulation of the microRNA let-7i by the amoeboid pathway has been shown to disrupt Rac1 signaling through suppressing expression of the mesenchymal proteins NEDD9 and DOCK3 in HNSCC cell lines $(111,112)$. Let-7i has also been found to repress expression of AURKA (113). As a counter, the transcriptional regulator Twist1, a known EMT inducer, has been shown to suppress expression of let-7i through the oncogene BMI1 (111-113). Another microRNA, miR-200c, has also been found to be upregulated by amoeboid signaling. Increased ratio of miR-200c to its other miR-200 family member miR-200a was found to induce MAT through inhibition of expression of cytoskeletal regulatory proteins MARCKS, FHOD1, and PPM1F in melanoma and breast cancer cells $(114,115)$. Besides microRNA, the amoeboid pathway is also capable of disrupting Rac1 signaling through inhibition of p27 ${ }^{\text {Kip1 }}$ expression via ROCK-dependent stimulation of the ERK pathway $(116,117)$. In addition, the amoeboid pathway can upregulate Rac1 GAP proteins such as ARHGAP22 in melanoma (36) or FilGAP in multiple cancers to hinder Rac1 activity (118-120). Similarly, the mesenchymal pathway can upregulate RhoA GAPs such as RASAL2 in astrocytomas to downregulate RhoA activity (121).

In melanoma, the mesenchymal pathway has been found to counter the amoeboid pathway through activation of Src by NEDD9, which phosphorylates and inhibits ROCK activity (35), and also through WAVE expression, although this exact mechanism is less well defined. It is hypothesized that an interactor of WAVE, Hem-1 (hematopoietic protein 1), may potentially interact with Rho GAPs or myosin phosphatase (36). Myosin phosphatase negatively controls amoeboid movement through dephosphorylation of MLC, and is known to be regulated through 
direct phosphorylation by ROCK itself and also through Wnt signaling pathways $(94,122)$. Wnt signaling proteins such as WNT5A are known activators of the RhoA/ROCK cascade and have been found to influence the amoeboid pathway $(123,124)$. In hepatocarcinoma cells, MMP inducer CD147 has been found to support the mesenchymal pathway through binding and inhibition of phosphorylation of annexin II, a phospholipid binding protein that is upregulated in amoeboid phenotype $(61,108)$. Together, this data illustrates the intense checks and balances that the mesenchymal and amoeboid pathways can enforce on each other to keep the opposite signaling networks suppressed.

\section{Treatment of Breast Cancer Invasion and Metastasis}

\section{1: Targeting the Mesenchymal Pathway}

Matrix metalloproteinases are an attractive target for stoppage of mesenchymal movement. Without these matrix degrading enzymes, tumor cells will encounter difficulty in being able to create tunnels and invade through the ECM. Whether through techniques such as siRNA knockdown or usage of MMP-targeting chemical compounds or small molecules, MMP inhibitors (MMPI) are a commonly used technique for targeting of cell invasion. Numerous MMPI which target many MMP proteins (broad spectrum) or a specific MMP protein have been designed and utilized over the years with varying degrees of success (125). Some MMPI have made it to clinical trials such as batimastat (phase I/II) (126-128) and marimastat (phase III) (129), but have not gained further traction due to different issues such as bioavailability, toxicity, or minimal effects on survival $(130,131)$. The only MMPI currently approved by the Food and Drug Administration is doxycycline, which is used as a treatment for periodontal disease (132). The difference in success between why some tumors respond to MMPIs better than others may be due to the potential of mixed cancer cell populations of both mesenchymal and amoeboid phenotypes and some populations leaning more heavily toward amoeboid, where MMP 
inhibitors would have less effect. Nevertheless, inhibition of MMPs in in vitro or in vivo animal models has been shown to decrease Rac1 activity/cell elongation, increase RhoA activity/cell roundedness, and subsequently decrease cell invasion $(70,88,105)$. This has been combined with targeting of UPAR in prostate and melanoma cancer cells, yielding exacerbated effects (70).

Multiple other proteins have been targeted for inhibition of the mesenchymal pathway. Depletion of NEDD9 has been associated with a decrease in overall invasion and metastasis, as well as switching cells to a more amoeboid phenotype (133). This also has been shown to hinder the activation and secretion of MMPs $(134,135)$. Administration of the AURKA inhibitor MLN8237 (alisertib) decreases tumor growth and metastasis of breast cancer (136).

An alternative option to "inhibit" the mesenchymal pathway could be to promote activation of the amoeboid pathway, thereby downregulating mesenchymal signaling. Use of calpeptin, a RhoA activator, has been used to switch mesenchymal melanoma cells to amoeboid migration, but with minimal effect on invasion (105).

\section{2: Targeting the Amoeboid Pathway}

Due to its vital role in regulation of actomyosin contractility and cytoskeletal rearrangement, the Rho kinase ROCK has become a popular drug target of the amoeboid pathway. Several ROCK inhibitor compounds have been designed - some of the earliest and most commonly tested being Y-27632 (137) and H-1152 (138). No ROCK inhibitors have yet been approved for human use in the United States by the Food and Drug Administration, however the compound fasudil has been permitted for clinical treatment of cerebral vasospasm in Japan and China $(139,140)$. Additionally, a derivative of fasudil called ripasudil has recently been approved for treatment of glaucoma in Japan (141). Despite no ROCK inhibitors being clinically available for treatment of human cancer, they have still shown 
promise against blocking invasion and metastasis of cancer cell lines in vitro and in animal models (92). A newly developed compound, AT13148, which blocks multiple AGC kinases including ROCK, has shown substantial benefit against melanoma metastasis in mice (142). A phase I clinical trial for the inhibitor AT13148 is currently ongoing for evaluation against multiple cancer types with results expected to conclude this year (ClinicalTrials.gov identifier NCT01585701) (140).

Knockdown or inhibition of various amoeboid pathway components besides ROCK have yielded promising results in hindering cell invasion and metastasis. The RhoA GEF p114RhoGEF was targeted in MDA-MB-231 TNBC cells and caused a decrease in migration, a decrease in RhoA activity, and an increase in Rac1 activity (87). Targeting of other RhoA GEFs such as Net1 has yielded similar results with decreases in BC cell migration and increases in elongated mesenchymal phenotype/MMP activity (89). PKCalpha inhibition switched melanoma and BC cells from rounded to elongated phenotype and decreased cell invasion, whereas activation of PKCalpha increased the percent of rounded cells, yet yielded no additional increase in invasion (103). ACTN4, a crosslinker of actin filaments at adherens junctions and focal adhesions, has been found to support rounded amoeboid morphology. Knockdown of ACTN4 decreased melanoma cell invasion, increased the persistence of FAs and switched cells to elongated phenotype (104). Additionally, chondramide, a naturally occurring compound that targets the actin cytoskeleton, has been shown to hinder amoeboid movement and breast cancer metastasis through inhibition of cell contractility (143).

\section{3: Dual Pathway Targeting}

Due to the fact that cancer cells have the ability to utilize both of these cell motility methods, the ideal treatment option may be one that hinders both pathways simultaneously. In doing so, the cell will not be able to invade even if it switches its phenotype to the opposite 
pathway. This theory has been previously attempted in literature using combinations such as MMP and ROCK inhibitors in pancreatic and glioblastoma cancer cell lines (88, 144), Rac1 siRNA with ROCK inhibitors in melanoma and glioblastoma cell lines $(36,145)$, and DOCK3 siRNA or NEDD9 siRNA with ROCK inhibitors in melanoma cell lines (36), and MMP inhibitor and Rho GEF siRNA in breast cancer cell lines (87). Use of this dual targeting strategy showed a promising synergistic decrease in cell invasion upon concurrent suppression of mesenchymal and amoeboid processes.

\section{4: Comparisons of Mouse Models}

In order to assess the viability of such a treatment strategy for clinical trials, an in vivo mouse model offers a safe alternative to human patients and is a prevalent representation for the study of cancer. Multiple different types of models exist, including genetically-engineered mouse models (GEM), xenograft models (XG), and patient-derived xenograft models (PDX), all offering their own advantages and disadvantages (146). GEMs allow for the genome of a mouse population to be altered to either express, delete, or mutate some target gene of interest. NEDD9 knockout animals have been previously made and are viable from birth (25). These models allow for the studying of tumor growth from the early stages of mouse development, but applicability of this knowledge is limited due to the growth of a murine tumor in a murine microenvironment, which may not correlate well with the development of human tumors. It is also a slow, time consuming, and expensive method.

Xenograft models (XG) are cheaper and faster to do, and they allow for the growth of a human tumor in a mouse using human cancer cell lines. However, this tumor of human cancer cells is still grown within a murine microenvironment, and in order for the tumor to propagate, the mouse host must lack a functional immune system, thus limiting our understanding of immune response to the tumor. PDX models are similar to XG models in that they also have 
similar concerns using a murine microenvironment and immune-compromised mice, however they differ by implantation of an actual piece of tumor tissue from a human patient into a mouse rather than utilization of immortalized cell lines. Unlike a cell line, this tumor tissue was originally grown in a human microenvironment and is a heterogeneous cell population, making this model one of the best systems to study human tumor growth, metastasis, and anti-cancer drug response. Disadvantages of PDX models include the scarcity and expensiveness of their source material, which must be isolated from human patient tumors, and the fact that they are less easily manipulated. Normal XG models do not have these issues, since cell lines are readily available and much simpler to engineer or alter for experimental procedures.

\section{Hypothesis}

It is currently unknown whether previous findings of NEDD9 having a pivotal role in the switch between mesenchymal/amoeboid migration processes in melanoma could be applied to other cancers, notably breast cancer $(35,36)$. The downstream targets of the NEDD9-dependent signaling pathway involved in regulation of mesenchymal migration in breast cancer are also currently unknown. The central hypothesis of this project was that simultaneous inhibition of key components of both the mesenchymal and amoeboid invasion pathways, including NEDD9 protein expression, will have a synergistic effect limiting breast cancer migration and metastasis in vitro and in vivo. 


\section{References}

1. DeSantis C, Ma J, Bryan L, Jemal A. Breast cancer statistics, 2013. CA Cancer J Clin. 2014;64(1):52-62. doi: 10.3322/caac.21203. PubMed PMID: 24114568.

2. DeSantis CE, Fedewa SA, Goding Sauer A, Kramer JL, Smith RA, Jemal A. Breast cancer statistics, 2015: Convergence of incidence rates between black and white women. CA Cancer J Clin. 2016;66(1):31-42. doi: 10.3322/caac.21320. PubMed PMID: 26513636.

3. Allred DC. Issues and updates: evaluating estrogen receptor-alpha, progesterone receptor, and HER2 in breast cancer. Mod Pathol. 2010;23 Suppl 2:S52-9. doi: 10.1038/modpathol.2010.55. PubMed PMID: 20436503.

4. Buzdar AU, Vergote I, Sainsbury R. The impact of hormone receptor status on the clinical efficacy of the new-generation aromatase inhibitors: a review of data from first-line metastatic disease trials in postmenopausal women. Breast J. 2004;10(3):211-7. doi: 10.1111/j.1075-122X.2004.21320.x. PubMed PMID: 15125747.

5. Early Breast Cancer Trialists' Collaborative G. Effects of chemotherapy and hormonal therapy for early breast cancer on recurrence and 15-year survival: an overview of the randomised trials. Lancet. 2005;365(9472):1687-717. doi: 10.1016/S0140-6736(05)66544-0. PubMed PMID: 15894097.

6. Engel RH, Kaklamani VG. HER2-positive breast cancer: current and future treatment strategies. Drugs. 2007;67(9):1329-41. PubMed PMID: 17547474.

7. Ross JS, Fletcher JA, Bloom KJ, Linette GP, Stec J, Symmans WF, Pusztai L, Hortobagyi GN. Targeted therapy in breast cancer: the HER-2/neu gene and protein. Mol Cell Proteomics. 2004;3(4):379-98. doi: 10.1074/mcp.R400001-MCP200. PubMed PMID: 14762215.

8. Hurvitz S, Mead M. Triple-negative breast cancer: advancements in characterization and treatment approach. Curr Opin Obstet Gynecol. 2016;28(1):59-69. doi: 10.1097/GCO.0000000000000239. PubMed PMID: 26694831.

9. Collignon J, Lousberg L, Schroeder H, Jerusalem G. Triple-negative breast cancer: treatment challenges and solutions. Breast Cancer (Dove Med Press). 2016;8:93-107. doi: 10.2147/BCTT.S69488. PubMed PMID: 27284266; PMCID: PMC4881925.

10. Bauer KR, Brown M, Cress RD, Parise CA, Caggiano V. Descriptive analysis of estrogen receptor (ER)negative, progesterone receptor (PR)-negative, and HER2-negative invasive breast cancer, the so-called triplenegative phenotype: a population-based study from the California cancer Registry. Cancer. 2007;109(9):1721-8. doi: 10.1002/cncr.22618. PubMed PMID: 17387718.

11. Foulkes WD, Stefansson IM, Chappuis PO, Begin LR, Goffin JR, Wong N, Trudel M, Akslen LA. Germline BRCA1 mutations and a basal epithelial phenotype in breast cancer. J Natl Cancer Inst. 2003;95(19):1482-5. PubMed PMID: 14519755.

12. Kong C, Wang C, Wang L, Ma M, Niu C, Sun X, Du J, Dong Z, Zhu S, Lu J, Huang B. NEDD9 is a positive regulator of epithelial-mesenchymal transition and promotes invasion in aggressive breast cancer. PLoS One. 2011;6(7):e22666. doi: 10.1371/journal.pone.0022666. PubMed PMID: 21829474; PMCID: PMC3145662.

13. Hernández-Caballero M. Molecular Mechanisms of Metastasis: Epithelial-Mesenchymal Transition, Anoikis and Loss of Adhesion2013 2013-01-23.

14. Friedl P, Wolf K. Plasticity of cell migration: a multiscale tuning model. J Cell Biol. 2010;188(1):11-9. doi: 10.1083/jcb.200909003. PubMed PMID: 19951899; PMCID: 2812848. 
15. Friedl P, Wolf K. Tumour-cell invasion and migration: diversity and escape mechanisms. Nat Rev Cancer. 2003;3(5):362-74. doi: 10.1038/nrc1075. PubMed PMID: 12724734.

16. Haeger A, Wolf K, Zegers MM, Friedl P. Collective cell migration: guidance principles and hierarchies. Trends Cell Biol. 2015. doi: 10.1016/j.tcb.2015.06.003. PubMed PMID: 26137890.

17. Pankova K, Rosel D, Novotny M, Brabek J. The molecular mechanisms of transition between mesenchymal and amoeboid invasiveness in tumor cells. Cell Mol Life Sci. 2010;67(1):63-71. doi: 10.1007/s00018-009-0132-1. PubMed PMID: 19707854; PMCID: 2801846.

18. Wolf K, Friedl P. Extracellular matrix determinants of proteolytic and non-proteolytic cell migration. Trends Cell Biol. 2011;21(12):736-44. doi: 10.1016/j.tcb.2011.09.006. PubMed PMID: 22036198.

19. Wolf K, Mazo I, Leung H, Engelke K, von Andrian UH, Deryugina El, Strongin AY, Brocker EB, Friedl P. Compensation mechanism in tumor cell migration: mesenchymal-amoeboid transition after blocking of pericellular proteolysis. J Cell Biol. 2003;160(2):267-77. PubMed PMID: 12527751.

20. Cougoule C, Van Goethem E, Le Cabec V, Lafouresse F, Dupre L, Mehraj V, Mege JL, Lastrucci C, Maridonneau-Parini I. Blood leukocytes and macrophages of various phenotypes have distinct abilities to form podosomes and to migrate in 3D environments. Eur J Cell Biol. 2012;91(11-12):938-49. doi: 10.1016/j.ejcb.2012.07.002. PubMed PMID: 22999511.

21. Gui P, Labrousse A, Van Goethem E, Besson A, Maridonneau-Parini I, Le Cabec V. Rho/ROCK pathway inhibition by the CDK inhibitor p27(kip1) participates in the onset of macrophage 3D-mesenchymal migration. J Cell Sci. 2014;127(Pt 18):4009-23. doi: 10.1242/jcs.150987. PubMed PMID: 25015295.

22. Van Goethem E, Poincloux R, Gauffre F, Maridonneau-Parini I, Le Cabec V. Matrix architecture dictates three-dimensional migration modes of human macrophages: differential involvement of proteases and podosome-like structures. J Immunol. 2010;184(2):1049-61. doi: 10.4049/jimmunol.0902223. PubMed PMID: 20018633.

23. Parri M, Chiarugi P. Rac and Rho GTPases in cancer cell motility control. Cell Commun Signal. 2010;8:23. doi: 10.1186/1478-811X-8-23. PubMed PMID: 20822528; PMCID: 2941746.

24. Ridley AJ. Rho GTPases and cell migration. J Cell Sci. 2001;114(Pt 15):2713-22. PubMed PMID: 11683406.

25. Guerrero MS, Parsons JT, Bouton AH. Cas and NEDD9 Contribute to Tumor Progression through Dynamic Regulation of the Cytoskeleton. Genes Cancer. 2012;3(5-6):371-81. doi: 10.1177/1947601912458585. PubMed PMID: 23226575; PMCID: 3513795.

26. Kang Y, Siegel PM, Shu W, Drobnjak M, Kakonen SM, Cordon-Cardo C, Guise TA, Massague J. A multigenic program mediating breast cancer metastasis to bone. Cancer Cell. 2003;3(6):537-49. PubMed PMID: 12842083.

27. Poincloux R, Lizarraga F, Chavrier P. Matrix invasion by tumour cells: a focus on MT1-MMP trafficking to invadopodia. J Cell Sci. 2009;122(Pt 17):3015-24. doi: 10.1242/jcs.034561. PubMed PMID: 19692588.

28. Wolf $\mathrm{K}$, Te Lindert M, Krause M, Alexander S, Te Riet J, Willis AL, Hoffman RM, Figdor CG, Weiss SJ, Friedl P. Physical limits of cell migration: control by ECM space and nuclear deformation and tuning by proteolysis and traction force. J Cell Biol. 2013;201(7):1069-84. doi: 10.1083/jcb.201210152. PubMed PMID: 23798731; PMCID: 3691458.

29. Friedl $\mathrm{P}$, Wolf $\mathrm{K}$, Lammerding J. Nuclear mechanics during cell migration. Curr Opin Cell Biol. 2011;23(1):55-64. doi: 10.1016/j.ceb.2010.10.015. PubMed PMID: 21109415; PMCID: 3073574. 
30. Wozniak MA, Keely PJ. Use of three-dimensional collagen gels to study mechanotransduction in T47D breast epithelial cells. Biol Proced Online. 2005;7:144-61. doi: 10.1251/bpo112. PubMed PMID: 16299584; PMCID: 1285185.

31. Harada T, Swift J, Irianto J, Shin JW, Spinler KR, Athirasala A, Diegmiller R, Dingal PC, Ivanovska IL, Discher DE. Nuclear lamin stiffness is a barrier to 3D migration, but softness can limit survival. J Cell Biol. 2014;204(5):66982. doi: 10.1083/jcb.201308029. PubMed PMID: 24567359; PMCID: PMC3941057.

32. Dittmer TA, Misteli T. The lamin protein family. Genome Biol. 2011;12(5):222. doi: 10.1186/gb-2011-125-222. PubMed PMID: 21639948; PMCID: PMC3219962.

33. Yilmaz M, Christofori G. Mechanisms of motility in metastasizing cells. Mol Cancer Res. 2010;8(5):629-42. doi: 10.1158/1541-7786.MCR-10-0139. PubMed PMID: 20460404.

34. Wheeler AP, Ridley AJ. Why three Rho proteins? RhoA, RhoB, RhoC, and cell motility. Exp Cell Res. 2004;301(1):43-9. doi: 10.1016/j.yexcr.2004.08.012. PubMed PMID: 15501444.

35. Ahn J, Sanz-Moreno V, Marshall CJ. The metastasis gene NEDD9 product acts through integrin beta3 and Src to promote mesenchymal motility and inhibit amoeboid motility. J Cell Sci. 2012;125(Pt 7):1814-26. doi: 10.1242/jcs.101444. PubMed PMID: 22328516.

36. Sanz-Moreno V, Gadea G, Ahn J, Paterson H, Marra P, Pinner S, Sahai E, Marshall CJ. Rac activation and inactivation control plasticity of tumor cell movement. Cell. 2008;135(3):510-23. PubMed PMID: 18984162.

37. Bolis A, Corbetta S, Cioce A, de Curtis I. Differential distribution of Rac1 and Rac3 GTPases in the developing mouse brain: implications for a role of Rac3 in Purkinje cell differentiation. Eur J Neurosci. 2003;18(9):2417-24. PubMed PMID: 14622142.

38. Ridley AJ. RhoA, RhoB and RhoC have different roles in cancer cell migration. J Microsc. 2013;251(3):2429. doi: 10.1111/jmi.12025. PubMed PMID: 23488932.

39. Vega FM, Fruhwirth G, Ng T, Ridley AJ. RhoA and RhoC have distinct roles in migration and invasion by acting through different targets. J Cell Biol. 2011;193(4):655-65. doi: 10.1083/jcb.201011038. PubMed PMID: 21576392; PMCID: PMC3166870.

40. Zawistowski JS, Sabouri-Ghomi M, Danuser G, Hahn KM, Hodgson L. A RhoC biosensor reveals differences in the activation kinetics of RhoA and RhoC in migrating cells. PLoS One. 2013;8(11):e79877. doi: 10.1371/journal.pone.0079877. PubMed PMID: 24224016; PMCID: PMC3818223.

41. Howe GA, Addison CL. RhoB controls endothelial cell morphogenesis in part via negative regulation of RhoA. Vasc Cell. 2012;4:1. doi: 10.1186/2045-824X-4-1. PubMed PMID: 22316440; PMCID: PMC3350406.

42. Ammer AG, Weed SA. Cortactin branches out: roles in regulating protrusive actin dynamics. Cell Motil Cytoskeleton. 2008;65(9):687-707. doi: 10.1002/cm.20296. PubMed PMID: 18615630; PMCID: PMC2561250.

43. Krause M, Gautreau A. Steering cell migration: lamellipodium dynamics and the regulation of directional persistence. Nat Rev Mol Cell Biol. 2014;15(9):577-90. doi: 10.1038/nrm3861. PubMed PMID: 25145849.

44. Beaty BT, Condeelis J. Digging a little deeper: the stages of invadopodium formation and maturation. Eur J Cell Biol. 2014;93(10-12):438-44. doi: 10.1016/j.ejcb.2014.07.003. PubMed PMID: 25113547; PMCID: PMC4262566.

45. Almalki SG, Agrawal DK. Effects of matrix metalloproteinases on the fate of mesenchymal stem cells. Stem Cell Res Ther. 2016;7(1):129. doi: 10.1186/s13287-016-0393-1. PubMed PMID: 27612636; PMCID: PMC5016871. 
46. Radisky ES, Radisky DC. Matrix metalloproteinase-induced epithelial-mesenchymal transition in breast cancer. J Mammary Gland Biol Neoplasia. 2010;15(2):201-12. doi: 10.1007/s10911-010-9177-x. PubMed PMID: $20440544 ;$ PMCID: PMC2886087.

47. Page-McCaw A, Ewald AJ, Werb Z. Matrix metalloproteinases and the regulation of tissue remodelling. Nat Rev Mol Cell Biol. 2007;8(3):221-33. doi: 10.1038/nrm2125. PubMed PMID: 17318226; PMCID: PMC2760082.

48. Egeblad M, Werb Z. New functions for the matrix metalloproteinases in cancer progression. Nat Rev Cancer. 2002;2(3):161-74. PubMed PMID: 11990853.

49. Bartlett JD, Smith CE. Modulation of cell-cell junctional complexes by matrix metalloproteinases. J Dent Res. 2013;92(1):10-7. doi: 10.1177/0022034512463397. PubMed PMID: 23053846; PMCID: PMC3521448.

50. Sternlicht MD, Werb Z. How matrix metalloproteinases regulate cell behavior. Annu Rev Cell Dev Biol. 2001;17:463-516. doi: 10.1146/annurev.cellbio.17.1.463. PubMed PMID: 11687497; PMCID: PMC2792593.

51. Lochter A, Galosy S, Muschler J, Freedman N, Werb Z, Bissell MJ. Matrix metalloproteinase stromelysin-1 triggers a cascade of molecular alterations that leads to stable epithelial-to-mesenchymal conversion and a premalignant phenotype in mammary epithelial cells. J Cell Biol. 1997;139(7):1861-72. PubMed PMID: 9412478; PMCID: PMC2132651.

52. Noe V, Fingleton B, Jacobs K, Crawford HC, Vermeulen S, Steelant W, Bruyneel E, Matrisian LM, Mareel M. Release of an invasion promoter E-cadherin fragment by matrilysin and stromelysin-1. J Cell Sci. 2001;114(Pt 1):111-8. PubMed PMID: 11112695.

53. Boire A, Covic L, Agarwal A, Jacques S, Sherifi S, Kuliopulos A. PAR1 is a matrix metalloprotease-1 receptor that promotes invasion and tumorigenesis of breast cancer cells. Cell. 2005;120(3):303-13. doi: 10.1016/j.cell.2004.12.018. PubMed PMID: 15707890.

54. Ribeiro AS, Albergaria A, Sousa B, Correia AL, Bracke M, Seruca R, Schmitt FC, Paredes J. Extracellular cleavage and shedding of P-cadherin: a mechanism underlying the invasive behaviour of breast cancer cells. Oncogene. 2010;29(3):392-402. doi: 10.1038/onc.2009.338. PubMed PMID: 19901964.

55. Deryugina El, Ratnikov BI, Postnova TI, Rozanov DV, Strongin AY. Processing of integrin alpha(v) subunit by membrane type 1 matrix metalloproteinase stimulates migration of breast carcinoma cells on vitronectin and enhances tyrosine phosphorylation of focal adhesion kinase. J Biol Chem. 2002;277(12):9749-56. doi: 10.1074/jbc.M110269200. PubMed PMID: 11724803.

56. Wolf K, Friedl P. Mapping proteolytic cancer cell-extracellular matrix interfaces. Clin Exp Metastasis. 2009;26(4):289-98. doi: 10.1007/s10585-008-9190-2. PubMed PMID: 18600304.

57. Abe K, Rossman KL, Liu B, Ritola KD, Chiang D, Campbell SL, Burridge K, Der CJ. Vav2 is an activator of Cdc42, Rac1, and RhoA. J Biol Chem. 2000;275(14):10141-9. PubMed PMID: 10744696.

58. Santy LC, Ravichandran KS, Casanova JE. The DOCK180/Elmo complex couples ARNO-mediated Arf6 activation to the downstream activation of Rac1. Curr Biol. 2005;15(19):1749-54. PubMed PMID: 16213822.

59. Samson T, Will C, Knoblauch A, Sharek L, von der Mark K, Burridge K, Wixler V. Def-6, a guanine nucleotide exchange factor for Rac1, interacts with the skeletal muscle integrin chain alpha7A and influences myoblast differentiation. J Biol Chem. 2007;282(21):15730-42. doi: 10.1074/jbc.M611197200. PubMed PMID: 17403664.

60. Tatsumoto T, Xie X, Blumenthal R, Okamoto I, Miki T. Human ECT2 is an exchange factor for Rho GTPases, phosphorylated in G2/M phases, and involved in cytokinesis. J Cell Biol. 1999;147(5):921-8. PubMed PMID: 10579713; PMCID: PMC2169345. 
61. Wang SJ, Cui HY, Liu YM, Zhao P, Zhang Y, Fu ZG, Chen ZN, Jiang JL. CD147 promotes Src-dependent activation of Rac1 signaling through STAT3/DOCK8 during the motility of hepatocellular carcinoma cells. Oncotarget. 2015;6(1):243-57. doi: 10.18632/oncotarget.2801. PubMed PMID: 25428919; PMCID: PMC4381592.

62. Tikhmyanova N, Tulin AV, Roegiers F, Golemis EA. Dcas supports cell polarization and cell-cell adhesion complexes in development. PLoS One. 2010;5(8):e12369. doi: 10.1371/journal.pone.0012369. PubMed PMID: 20808771; PMCID: PMC2927436.

63. Bradbury P, Mahmassani M, Zhong J, Turner K, Paul A, Verrills NM, O'Neill GM. PP2A phosphatase suppresses function of the mesenchymal invasion regulator NEDD9. Biochim Biophys Acta. 2012;1823(2):290-7. doi: 10.1016/j.bbamcr.2011.10.011. PubMed PMID: 22061964.

64. Kim M, Gans JD, Nogueira C, Wang A, Paik JH, Feng B, Brennan C, Hahn WC, Cordon-Cardo C, Wagner SN, Flotte TJ, Duncan LM, Granter SR, Chin L. Comparative oncogenomics identifies NEDD9 as a melanoma metastasis gene. Cell. 2006;125(7):1269-81. Epub 2006/07/04. doi: S0092-8674(06)00718-5 [pii]

10.1016/j.cell.2006.06.008. PubMed PMID: 16814714.

65. Case LB, Baird MA, Shtengel G, Campbell SL, Hess HF, Davidson MW, Waterman CM. Molecular mechanism of vinculin activation and nanoscale spatial organization in focal adhesions. Nat Cell Biol. 2015;17(7):880-92. doi: 10.1038/ncb3180. PubMed PMID: 26053221; PMCID: PMC4490039.

66. Ferrara N, Davis-Smyth T. The biology of vascular endothelial growth factor. Endocr Rev. 1997;18(1):4-25. doi: 10.1210/edrv.18.1.0287. PubMed PMID: 9034784.

67. Kanthou C, Dachs GU, Lefley DV, Steele AJ, Coralli-Foxon C, Harris S, Greco O, Dos Santos SA, ReyesAldasoro CC, English WR, Tozer GM. Tumour cells expressing single VEGF isoforms display distinct growth, survival and migration characteristics. PLoS One. 2014;9(8):e104015. doi: 10.1371/journal.pone.0104015. PubMed PMID: $25119572 ;$ PMCID: PMC4131915.

68. Di Benedetto M, Toullec A, Buteau-Lozano H, Abdelkarim M, Vacher S, Velasco G, Christofari M, Pocard M, Bieche I, Perrot-Applanat M. MDA-MB-231 breast cancer cells overexpressing single VEGF isoforms display distinct colonisation characteristics. Br J Cancer. 2015;113(5):773-85. doi: 10.1038/bjc.2015.267. PubMed PMID: 26196186; PMCID: PMC4559830.

69. Plouet J, Moro F, Bertagnolli S, Coldeboeuf N, Mazarguil H, Clamens S, Bayard F. Extracellular cleavage of the vascular endothelial growth factor 189 -amino acid form by urokinase is required for its mitogenic effect. J Biol Chem. 1997;272(20):13390-6. PubMed PMID: 9148962.

70. Margheri F, Luciani C, Taddei ML, Giannoni E, Laurenzana A, Biagioni A, Chilla A, Chiarugi P, Fibbi G, Del Rosso M. The receptor for urokinase-plasminogen activator (UPAR) controls plasticity of cancer cell movement in mesenchymal and amoeboid migration style. Oncotarget. 2014;5(6):1538-53. doi: 10.18632/oncotarget.1754. PubMed PMID: 24681666; PMCID: PMC4039230.

71. Wu FY, Wang SE, Sanders ME, Shin I, Rojo F, Baselga J, Arteaga CL. Reduction of cytosolic p27(Kip1) inhibits cancer cell motility, survival, and tumorigenicity. Cancer Res. 2006;66(4):2162-72. doi: 10.1158/0008-5472.CAN05-3304. PubMed PMID: 16489017.

72. McAllister SS, Becker-Hapak M, Pintucci G, Pagano M, Dowdy SF. Novel p27(kip1) C-terminal scatter domain mediates Rac-dependent cell migration independent of cell cycle arrest functions. Mol Cell Biol. 2003;23(1):216-28. PubMed PMID: 12482975; PMCID: PMC140659. 
73. Denicourt C, Saenz CC, Datnow B, Cui XS, Dowdy SF. Relocalized p27Kip1 tumor suppressor functions as a cytoplasmic metastatic oncogene in melanoma. Cancer Res. 2007;67(19):9238-43. doi: 10.1158/0008-5472.CAN07-1375. PubMed PMID: 17909030.

74. Sharma SS, Pledger WJ. The non-canonical functions of p27(Kip1) in normal and tumor biology. Cell Cycle. 2016;15(9):1189-201. doi: 10.1080/15384101.2016.1157238. PubMed PMID: 27082696; PMCID: PMC4889241.

75. Pugacheva EN, Golemis EA. The focal adhesion scaffolding protein HEF1 regulates activation of the AuroraA and Nek2 kinases at the centrosome. Nat Cell Biol. 2005;7(10):937-46. PubMed PMID: 16184168.

76. Pugacheva EN, Jablonski SA, Hartman TR, Henske EP, Golemis EA. HEF1-dependent Aurora A activation induces disassembly of the primary cilium. Cell. 2007;129(7):1351-63. PubMed PMID: 17604723.

77. Bischoff JR, Anderson L, Zhu Y, Mossie K, Ng L, Souza B, Schryver B, Flanagan P, Clairvoyant F, Ginther C, Chan CS, Novotny M, Slamon DJ, Plowman GD. A homologue of Drosophila aurora kinase is oncogenic and amplified in human colorectal cancers. Embo J. 1998;17(11):3052-65. PubMed PMID: 9606188.

78. Miyoshi Y, Iwao K, Egawa C, Noguchi S. Association of centrosomal kinase STK15/BTAK mRNA expression with chromosomal instability in human breast cancers. Int J Cancer. 2001;92(3):370-3. PubMed PMID: 11291073.

79. Sen S, Zhou H, White RA. A putative serine/threonine kinase encoding gene BTAK on chromosome $20 \mathrm{q} 13$ is amplified and overexpressed in human breast cancer cell lines. Oncogene. 1997;14(18):2195-200. PubMed PMID: 9174055.

80. Zhou H, Kuang J, Zhong L, Kuo WL, Gray JW, Sahin A, Brinkley BR, Sen S. Tumour amplified kinase STK15/BTAK induces centrosome amplification, aneuploidy and transformation. Nat Genet. 1998;20(2):189-93. PubMed PMID: 9771714.

81. Ferrari S, Marin O, Pagano MA, Meggio F, Hess D, El-Shemerly M, Krystyniak A, Pinna LA. Aurora-A site specificity: a study with synthetic peptide substrates. Biochem J. 2005;390(Pt 1):293-302. doi: 10.1042/BJ20050343. PubMed PMID: 16083426; PMCID: PMC1188270.

82. Agnese V, Bazan V, Fiorentino FP, Fanale D, Badalamenti G, Colucci G, Adamo V, Santini D, Russo A. The role of Aurora-A inhibitors in cancer therapy. Ann Oncol. 2007;18 Suppl 6:vi47-52. PubMed PMID: 17591831.

83. Siggelkow W, Boehm D, Gebhard S, Battista M, Sicking I, Lebrecht A, Solbach C, Hellwig B, Rahnenfuhrer J, Koelbl H, Gehrmann M, Marchan R, Cadenas C, Hengstler JG, Schmidt M. Expression of aurora kinase A is associated with metastasis-free survival in node-negative breast cancer patients. BMC Cancer. 2012;12:562. doi: 10.1186/1471-2407-12-562. PubMed PMID: 23186136; PMCID: 3530429.

84. Kozyreva VK, McLaughlin SL, Livengood RH, Calkins RA, Kelley LC, Rajulapati A, Ice RJ, Smolkin MB, Weed SA, Pugacheva EN. NEDD9 regulates actin dynamics through cortactin deacetylation in an AURKA/HDAC6dependent manner. Mol Cancer Res. 2014;12(5):681-93. doi: 10.1158/1541-7786.MCR-13-0654. PubMed PMID: 24574519; PMCID: 4020952.

85. Weaver AM, Heuser JE, Karginov AV, Lee WL, Parsons JT, Cooper JA. Interaction of cortactin and N-WASp with Arp2/3 complex. Curr Biol. 2002;12(15):1270-8. PubMed PMID: 12176354.

86. Molli PR, Li DQ, Bagheri-Yarmand R, Pakala SB, Katayama H, Sen S, lyer J, Chernoff J, Tsai MY, Nair SS, Kumar R. Arpc1b, a centrosomal protein, is both an activator and substrate of Aurora A. J Cell Biol. 2010;190(1):101-14. doi: 10.1083/jcb.200908050. PubMed PMID: 20603326; PMCID: 2911675. 
87. Terry SJ, Elbediwy A, Zihni C, Harris AR, Bailly M, Charras GT, Balda MS, Matter K. Stimulation of cortical myosin phosphorylation by p114RhoGEF drives cell migration and tumor cell invasion. PLoS One. 2012;7(11):e50188. doi: 10.1371/journal.pone.0050188. PubMed PMID: 23185572; PMCID: PMC3501466.

88. Yan S, Xue H, Zhang P, Han X, Guo X, Yuan G, Deng L, Li G. MMP inhibitor llomastat induced amoeboidlike motility via activation of the Rho signaling pathway in glioblastoma cells. Tumour Biol. 2016. doi: 10.1007/s13277-016-5464-5. PubMed PMID: 27743382.

89. Carr HS, Zuo Y, Oh W, Frost JA. Regulation of focal adhesion kinase activation, breast cancer cell motility, and amoeboid invasion by the RhoA guanine nucleotide exchange factor Net1. Mol Cell Biol. 2013;33(14):277386. doi: 10.1128/MCB.00175-13. PubMed PMID: 23689132; PMCID: PMC3700125.

90. Wyse MM, Goicoechea S, Garcia-Mata R, Nestor-Kalinoski AL, Eisenmann KM. mDia2 and CXCL12/CXCR4 chemokine signaling intersect to drive tumor cell amoeboid morphological transitions. Biochem Biophys Res Commun. 2017;484(2):255-61. doi: 10.1016/j.bbrc.2017.01.087. PubMed PMID: 28115158; PMCID: PMC5316376.

91. Hahmann C, Schroeter T. Rho-kinase inhibitors as therapeutics: from pan inhibition to isoform selectivity. Cell Mol Life Sci. 2010;67(2):171-7. doi: 10.1007/s00018-009-0189-x. PubMed PMID: 19907920.

92. Morgan-Fisher M, Wewer UM, Yoneda A. Regulation of ROCK activity in cancer. J Histochem Cytochem. 2013;61(3):185-98. doi: 10.1369/0022155412470834. PubMed PMID: 23204112; PMCID: PMC3636696.

93. Liao JK, Seto M, Noma K. Rho kinase (ROCK) inhibitors. J Cardiovasc Pharmacol. 2007;50(1):17-24. doi: 10.1097/FJC.0b013e318070d1bd. PubMed PMID: 17666911; PMCID: PMC2692906.

94. Kawano $\mathrm{Y}$, Fukata $\mathrm{Y}$, Oshiro N, Amano M, Nakamura T, Ito M, Matsumura F, Inagaki M, Kaibuchi K. Phosphorylation of myosin-binding subunit (MBS) of myosin phosphatase by Rho-kinase in vivo. J Cell Biol. 1999;147(5):1023-38. PubMed PMID: 10579722; PMCID: PMC2169354.

95. Ohashi K, Nagata K, Maekawa M, Ishizaki T, Narumiya S, Mizuno K. Rho-associated kinase ROCK activates LIM-kinase 1 by phosphorylation at threonine 508 within the activation loop. J Biol Chem. 2000;275(5):3577-82. PubMed PMID: 10652353.

96. Mishima T, Naotsuka M, Horita Y, Sato M, Ohashi K, Mizuno K. LIM-kinase is critical for the mesenchymalto-amoeboid cell morphological transition in 3D matrices. Biochem Biophys Res Commun. 2010;392(4):577-81. doi: 10.1016/j.bbrc.2010.01.075. PubMed PMID: 20100465.

97. Wyse MM, Lei J, Nestor-Kalinoski AL, Eisenmann KM. Dia-interacting protein (DIP) imposes migratory plasticity in mDia2-dependent tumor cells in three-dimensional matrices. PLoS One. 2012;7(9):e45085. doi: 10.1371/journal.pone.0045085. PubMed PMID: 23024796; PMCID: PMC3443221.

98. Kitzing TM, Wang Y, Pertz O, Copeland JW, Grosse R. Formin-like 2 drives amoeboid invasive cell motility downstream of RhoC. Oncogene. 2010;29(16):2441-8. doi: 10.1038/onc.2009.515. PubMed PMID: 20101212.

99. Gao Y, Wang Z, Hao Q, Li W, Xu Y, Zhang J, Zhang W, Wang S, Liu S, Li M, Xue X, Zhang W, Zhang C, Zhang $\mathrm{Y}$. Loss of ERalpha induces amoeboid-like migration of breast cancer cells by downregulating vinculin. Nat Commun. 2017;8:14483. doi: 10.1038/ncomms14483. PubMed PMID: 28266545; PMCID: PMC5344302.

100. Lorentzen A, Bamber J, Sadok A, Elson-Schwab I, Marshall CJ. An ezrin-rich, rigid uropod-like structure directs movement of amoeboid blebbing cells. J Cell Sci. 2011;124(Pt 8):1256-67. doi: 10.1242/jcs.074849. PubMed PMID: 21444753.

101. Cantelli G, Orgaz JL, Rodriguez-Hernandez I, Karagiannis P, Maiques O, Matias-Guiu X, Nestle FO, Marti RM, Karagiannis SN, Sanz-Moreno V. TGF-beta-Induced Transcription Sustains Amoeboid Melanoma Migration 
and Dissemination. Curr Biol. 2015;25(22):2899-914. doi: 10.1016/j.cub.2015.09.054. PubMed PMID: 26526369; PMCID: PMC4651903.

102. Lehmann S, Te Boekhorst V, Odenthal J, Bianchi R, van Helvert S, Ikenberg K, Ilina O, Stoma S, Xandry J, Jiang L, Grenman R, Rudin M, Friedl P. Hypoxia Induces a HIF-1-Dependent Transition from Collective-to-Amoeboid Dissemination in Epithelial Cancer Cells. Curr Biol. 2017;27(3):392-400. doi: 10.1016/j.cub.2016.11.057. PubMed PMID: 28089517.

103. Vaskovicova K, Szabadosova E, Cermak V, Gandalovicova A, Kasalova L, Rosel D, Brabek J. PKCalpha promotes the mesenchymal to amoeboid transition and increases cancer cell invasiveness. BMC Cancer. 2015;15:326. doi: 10.1186/s12885-015-1347-1. PubMed PMID: 25924946; PMCID: PMC4423130.

104. Shao H, Li S, Watkins SC, Wells A. alpha-Actinin-4 is required for amoeboid-type invasiveness of melanoma cells. J Biol Chem. 2014;289(47):32717-28. doi: 10.1074/jbc.M114.579185. PubMed PMID: 25296750; PMCID: PMC4239623.

105. Taddei ML, Giannoni E, Morandi A, Ippolito L, Ramazzotti M, Callari M, Gandellini P, Chiarugi P. Mesenchymal to amoeboid transition is associated with stem-like features of melanoma cells. Cell Commun Signal. 2014;12:24. doi: 10.1186/1478-811X-12-24. PubMed PMID: 24690323; PMCID: PMC4022383.

106. Seol HJ, Chang JH, Yamamoto J, Romagnuolo R, Suh Y, Weeks A, Agnihotri S, Smith CA, Rutka JT. Overexpression of CD99 Increases the Migration and Invasiveness of Human Malignant Glioma Cells. Genes Cancer. 2012;3(9-10):535-49. doi: 10.1177/1947601912473603. PubMed PMID: 23486730; PMCID: PMC3591096.

107. Pankova D, Jobe N, Kratochvilova M, Buccione R, Brabek J, Rosel D. NG2-mediated Rho activation promotes amoeboid invasiveness of cancer cells. Eur J Cell Biol. 2012;91(11-12):969-77. doi: 10.1016/j.ejcb.2012.05.001. PubMed PMID: 22699001.

108. Zhao P, Zhang W, Wang SJ, Yu XL, Tang J, Huang W, Li Y, Cui HY, Guo YS, Tavernier J, Zhang SH, Jiang JL, Chen ZN. HAb18G/CD147 promotes cell motility by regulating annexin II-activated RhoA and Rac1 signaling pathways in hepatocellular carcinoma cells. Hepatology. 2011;54(6):2012-24. doi: 10.1002/hep.24592. PubMed PMID: 21809360.

109. Borrull A, Ghislin S, Deshayes F, Lauriol J, Alcaide-Loridan C, Middendorp S. Nanog and Oct4 overexpression increases motility and transmigration of melanoma cells. J Cancer Res Clin Oncol. 2012;138(7):1145-54. doi: 10.1007/s00432-012-1186-2. PubMed PMID: 22406932.

110. Caley MP, King H, Shah N, Wang K, Rodriguez-Teja M, Gronau JH, Waxman J, Sturge J. Tumor-associated Endo180 requires stromal-derived LOX to promote metastatic prostate cancer cell migration on human ECM surfaces. Clin Exp Metastasis. 2016;33(2):151-65. doi: 10.1007/s10585-015-9765-7. PubMed PMID: 26567111; PMCID: PMC4761374.

111. Yang $\mathrm{WH}$, Lan $\mathrm{HY}$, Huang $\mathrm{CH}$, Tai SK, Tzeng $\mathrm{CH}$, Kao SY, Wu KJ, Hung MC, Yang MH. RAC1 activation mediates Twist1-induced cancer cell migration. Nat Cell Biol. 2012;14(4):366-74. doi: 10.1038/ncb2455. PubMed PMID: 22407364.

112. Yang $\mathrm{WH}$, Lan HY, Tai SK, Yang MH. Repression of bone morphogenetic protein 4 by let-7i attenuates mesenchymal migration of head and neck cancer cells. Biochem Biophys Res Commun. 2013;433(1):24-30. doi: 10.1016/j.bbrc.2013.02.076. PubMed PMID: 23454123.

113. Chou CH, Yang NK, Liu TY, Tai SK, Hsu DS, Chen YW, Chen YJ, Chang CC, Tzeng CH, Yang MH. Chromosome instability modulated by BMI1-AURKA signaling drives progression in head and neck cancer. Cancer Res. 2013;73(2):953-66. doi: 10.1158/0008-5472.CAN-12-2397. PubMed PMID: 23204235. 
114. Elson-Schwab I, Lorentzen A, Marshall CJ. MicroRNA-200 family members differentially regulate morphological plasticity and mode of melanoma cell invasion. PLoS One. 2010;5(10). doi: 10.1371/journal.pone.0013176. PubMed PMID: 20957176; PMCID: PMC2949394.

115. Jurmeister S, Baumann M, Balwierz A, Keklikoglou I, Ward A, Uhlmann S, Zhang JD, Wiemann S, Sahin O. MicroRNA-200c represses migration and invasion of breast cancer cells by targeting actin-regulatory proteins FHOD1 and PPM1F. Mol Cell Biol. 2012;32(3):633-51. doi: 10.1128/MCB.06212-11. PubMed PMID: 22144583; PMCID: PMC3266604.

116. Liu AJ, Ling F, Wang D, Wang Q, Lu XD, Liu YL. Fasudil inhibits platelet-derived growth factor-induced human pulmonary artery smooth muscle cell proliferation by up-regulation of p27kip(1) via the ERK signal pathway. Chin Med J (Engl). 2011;124(19):3098-104. PubMed PMID: 22040563.

117. Delmas C, Manenti S, Boudjelal A, Peyssonnaux C, Eychene A, Darbon JM. The p42/p44 mitogen-activated protein kinase activation triggers p27Kip1 degradation independently of CDK2/cyclin E in NIH 3T3 cells. J Biol Chem. 2001;276(37):34958-65. doi: 10.1074/jbc.M101714200. PubMed PMID: 11418594.

118. Nishi T, Takahashi H, Hashimura M, Yoshida T, Ohta Y, Saegusa M. FilGAP, a Rac-specific Rho GTPaseactivating protein, is a novel prognostic factor for follicular lymphoma. Cancer Med. 2015;4(6):808-18. doi: 10.1002/cam4.423. PubMed PMID: 25641953; PMCID: PMC4472203.

119. Hara A, Hashimura M, Tsutsumi K, Akiya M, Inukai M, Ohta Y, Saegusa M. The role of FilGAP, a Rac-specific Rho-GTPase-activating protein, in tumor progression and behavior of astrocytomas. Cancer Med. 2016;5(12):3412-25. doi: 10.1002/cam4.937. PubMed PMID: 27790861; PMCID: PMC5224849.

120. Saito K, Ozawa Y, Hibino K, Ohta Y. FilGAP, a Rho/Rho-associated protein kinase-regulated GTPaseactivating protein for Rac, controls tumor cell migration. Mol Biol Cell. 2012;23(24):4739-50. doi: 10.1091/mbc.E12-04-0310. PubMed PMID: 23097497; PMCID: PMC3521682.

121. Weeks A, Okolowsky N, Golbourn B, Ivanchuk S, Smith C, Rutka JT. ECT2 and RASAL2 mediate mesenchymal-amoeboid transition in human astrocytoma cells. Am J Pathol. 2012;181(2):662-74. doi: 10.1016/j.ajpath.2012.04.011. PubMed PMID: 22683310.

122. Weiser DC, Row RH, Kimelman D. Rho-regulated myosin phosphatase establishes the level of protrusive activity required for cell movements during zebrafish gastrulation. Development. 2009;136(14):2375-84. doi: 10.1242/dev.034892. PubMed PMID: 19515695; PMCID: PMC2729349.

123. Linke F, Zaunig S, Nietert MM, von Bonin F, Lutz S, Dullin C, Janovska P, Beissbarth T, Alves F, Klapper W, Bryja V, Pukrop T, Trumper L, Wilting J, Kube D. WNT5A: a motility-promoting factor in Hodgkin lymphoma. Oncogene. 2017;36(1):13-23. doi: 10.1038/onc.2016.183. PubMed PMID: 27270428.

124. Otto A, Collins-Hooper H, Patel A, Dash PR, Patel K. Adult skeletal muscle stem cell migration is mediated by a blebbing/amoeboid mechanism. Rejuvenation Res. 2011;14(3):249-60. doi: 10.1089/rej.2010.1151. PubMed PMID: 21453013.

125. Muvva C, Patra S, Venkatesan S. MMpl: A WideRange of Available Compounds of Matrix Metalloproteinase Inhibitors. PLoS One. 2016;11(8):e0159321. doi: 10.1371/journal.pone.0159321. PubMed PMID: 27509041; PMCID: PMC4979873.

126. Parsons SL, Watson SA, Steele RJ. Phase I/II trial of batimastat, a matrix metalloproteinase inhibitor, in patients with malignant ascites. Eur J Surg Oncol. 1997;23(6):526-31. PubMed PMID: 9484924. 
127. Macaulay VM, O'Byrne KJ, Saunders MP, Braybrooke JP, Long L, Gleeson F, Mason CS, Harris AL, Brown P, Talbot DC. Phase I study of intrapleural batimastat (BB-94), a matrix metalloproteinase inhibitor, in the treatment of malignant pleural effusions. Clin Cancer Res. 1999;5(3):513-20. PubMed PMID: 10100701.

128. Wojtowicz-Praga S, Low J, Marshall J, Ness E, Dickson R, Barter J, Sale M, McCann P, Moore J, Cole A, Hawkins MJ. Phase I trial of a novel matrix metalloproteinase inhibitor batimastat (BB-94) in patients with advanced cancer. Invest New Drugs. 1996;14(2):193-202. PubMed PMID: 8913840.

129. Sparano JA, Bernardo P, Stephenson P, Gradishar WJ, Ingle JN, Zucker S, Davidson NE. Randomized phase III trial of marimastat versus placebo in patients with metastatic breast cancer who have responding or stable disease after first-line chemotherapy: Eastern Cooperative Oncology Group trial E2196. J Clin Oncol. 2004;22(23):4683-90. doi: 10.1200/JCO.2004.08.054. PubMed PMID: 15570070.

130. Rothenberg ML, Nelson AR, Hande KR. New drugs on the horizon: matrix metalloproteinase inhibitors. Stem Cells. 1999;17(4):237-40. doi: 10.1002/stem.170237. PubMed PMID: 10437989.

131. Jablonska-Trypuc A, Matejczyk M, Rosochacki S. Matrix metalloproteinases (MMPs), the main extracellular matrix (ECM) enzymes in collagen degradation, as a target for anticancer drugs. J Enzyme Inhib Med Chem. 2016;31(sup1):177-83. doi: 10.3109/14756366.2016.1161620. PubMed PMID: 27028474.

132. Preshaw PM, Hefti AF, Jepsen S, Etienne D, Walker C, Bradshaw MH. Subantimicrobial dose doxycycline as adjunctive treatment for periodontitis. A review. J Clin Periodontol. 2004;31(9):697-707. doi: 10.1111/j.1600051X.2004.00558.x. PubMed PMID: 15312090.

133. Domingues MJ, Rambow F, Job B, Papon L, Liu W, Larue L, Bonaventure J. beta-catenin inhibitor ICAT modulates the invasive motility of melanoma cells. Cancer Res. 2014;74(7):1983-95. doi: 10.1158/0008-5472.CAN13-0920. PubMed PMID: 24514042.

134. McLaughlin SL, Ice RJ, Rajulapati A, Kozyulina PY, Livengood RH, Kozyreva VK, Loskutov YV, Culp MV, Weed SA, Ivanov AV, Pugacheva EN. NEDD9 depletion leads to MMP14 inactivation by TIMP2 and prevents invasion and metastasis. Mol Cancer Res. 2014;12(1):69-81. doi: 10.1158/1541-7786.MCR-13-0300. PubMed PMID: 24202705; PMCID: 3946989.

135. Loskutov YV, Kozyulina PY, Kozyreva VK, Ice RJ, Jones BC, Roston TJ, Smolkin MB, Ivanov AV, Wysolmerski RB, Pugacheva EN. NEDD9/Arf6-dependent endocytic trafficking of matrix metalloproteinase 14: a novel mechanism for blocking mesenchymal cell invasion and metastasis of breast cancer. Oncogene. 2014. doi: 10.1038/onc.2014.297. PubMed PMID: 25241893.

136. Ice RJ, McLaughlin SL, Livengood RH, Culp MV, Eddy ER, Ivanov AV, Pugacheva EN. NEDD9 depletion destabilizes Aurora A kinase and heightens the efficacy of Aurora A inhibitors: implications for treatment of metastatic solid tumors. Cancer Res. 2013;73(10):3168-80. doi: 10.1158/0008-5472.CAN-12-4008. PubMed PMID: 23539442; PMCID: 3667743.

137. Uehata $M$, Ishizaki T, Satoh H, Ono T, Kawahara T, Morishita T, Tamakawa H, Yamagami K, Inui J, Maekawa M, Narumiya S. Calcium sensitization of smooth muscle mediated by a Rho-associated protein kinase in hypertension. Nature. 1997;389(6654):990-4. doi: 10.1038/40187. PubMed PMID: 9353125.

138. Sasaki Y, Suzuki M, Hidaka H. The novel and specific Rho-kinase inhibitor (S)-(+)-2-methyl-1-[(4-methyl-5isoquinoline)sulfonyl]-homopiperazine as a probing molecule for Rho-kinase-involved pathway. Pharmacol Ther. 2002;93(2-3):225-32. PubMed PMID: 12191614.

139. Tanaka K, Minami H, Kota M, Kuwamura K, Kohmura E. Treatment of cerebral vasospasm with intraarterial fasudil hydrochloride. Neurosurgery. 2005;56(2):214-23; discussion -23. PubMed PMID: 15670369. 
140. Feng Y, LoGrasso PV, Defert O, Li R. Rho Kinase (ROCK) Inhibitors and Their Therapeutic Potential. J Med Chem. 2016;59(6):2269-300. doi: 10.1021/acs.jmedchem.5b00683. PubMed PMID: 26486225.

141. Garnock-Jones KP. Ripasudil: first global approval. Drugs. 2014;74(18):2211-5. doi: 10.1007/s40265-0140333-2. PubMed PMID: 25414122.

142. Sadok A, McCarthy A, Caldwell J, Collins I, Garrett MD, Yeo M, Hooper S, Sahai E, Kuemper S, Mardakheh FK, Marshall CJ. Rho kinase inhibitors block melanoma cell migration and inhibit metastasis. Cancer Res. 2015;75(11):2272-84. doi: 10.1158/0008-5472.CAN-14-2156. PubMed PMID: 25840982.

143. Menhofer MH, Kubisch R, Schreiner L, Zorn M, Foerster F, Mueller R, Raedler JO, Wagner E, Vollmar AM, Zahler $\mathrm{S}$. The actin targeting compound Chondramide inhibits breast cancer metastasis via reduction of cellular contractility. PLoS One. 2014;9(11):e112542. doi: 10.1371/journal.pone.0112542. PubMed PMID: 25391145; PMCID: PMC4229209.

144. Fujita M, Otsuka Y, Yamada S, Iwakawa M, Imai T. X-ray irradiation and Rho-kinase inhibitor additively induce invasiveness of the cells of the pancreatic cancer line, MIAPaCa-2, which exhibits mesenchymal and amoeboid motility. Cancer Sci. 2011;102(4):792-8. doi: 10.1111/j.1349-7006.2011.01852.x. PubMed PMID: 21214671.

145. Yamazaki D, Kurisu S, Takenawa T. Involvement of Rac and Rho signaling in cancer cell motility in 3D substrates. Oncogene. 2009;28(13):1570-83. doi: 10.1038/onc.2009.2. PubMed PMID: 19234490.

146. Moro M, Bertolini G, Tortoreto M, Pastorino U, Sozzi G, Roz L. Patient-derived xenografts of non small cell lung cancer: resurgence of an old model for investigation of modern concepts of tailored therapy and cancer stem cells. J Biomed Biotechnol. 2012;2012:568567. doi: 10.1155/2012/568567. PubMed PMID: 22547927; PMCID: PMC3324927. 


\section{CHAPTER 2: PAPER PUBLISHED IN MOLECULAR CANCER RESEARCH, 2017}

Title: Dual Targeting of Mesenchymal and Amoeboid Motility Hinders Metastatic Behavior

Authors and affiliations: Brandon C. Jones ${ }^{1}$, Laura C. Kelley ${ }^{2}$, Yuriy V. Loskutov ${ }^{2}$, Kristina M. Marinak $^{2}$, Varvara K. Kozyreva ${ }^{2}$, Matthew B. Smolkin ${ }^{3}$, and Elena N. Pugacheva1,2\#

${ }^{1}$ Department of Biochemistry, ${ }^{2}$ West Virginia University Cancer Institute, ${ }^{3}$ Department of Pathology, West Virginia University School of Medicine, Morgantown, WV, USA 26506.

Running Title: Targeting NEDD9/ROCK Inhibits TNBC Metastasis

Keywords: NEDD9, mesenchymal, amoeboid, breast cancer, metastasis

Financial support: This research was supported by grants CA148671 (E.N.P) and KG100539 (E.N.P) from the $\mathrm{NIH} / \mathrm{NCl}$ and Susan G. Komen for the Cure foundation, and in part by a NIH/NCRR 5 P2O RR016440-09 (L.F.G). The WVU HSC Core Facilities were supported by the NIH grants P30GM103488, S10-RR026378, S10-RR020866, S10-OD016165, and GM103434.

Corresponding author: "Elena N. Pugacheva, Department of Biochemistry and West Virginia University Cancer Institute, 1 Medical Center Drive, West Virginia University School of Medicine, Morgantown, WV, 26506. Phone: (304) 293-5295; Fax: (304) 293-4667; Email: epugacheva@hsc.wvu.edu.

Conflicts of interest: The authors declare no conflicts of interest.

Disclaimers: This manuscript contains original work only and has not been published or submitted elsewhere. All of the authors have directly participated in the planning, execution and/or analysis of this study and have approved the submitted version of this manuscript. 


\section{Abstract}

Commonly upregulated in human cancers, the scaffolding protein NEDD9/HEF1 is a known regulator of mesenchymal migration and cancer cell plasticity. However, the functional role of NEDD9 as a regulator of different migration/invasion modes in the context of breast cancer metastasis is currently unknown. Here, it is reported that NEDD9 is necessary for both mesenchymal and amoeboid individual cell migration/invasion in triple-negative breast cancer (TNBC). NEDD9 deficiency results in acquisition of the amoeboid morphology, but severely limits all types of cell motility. Mechanistically, NEDD9 promotes mesenchymal migration via VAV2-dependent Rac1 activation, and depletion of VAV2 impairs the ability of NEDD9 to activate Rac1. Additionally, NEDD9 supports a mesenchymal phenotype through stimulating polymerization of actin via promoting CTTN phosphorylation in an AURKA-dependent manner. Interestingly, an increase in RhoA activity in NEDD9-depleted cells does not facilitate a switch to functional amoeboid motility, indicating a role of NEDD9 in the regulation of downstream RhoA signaling effectors. Simultaneous depletion of NEDD9 or inhibition of AURKA in combination with inhibition of the amoeboid driver ROCK results in an additional decrease in cancer cell migration/invasion. Finally, we confirmed that a dual targeting strategy is a viable and efficient therapeutic approach to hinder the metastasis of breast cancer in xenograft models, showcasing the important need for further clinical evaluation of this regimen in order to impede the spread of disease and improve patient survival.

Implications: This study provides new insight into the therapeutic benefit of combining NEDD9 depletion with ROCK inhibition to reduce tumor cell dissemination and discovers a new regulatory role of NEDD9 in the modulation of VAV2-dependent activation of Rac1 and actin polymerization. 


\section{Introduction}

Scaffolding protein NEDD9/HEF1, commonly overexpressed in many human cancers, is a critical regulator of cancer cell migration $(1,2)$. Cancer cells are capable of migrating either collectively or individually (3-5). In collective migration, cells retain most of their epithelial characteristics including cell-cell adhesions and invade as a sheet (6), thus enabling regional invasion and lymphatic-based metastasis. Alternatively, individual migration is distinguished by a loss of cell-cell adhesions and the ability to invade via two different methods known as mesenchymal and amoeboid (7-9), leading to blood-borne metastasis. Depending on extracellular matrix (ECM) composition and rigidity of the tumor microenvironment, the mesenchymal and amoeboid modes can be used interchangeably by the same cell population $(3,8)$. Initial nascent adhesions are highly present in amoeboid cells, consisting of integrin, talin, and non-phosphorylated paxillin. The recruitment of vinculin and FAK/SrC complex and activation/phosphorylation of paxillin and FAK is indicative of focal adhesion (FA) maturation, which can culminate in formation of very elongated fibrillar adhesions (10), which are often found in mesenchymal cells.

Elevated expression of NEDD9 protein is required for individual mesenchymal migration of diverse tumor cells $(1,11,12)$. Mesenchymal migration is characterized by an elongated cell morphology, multiple focal/3D adhesions, and the ability to degrade ECM by matrix metalloproteinases (MMPs) $(7,13)$, creating a path through the basement membrane/tissue. A master regulator of mesenchymal migration, Rac1 GTPase, is activated by a number of guanine nucleotide exchange factors (GEFs), including melanoma-specific DOCK3 (14), which is recruited/activated by NEDD9 (15). Rac1 activates the WAVE regulatory complex leading to polymerization of actin filaments (16). We have previously shown that NEDD9 also activates and stabilizes Aurora A kinase (AURKA) (17), which phosphorylates and activates histone deacetylase HDAC6 (18), leading to deacetylation and subsequent increased activity of the actin branching/stabilizing protein cortactin (CTTN) (19), which is necessary for lamellipodia and invadopodia formation - structures that define mesenchymal invasion. 
Rac1-driven mesenchymal migration runs counter to the corresponding RhoA GTPase and ROCKII kinase-driven amoeboid pathway. Amoeboid migration is characterized by a rounder cell morphology, small/weak adhesions, and increased cell contractility $(7,20)$. This type of locomotion does not typically rely on matrix degradation, and instead slightly deforms the cell shape to squeeze through pre-existing gaps in the ECM (21). Because of this, amoeboid movement is more suited for invasion through less dense and more elastic matrices such as collagens. Mechanistically, RhoA binds and activates ROCKII which phosphorylates myosin II light chain (MLC2), thus increasing actomyosin contractility and amoeboid invasion. NEDD9 contributes to downregulation of the amoeboid pathway through binding/activating Src kinase, leading to phosphorylation/inhibition of ROCKII (11).

The impact of NEDD9 on collective tumor cell invasion has not been explored. However, collective migration of lymphocytes in NEDD9 knockout mice was shown to be significantly reduced (22), and neuronal tube formation in mouse and chick embryos was inhibited upon NEDD9 depletion (23). We have shown that a decrease in NEDD9 expression leads to significant deficiency in activation of MMPs $(24,25)$, suggesting a deficiency of these cells to create tunnels through the matrix.

Since individual tumor cells are capable of utilizing either one of these modes of movement, simultaneous targeting of both pathways may provide significant clinical benefit against metastatic cancers $(14,26)$. In this current study, we define the molecular mechanisms of NEDD9-dependent Rac1 activation and the efficacy of combined inhibition of both types of cell movement to hinder the metastasis of triple negative breast cancer (TNBC). 


\section{Materials and Methods}

\section{Cell lines, RNAs, and plasmids}

TNBC cell lines MDA-MB-231LN (Caliper); Hs578T, HCC1143, BT549, HCC1395 (American Type Culture Collection); and SUM159 (gift from Dr. Boerner, Karmanos Cancer Institute) were authenticated and propagated for less than 6 months. si/sh/sgRNAs and plasmids used in this study are described in detail in the Supplementary Materials and Methods. The plasmids/RNAs were introduced via nucleofection (Amaxa) according to manufacturer's recommendation or virus infection (293T packaging cells, LifeTechnologies) as previously described (24).

\section{Recombinant protein production}

Recombinant AURKA (19), wild type and N/C-term CTTN (27), and GST and GST-PBD proteins were produced as previously described (28).

\section{Cell morphology analysis}

$10^{4}$ cells were plated on 2D or in 3D $1.5 \mathrm{mg} / \mathrm{ml}$ collagen (Advanced BioMatrix) or $4 \mathrm{mg} / \mathrm{ml}$ Matrigel (Corning) as previously described (30). Cells were treated with 50 or $100 \mu \mathrm{M}$ Y-27632 (ApexBio) where indicated. Cells were brightfield imaged on a Leica DM/IL microscope. Cell elongation was measured as a function of cell length divided by cell width (Image J software/NIH).

\section{Western blotting}

Western blots were performed as previously described (24). Further details and a list of antibodies used can be found in the Supplemental Material and Methods.

\section{Immunofluorescence}

The edges of $18 \mathrm{~mm}$ round glass coverslips (Fisher) were coated with a Super-HT-PAP-PEN hydrophobic slide marker and coated inside with $0.01 \%$ poly-L-lysine (Electron Microscopy Sciences). For 3D matrix embedding, $2.5 \times 10^{4}$ cells suspended in $200 \mu \mathrm{l}$ of $1.5 \mathrm{mg} / \mathrm{ml}$ collagen-I or $4 \mathrm{mg} / \mathrm{ml}$ Matrigel plug were loaded on the coverslips. Coverslips were placed into a 12-well plate and incubated in a $37^{\circ} \mathrm{C}$ humid chamber during polymerization. Full media was added, and the cells were allowed to 
acclimate to the matrix for 48 hours. Fixation and immunofluorescence staining was carried out as previously described (29). The list of used antibodies and quantification details are provided in the Supplemental Material and Methods.

\section{Collagen gel contraction assay}

$1 \times 10^{6}$ cells per sample were suspended in $1.5 \mathrm{mg} / \mathrm{ml}$ collagen and inserted into a well in a $12-$ well plate. Triplicate wells were included per cell line and a well with no cells was included as control. Once polymerized, media was placed on top of the collagen plug. After 24 hours, the collagen plugs were detached from the walls and bottom of the well. Gels were imaged (Syngene/G-Box) every 15 minutes for the first few hours followed by hourly images up to 24 hours. Gel area was measured by manual outlining of the collagen plugs and analyzed in ImageJ.

\section{Radioactive kinase assays}

$2.5 \mu \mathrm{Ci}$ of $\left[\mathrm{Y}^{-32} \mathrm{P}\right]-\mathrm{ATP}$ (Perkin Elmer) suspended in kinase buffer (28) was added to recombinant AURKA and/or CTTN (25-50ng) protein and incubated for 30 minutes at $30^{\circ} \mathrm{C}$. Samples were then subjected to gel electrophoresis and membrane transfer followed by X-ray film exposure for 2 hours to visualize phosphorylation and western blotting to visualize total protein level.

\section{Actin polymerization assays}

Actin polymerization assays were carried out according to manufacturer's recommendation (Cytoskeleton). Recombinant AURKA (3mM), CTTN (75nM), Arp2/3 (50nM, Cytoskeleton) or WASPVCA domain $(5 \mu \mathrm{M}$, Cytoskeleton) suspended in magnesium/ATP cocktail were added to $5 \mu \mathrm{M}$ pyrenelabeled G-actin in a 96-well plate and actin polymerization was measured based on the increase of fluorescence at excitation $365 \mathrm{~nm} / \mathrm{emission} 407 \mathrm{~nm}$ every 30 seconds for 20 minutes at $30^{\circ} \mathrm{C}$ using a GENios plate-reader (Tecan).

\section{Cell kymography}

Kymography analysis was carried out as previously described (19). In brief, cells were plated on glass bottom dishes (Fisher Scientific) 48 hours after nucleofection with mCherry-LifeAct. Cells 
were then treated overnight with 100nM AURKA inhibitor MLN8237 (Selleckchem) and live-imaged the next day every 45 seconds for 60 minutes. Kymograms were compiled from a perpendicular 1 pixel-width line from each frame on the same spot of the cell membrane.

\section{Active Rac1 pulldown assays}

Cells were nucleofected with the indicated plasmids/siRNAs and allowed to recover overnight, followed by suspension of $1.5 \times 10^{5}$ cells in $450 \mu \mathrm{l}$ of $1.5 \mathrm{mg} / \mathrm{ml}$ collagen-I or $4 \mathrm{mg} / \mathrm{ml}$ Matrigel. In indicated assays, cells were also treated overnight with $4 \mu \mathrm{M}$ EHop-016 (ApexBio). After 24 hours, cells were lysed for 10 minutes on ice with $1 X$ Rac1 lysis buffer as previously described (30). Lysates were spun down at max speed for 12 minutes at $4^{\circ} \mathrm{C}$ and supernatants were added to Glutathione-4FastFlow sepharose (GEHealthcare) loaded with GST or GST-PBD protein, rotating at $4^{\circ} \mathrm{C}$ for at least 1 hour. Sepharose was then washed three times with lysis buffer, boiled in Laemmli buffer and subjected to gel electrophoresis and western blotting.

\section{Active Rac1 and RhoA G-LISA assays}

G-LISA activation assays for Rac1 and RhoA were performed as recommended by the manufacturer's protocol (Cytoskeleton).

\section{Immunoprecipitations of GEF proteins}

pcDNA3.1-mRFP-NEDD9 and Rac1 GEF-expressing plasmids were co-transfected into 293T cells using TurboFect (ThermoFisher) per manufacturer protocol. After 24 hours, cells were lysed with PTY lysis buffer and processed as previously described (28). Lysates were precleared with proteinA/G-sepharose (GEHealthcare) for 1 hour at $4^{\circ} \mathrm{C}$. Mouse IgG control/or anti-NEDD9 (2G9) proteinA/G sepharose, or anti-HA/anti-FLAG EZview-Red antibody (Sigma) were added to precleared lysates for 12 hours rotating at $4^{\circ} \mathrm{C}$. Beads were then washed three times with PTY buffer. To elute proteins from the beads, $10 \%$ ammonia hydroxide was added for 15 seconds followed by speed-vacuum centrifuge to remove ammonia hydroxide. Protein was then resuspended in Laemmli buffer for gel electrophoresis and western blotting. The IP of CTTN is detailed in the Supplemental Materials and 
Methods.

\section{Live-cell imaging of individual cell invasion}

Cells treated with si/sgRNAs against NEDD9 or RhoA and/or overexpressing CA-RhoA and/or treated with $50 \mu \mathrm{M}$ Y-27632 or $100 \mathrm{nM}$ MLN8237 for $24 \mathrm{~h}$ were re-suspended in $1.5 \mathrm{mg} / \mathrm{ml}$ collagen and placed into 3D-Chemotaxis $\mu$-slides (Ibidi) according to manufacturer protocol. Fetal bovine serum was added to the left media reservoir to create a chemoattractant gradient. When used, Y-27632 and/or MLN8237 were also added to both reservoirs to keep the drugs present during the assay. Cells were imaged every 15 minutes via DIC 10X objective on a Nikon Sweptfield/Eclipse/TE2000-E confocal microscope for 23 hours. Time lapse images were imported into ImageJ software and combined to form video files. Quantification methods are detailed in the Supplemental Materials and Methods.

\section{Live-cell imaging of collective cell invasion}

$1 \times 10^{5}$ cells in full medium were plated on top of $4-5 \mathrm{mg} / \mathrm{ml}$ Matrigel-coated delta-T dishes (Bioptechs). After 1 hour, the medium was removed and the cell layer was covered with more Matrigel. After polymerizing for 30 minutes at $37^{\circ} \mathrm{C}$, media was re-added. Live-cell imaging was conducted every 10 minutes for 24 hours at $37^{\circ} \mathrm{C}$ via Nikon Sweptfield/Eclipse/TE2000-E confocal microscope (20X objective). Time lapse images were imported into ImageJ software and combined to form video files. Quantification methods are detailed in the Supplemental Materials and Methods.

\section{Fluorescent imaging of collective cell invasion sandwich assay}

Cells were pretreated overnight with $50 \mu \mathrm{M}$ Y-27632 or 100nM MLN8237, and 3x104 cells were plated in 8-well chamber slides (ThermoFisher) coated with $150 \mu \mathrm{l}$ mg/ml Matrigel. After 1 hour, the medium was removed and the cells covered with another $200 \mu l$ Matrigel, followed by full media after Matrigel polymerization. Cells were live imaged in $5 \mu \mathrm{m}$ Z-steps away from the cell seeding position at 72 hours using a Nikon Sweptfield/Eclipse/TE2000-E confocal microscope. Invasion was quantified by total cell fluorescence intensity at the furthest distance cells reached $(100 \mu \mathrm{m}) .3 \mathrm{D}$ invasion boxes 
were constructed using the Volume-Viewer plugin for ImageJ to show cell fluorescence signal throughout the Matrigel from the seeding position.

\section{Mouse xenograft study}

Animals were housed in the WVU Animal Facility under pathogen-free conditions according to

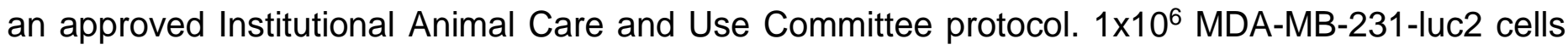
expressing doxycycline-inducible pTRIPZ-RFP-shControl or shNEDD9 (25) were suspended in $4 \mathrm{mg} / \mathrm{ml}$ Matrigel (Trevigen) and injected into the mammary fat pad of 6-8-weeks old immunodeficient

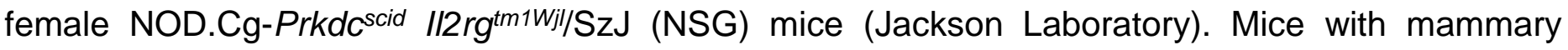
tumors $\left(150-200 \mathrm{~mm}^{3}\right)$ were pre-treated in neoadjuvant settings with $10 \mathrm{mg} / \mathrm{kg}$ AURKA inhibitor MLN8237 via oral gavage for 1 week (4 days on, 3 days off) as previously described to temporarily halt metastasis, but continue mammary tumor growth (31). shRNA expression in tumor cells was induced via introduction of doxycycline-containing food (Bio-Serv) in combination with vehicle or $10 \mathrm{mg} / \mathrm{kg}$ Y-27632 which was administered by oral gavage for 3 weeks ( 4 days on, 3 days off). Tumor growth and dissemination was evaluated weekly through in vivo whole-body bioluminescence imaging (BLI) using an IVIS/Lumina-II system as previously described (17). After 3 weeks, lungs, mammary tumors, and blood were collected for analysis. Paraffin-embedded lung sections were stained by hematoxylin and eosin (H\&E) and analyzed for the number of metastases per lung area by a pathologist as previously described (17). Primary tumors were analyzed for NEDD9 expression by western blot. Ten mice per both shRNA groups (further separated into 5 per drug group for a total of 20 mice) were used based on statistical analysis.

\section{Quantification of circulating tumor cells}

Submandibular mouse blood samples were collected into EDTA-coated tubes on ice to prevent clotting. Erythrocytes were lysed and removed from blood via incubation with RBC lysis buffer (eBioscience) according to manufacturer's protocol. Cells were fixed in 2\% paraformaldehyde for 10 minutes, followed by centrifugation at $500 \mathrm{~g}$ for 5 minutes at $4^{\circ} \mathrm{C}$, and resuspended in $1 \%$ BSA/PBS. 
Flow cytometry (FACS) was performed using a BD Biosciences/LSR Fortessa to count RFP-positive circulating tumor cells in the blood samples. Final counts were normalized to initial primary tumor size at week zero.

\section{Statistical analysis}

One-way ANOVA or student's $t$-test statistical analyses were performed with GraphPad Prism software where noted. $p \leq 0.05$ was considered to be significant $\left({ }^{*}\right)$. Experimental values were reported as the mean \pm SEM (standard error of mean). 


\section{Results}

\section{TNBC cell morphology changes upon NEDD9 and ROCK inhibition}

Metastatic TNBC cell lines with primarily mesenchymal morphology (MDA-MB-231, BT549, HCC1143, HCC1395, Hs578T and SUM159) were used to assess the role of NEDD9 in switching cells from mesenchymal to amoeboid morphology. NEDD9 was depleted using previously characterized siRNAs $(17,32)$ (Fig.1A) in a SMARTpool, and the changes in individual cell morphology were monitored using live cell imaging microscopy when plated in 2D or suspended in 3D matrix (collagen I or Matrigel).

In 2D, control (siCon) cells have well-defined elongated morphology, while NEDD9-depleted (siNEDD9) cells show up to a $40 \%$ decrease in cell elongation (Fig.S1A-B) reflected by a decrease in the ratio of cell length over cell width. In 3D matrix, the pore size is a critical determinant of cell morphology and migration type (20). The average pore size of the collagen I matrix used was about $15 \mu \mathrm{m}^{2}$ (Fig.S1C-D), which supports both amoeboid and mesenchymal movement (33). Alternatively, the tightly-packed fibers that make up Matrigel are not conducive for amoeboid migration $(<1 \mu \mathrm{m})$ and are permissive primarily for matrix-degrading mesenchymal movement. Interestingly, when seeded in either of these 3D scaffolds, siNEDD9 cells show acquisition of rounded amoeboid morphology and up to a $50 \%$ decrease in cell elongation (Fig.1B-C), which is similar to $2 \mathrm{D}$ results.

Knockout of NEDD9 using sgRNAs and CRISPR/Cas9 technology led to similar changes in morphology with less variability in cell elongation and showing an elongation ratio closer to 1 , indicating that they are more circular with similar cell length and width (Fig.S1E-F). This phenotype was similar to cells overexpressing constitutively active RhoA GTPase (Fig.1D-F), suggesting RhoA activity may be high in NEDD9 deficient cells. Importantly, almost all TNBC cells demonstrated significant plasticity in their ability to not only be able to switch to amoeboid morphology, but also be able to increase mesenchymal morphology, which was confirmed as control cells became further elongated upon application of the well-characterized Rho kinase inhibitor, Y-27632 (Fig.1G-H). 


\section{NEDD9 depletion leads to increased myosin light chain phosphorylation but decreased contractility}

Next, we tested if the acquisition of amoeboid morphology by NEDD9-deficient TNBC cells is accompanied by a switch to amoeboid migration, which could potentially promote intra/extravasation during metastasis of breast cancer. Actomyosin contractility and force-mediated remodeling of the matrix is a signature of the amoeboid type of cell migration (34). A key driver of actomyosin contractility is the Rho kinase ROCK, which phosphorylates myosin II light chain (MLC2) (35). In both collagen and Matrigel, NEDD9 deficiency resulted in up to a threefold increase in pMLC2 (Fig.2A-D, Fig.S1J), which co-localized with cortical actin around the cell membrane.

Interestingly, despite this increase in pMLC2 in NEDD9-depleted cells, there was a significant decrease in the ability of the collective cell population to contract floating collagen gels (Fig.2E-F), indicating that morphologically amoeboid NEDD9-depleted cells may not possess all of the mechanistic properties of amoeboid cells. The inability of NEDD9-deficient cells to translate the increased pMLC2 signaling to matrix deformation/contraction may be indicative of impaired adhesion or actin dynamics connecting the internal and external forces of the cell.

\section{NEDD9 depletion leads to a decrease in mature focal adhesion dynamics}

Mature, large focal adhesions have been associated with the mesenchymal phenotype, whereas a decrease in size and maturity has been linked to amoeboid morphology $(36,37)$. Staining for phospho-FAK ( $p F A K^{Y 397}$ ) or phospho-paxillin ( $p^{2}$ axillin $^{Y 31}$ ) has been commonly used to label mature focal adhesions $(37,38)$. Immunofluorescence analysis shows up to a twofold decrease in the number of adhesions positive for $\mathrm{pFAK}^{\mathrm{Y397}}$ and pPaxillin ${ }^{\mathrm{Y31}}$ upon NEDD9 depletion (Fig.2G-J, S1GJ), indicating a critical role of NEDD9 in adhesion maturation. The decrease in FAK and paxillin phosphorylation was further confirmed by western blot in multiple breast cancer cell lines (Fig.2K-M, S2). NEDD9 deficiency trended toward a decrease in the number of adhesions containing the more mature/stable focal adhesion marker vinculin (39), which would be concurrent with amoeboid 
phenotype, however the length of many of these adhesions was increased compared to control, suggesting the stabilization of fibrillar adhesions (Fig.S3). Nevertheless, NEDD9-depleted cells also had an increase in the total number of small adhesions that contained talin (Fig.S4), which is one of the first proteins recruited to focal contacts/adhesions (39). This indicates that there is an increase in small, weak nascent adhesions and a decrease in mature adhesions, which is concurrent with amoeboid phenotype (40). This may suggest that NEDD9 is not needed for adhesion initiation but is required for fibrillary adhesion disassembly. Such duality may potentially affect both mesenchymal and amoeboid adhesion dynamics.

\section{NEDD9 regulates AURKA-driven phosphorylation of CTTN and stability of actin filaments}

Amoeboid morphology is characterized by a decrease in filamentous actin polymerization while the mesenchymal elongated shape relies on an increase in filamentous actin (7). Previously, we have shown that NEDD9 binds and activates AURKA and the actin stabilizing protein CTTN, which results in an increase in actin polymerization and stabilization of lamellar protrusions and invadopodia (19). Here we show that AURKA directly phosphorylates CTTN (Fig.3A) at the (C-terminus 350-546aa) (Fig.3B, S5). To assess the impact of this phosphorylation on actin dynamics, an in vitro actin polymerization assay was carried out using recombinant AURKA and CTTN proteins. Incubation of AURKA with CTTN resulted in a significant increase in the actin polymerization rate (Fig.3C) compared to CTTN without AURKA. AURKA alone or in combination with Arp2/3 and WASP did not significantly affect actin polymerization, indicating that CTTN is the major substrate of AURKA in this assay. Moreover, kymography analysis of mCherry-LifeAct-expressing cells shows that the inhibition of AURKA results in a complete blockade of lamellar protrusions (Fig.3D-F), indicating that AURKA has a key role in cellular actin dynamics.

\section{NEDD9 depletion decreases Rac1 activity in breast cancer cells}

Rac1 GTPase has been shown to be one of the key drivers of mesenchymal migration/morphology. To measure Rac1 activity in cells grown in either 3D collagen or Matrigel, GST- 
tagged PBD (PAK p21 binding domain) protein was used to specifically pull down Rac1-GTP. Cells overexpressing dominant negative Rac1 (DN) or constitutively active Rac1 (CA) were used as controls (Fig.S6A). NEDD9 depletion resulted in a significant decrease in the amount of active Rac1 in cells grown in both scaffolds (Fig.4A-B). This was consistent when repeated in two other mesenchymal breast cancer cell lines as well, Hs578T and HCC1143 (Fig.S6B-C). As a complementary approach, Rac1 G-LISA assays (41) were used to evaluate the effect of NEDD9 depletion. Similarly to the active Rac1 pulldown assay, Rac1 G-LISA shows a decrease in the amount of active Rac1 (Fig.4B, Fig.S6D). Additionally, the RhoA G-LISA shows an increase in the amount of active RhoA, which is concurrent with amoeboid phenotype (Fig.4C).

\section{NEDD9 drives Rac1 activity through interaction with GEF VAV2}

Previously, it was shown in melanoma cells that NEDD9 activates Rac1 via interaction with the Rac1-GEF DOCK3 (15). Based on the breast cancer cell expression profiles of different GEFs and their downstream effectors, several potential Rac1 GEF candidates were examined for their ability to bind NEDD9 in co-immunoprecipitation experiments including DOCK4, DOCK180, VAV2, Tiam1, GEF-H1, ARHGEF2, ARHGEF4, DEF6, ECT2, and DBL (Supplementary Table 1). Some GEFs (such as DEF6, Fig.S6E) were co-immunoprecipitated with NEDD9 using anti-NEDD9 specific monoclonal (2G9) antibody, however only VAV2 was found to also reciprocally pull down NEDD9 (Fig.4D, Fig.S6F) when immunoprecipitating VAV2. To confirm that VAV2 is required for Rac1 activation in breast cancer cells, active Rac1 pulldowns were performed on cells treated with siCon or siRNA targeting VAV2 (Fig.4E). VAV2 depletion resulted in a 40-60\% reduction in activity of Rac1 (Fig.4F), supporting the notion that VAV2 is a critical downstream effector of NEDD9-dependent Rac1 activation. Importantly, treatment of siCon cells with EHop-016 (42), a small molecular compound which inhibits Rac1 activation by VAV2 through interaction with Rac1's VAV2-binding site, resulted in a reduction in Rac1 activity that was similar to the effect caused by siNEDD9 (Fig.S6G-H). This inhibition effect by EHop-016 was not found to be additive when combined with NEDD9 depletion. 
Additionally, an increase in Rac1 activity through NEDD9 overexpression was able to be blocked by VAV2 knockdown, further supporting that NEDD9-induced Rac1 activity is VAV2 dependent (Fig.4G).

\section{Simultaneous targeting of NEDD9 and ROCK/RhoA hinders breast cancer cell motility/invasion} in vitro

Since NEDD9 depletion supports the ROCK/RhoA pathway, knockdown of NEDD9 was combined with the ROCK-targeting compound Y-27632 to test for an additional therapeutic benefit in 3D invasion assays. NEDD9 depletion alone (via siRNA or sgRNA) led to an increase in amoeboid morphology and drastically decreased invasion (Fig.5A-E, Vid.S1; Fig.S7A-D, Vid.S2), similar to the overexpression of constitutively active RhoA (Fig.S7F-J, Vid.S3). Combination of Y-27632+siNEDD9 led to an increase in leading edge speed (extension/retraction), but decreased the cell body speed, thus rendering the elongated cell immobile (Fig.5C). The directionality and elongation of Y-27632treated cells was significantly increased regardless of NEDD9 depletion (Fig.5D-E). As a complementary approach, RhoA depletion was performed and resulted in comparable trends (Fig.S8, Vid.S4). Effects on invasion were also evaluated using Hs578T and HCC1143 cells treated with siNEDD9, confirming similar results (Fig.S9, Vid.S5-6). Additionally, the AURKA inhibitor MLN8237 was tested as a substitute for siNEDD9 in combination treatments. Cell invasion distance was found to be decreased with MLN8237/Y-27632 treatment, and was similar to the efficacy of siNEDD9/Y27632 treatment (Fig.S10A-B, Vid.S7). This suggests that MLN8237/Y-27632 could potentially be a viable combination regimen as well.

\section{NEDD9 is required for collective migration in 3D matrix}

To test the impact of NEDD9 depletion on collective tumor cell invasion, cells were seeded in high density while sandwiched in between two Matrigel layers and time lapse microscopy was performed. Control cells invaded as strand-like collective streams ("highways"), similar to previous observations (9) (Fig.5F, Vid.S8). Formation of these streams is diminished following NEDD9 knockdown, which suggests the cells have minimal matrix degradation and/or rearrangement capacity. 
This deficiency in path-generating activity is required for leading cells during collective invasion. Additionally, cell speed and directionality were both significantly decreased in NEDD9-depleted cells (Fig.5G-H), which corroborates with a significant reduction in their invasion distance (Fig.5I-K). Furthermore, inhibition of AURKA yielded a similar decrease in collective cell invasion compared to NEDD9 depletion (Fig.S10C-D), again suggesting that AURKA could be a viable therapeutic target.

\section{Combination of NEDD9 knockdown and Y-27632 treatment hinders breast cancer cell invasion} and metastasis in vivo

MDA-MB-231-luc2 pTRIPZ-RFP-shControl or shNEDD9 cells were injected into the mammary fat pad of NSG mice. After 2.5 weeks, mice were treated with the AURKA inhibitor MLN8237 (4 days on, 3 days off) to prevent pulmonary metastases outgrowth without any effect on the mammary tumor growth as we previously reported (17). 72 hours post-MLN8237 pretreatment, mice with tumors were subjected to doxycycline-induced shCon or shNEDD9 expression and administration of Y-27632 compound for 3 weeks (Fig.6A). Primary tumor growth was measured weekly and was significantly reduced in shNEDD9/Y-27632 combination-treated animals compared to vehicle (Fig.6B-C). At the end of the study, NEDD9 depletion was confirmed in the mammary tumors by western blot (Fig.6DE). To measure the metastatic ability of the tumor cells, terminal blood samples were collected and analyzed after euthanization for circulating tumor cells (CTCs) using flow cytometry. Nearly a $40 \%$ reduction in the number of CTCs was documented with shNEDD9 induction, which decreased even further with addition of Y-27632 (Fig.6F). A significant abatement in the number of metastases per lung area was seen with NEDD9 knockdown, and an even more pronounced inhibition was seen in combination with Y-27632 (Fig.6G), supporting our hypothesis that dual targeting of both the mesenchymal and amoeboid pathways via NEDD9 and ROCK/RhoA can be a promising therapy against breast cancer metastasis (Fig.6H). 


\section{Discussion}

NEDD9 protein is found consistently upregulated in TNBCs and highly correlates with invasive/metastatic spread $(1,17)$. Our findings provide a mechanistic explanation for NEDD9-driven invasion processes and strongly advocates for the combination of anti-NEDD9/AURKA and antiROCK targeting compounds to inhibit these movement signaling cascades. In this study, we report that deficiency in NEDD9 signaling itself leads to inhibition of key aspects of both mesenchymal and amoeboid migration in TNBC cells, resulting in substantial hindrance on cell invasion and metastasis. Similar to results in melanoma (14), NEDD9 deficiency in TNBC cells results in rounded/amoeboid morphology along with a decrease in the total number of mature ( $\mathrm{pFAK/pPaxillin} \mathrm{positive)} \mathrm{adhesions}$ and an increase in the number of nascent adhesions (40). However, these cells also saw an increase in long fibrillar adhesions (Fig.S3D). These findings suggest that NEDD9 is also required for the disassembly of fibrillar adhesions similar to vinculin (43), which regulates the recruitment and release of focal adhesion proteins in a force-dependent manner (44). The role of NEDD9/HEF1 as a sensor of altered adhesion states has been previously reported (45). A decrease in disassembly could be due to matrix metalloprotease inhibition (46), as previously reported by our group (24). Hindered disassembly of FAs would be in disagreement with a previously noted increase in adhesion turnover of NEDD9-KO or mutant NEDD9 (Y189A) expressing fibroblasts in 2D cultures $(47,48)$, however the structure, composition, and dynamics of adhesions in 2D fibroblasts may be different from 3D tumor cells.

NEDD9 deficiency led to an increase in myosin-phosphorylated amoeboid-like cells, but this increase in pMLC2 did not translate to increased collective-cell contractility or invasion in 3D matrix. This disconnect may suggest a potential de-coupling between the actin filaments and myosin motors during cell body contraction (49). Alternatively, the inability of NEDD9-deficient cells to disassemble adhesions as we have suggested would limit amoeboid movement, which is in agreement with our previous reports on integrin dynamics (32). 
Consistent with past findings, we found that NEDD9 deficiency resulted in over a 50\% decrease in active Rac1, suggesting that NEDD9 is critical for Rac1 activation to occur in TNBC cells. We discovered that an interaction between NEDD9 and the Rac1-GEF protein VAV2 is required for Rac1 activation. Similar to NEDD9 depletion, loss of VAV2 yields a comparable decrease in Rac1 activity. Furthermore, the small molecule compound EHop-016, which efficiently blocks the interaction of Rac1 with VAV2 (42), did not cause an additive effect on Rac1 inhibition when given to siNEDD9 cells, suggesting that NEDD9 and VAV2 share the same pathway to Rac1 activation. The potential clinical application of this compound has yet to be determined, however another VAV-family targeting drug, the purine analogue azathioprine, was recently found to inhibit pancreatic cancer metastasis (50). Additionally, overexpression of NEDD9 increased Rac1 activity, which was abrogated upon depletion of VAV2, supporting that NEDD9's influence on Rac1 activation is VAV2-dependent. Selecting NEDD9 as a therapeutic target could potentially be more beneficial than targeting VAV2 due to its upstream placement in the mesenchymal pathway and the multiple downstream branches that it links to including VAV2/Rac1 and AURKA/CTTN. The effect of AURKA inhibition on actin dynamics in TNBCs and its ability to regulate filamentous actin polymerization via phosphorylation of CTTN suggests a potential mechanistic explanation for the mesenchymal to amoeboid morphology changes observed upon NEDD9 depletion and provides additional venues to explore CTTN/AURKA signaling in TNBC metastasis.

In collagen invasion assays, both NEDD9-deficient and MLN8237-treated cells underwent a drastic reduction in cell invasion. It was anticipated that amoeboid cells could potentially move faster with a more erratic cell trajectory. While a small decrease in directionality was seen upon NEDD9 depletion, it was not significant. Inhibition of ROCK or RhoA in NEDD9-deficient TNBC cells reverted them back to an elongated cell shape, but not their original migration proficiency. These combinationtreated cells also had a significant increase in cell directionality - this is likely due to their significant increase in cell length which was even higher than control cells. 
The substantially impeded movement of combination-treated cells could be related to the large difference in speed observed between the CB and LE. LE speed remains high, continuing to protrude and retract, but the cell is incompetent to degrade matrix and/or make anchor points, due to NEDD9 deficiency. Meanwhile, the cell rear cannot efficiently contract due to inhibition of ROCK/RhoA, leaving the CB more immobile. This combination therefore results in a severe gap between a stagnant, immotile CB along with a quickly protruding/retracting, yet functionally impaired LE. These results support the notion that simultaneous inhibition of both the NEDD9/AURKA and ROCK/RhoA pathways could be an efficient anti-migratory/metastasis treatment option. These conclusions were further supported by our findings in an in vivo breast cancer xenograft mouse model, demonstrating a significant reduction in the number of circulating tumor cells and pulmonary metastases of mice that received combination treatment. These findings are also in agreement with previously published reports of NEDD9 depletion showing a decrease in the invasion and dissemination of diverse cancer types in vivo $(1,2)$.

In conclusion, while NEDD9-deficient cells may have many hallmarks of amoeboid phenotype, we have shown that amoeboid movement appears defective in some respects such as decreased cell contractility. Nonetheless, depletion of RhoA or addition of ROCK inhibitor to NEDD9-deficient cells provided additional benefit in further hindrance of cell invasion/metastasis. Through concurrent targeting of these pathways, this approach merits further evaluation as a clinical option to augment breast cancer patient survival. 


\section{Acknowledgments}

The authors would like to thank and acknowledge the WVU Shared Research Facilities and the MBRCC and HSC core facilities including the WVU Microscope Imaging Facility (supported by the MBRCC and NIH grants P20 RR016440, P30 RR032138/GM103488 and P20 RR016477) and the WVU Flow Cytometry Core Facility (supported by the NIH equipment grant number S100D016165 and the Institutional Development Award (IDeA) from the National Institute of General Medical Sciences of NIH under grant numbers P30GM103488 (CoBRE) and P20GM103434 (INBRE)). 


\section{References}

1. Kong C, Wang C, Wang L, Ma M, Niu C, Sun X, Du J, Dong Z, Zhu S, Lu J, Huang B. NEDD9 is a positive regulator of epithelial-mesenchymal transition and promotes invasion in aggressive breast cancer. PLoS One. 2011;6(7):e22666. doi: 10.1371/journal.pone.0022666. PubMed PMID: 21829474; PMCID: 3145662.

2. Kim M, Gans JD, Nogueira C, Wang A, Paik JH, Feng B, Brennan C, Hahn WC, Cordon-Cardo C, Wagner SN, Flotte TJ, Duncan LM, Granter SR, Chin L. Comparative oncogenomics identifies NEDD9 as a melanoma metastasis gene. Cell. 2006;125(7):1269-81. Epub 2006/07/04. doi: S00928674(06)00718-5 [pii]

10.1016/j.cell.2006.06.008. PubMed PMID: 16814714.

3. Friedl P, Wolf K. Plasticity of cell migration: a multiscale tuning model. J Cell Biol. 2010;188(1):11-9. doi: 10.1083/jcb.200909003. PubMed PMID: 19951899; PMCID: 2812848.

4. Friedl P, Wolf K. Tumour-cell invasion and migration: diversity and escape mechanisms. Nat Rev Cancer. 2003;3(5):362-74. doi: 10.1038/nrc1075. PubMed PMID: 12724734.

5. Haeger A, Wolf $\mathrm{K}$, Zegers MM, Friedl P. Collective cell migration: guidance principles and hierarchies. Trends Cell Biol. 2015. doi: 10.1016/j.tcb.2015.06.003. PubMed PMID: 26137890.

6. Yilmaz M, Christofori G. Mechanisms of motility in metastasizing cells. Mol Cancer Res. 2010;8(5):629-42. doi: 10.1158/1541-7786.MCR-10-0139. PubMed PMID: 20460404.

7. Pankova K, Rosel D, Novotny M, Brabek J. The molecular mechanisms of transition between mesenchymal and amoeboid invasiveness in tumor cells. Cell Mol Life Sci. 2010;67(1):63-71. doi: 10.1007/s00018-009-0132-1. PubMed PMID: 19707854; PMCID: 2801846.

8. Wolf K, Friedl P. Extracellular matrix determinants of proteolytic and non-proteolytic cell migration. Trends Cell Biol. 2011;21(12):736-44. doi: 10.1016/j.tcb.2011.09.006. PubMed PMID: 22036198. 
9. Wolf K, Mazo I, Leung H, Engelke K, von Andrian UH, Deryugina El, Strongin AY, Brocker EB, Friedl P. Compensation mechanism in tumor cell migration: mesenchymal-amoeboid transition after blocking of pericellular proteolysis. J Cell Biol. 2003;160(2):267-77. PubMed PMID: 12527751.

10. Case LB, Baird MA, Shtengel G, Campbell SL, Hess HF, Davidson MW, Waterman CM. Molecular mechanism of vinculin activation and nanoscale spatial organization in focal adhesions. Nature cell biology. 2015;17(7):880-92. doi: 10.1038/ncb3180. PubMed PMID: 26053221; PMCID: 4490039.

11. Ahn J, Sanz-Moreno V, Marshall CJ. The metastasis gene NEDD9 product acts through integrin beta3 and Src to promote mesenchymal motility and inhibit amoeboid motility. J Cell Sci.125(Pt 7):1814-26. PubMed PMID: 22328516.

12. Bradbury P, Mahmassani M, Zhong J, Turner K, Paul A, Verrills NM, O'Neill GM. PP2A phosphatase suppresses function of the mesenchymal invasion regulator NEDD9. Biochim Biophys Acta.1823(2):290-7. PubMed PMID: 22061964.

13. Parri M, Chiarugi P. Rac and Rho GTPases in cancer cell motility control. Cell Commun Signal. 2010;8:23. doi: 10.1186/1478-811X-8-23. PubMed PMID: 20822528; PMCID: 2941746.

14. Sanz-Moreno V, Gadea G, Ahn J, Paterson H, Marra P, Pinner S, Sahai E, Marshall CJ. Rac activation and inactivation control plasticity of tumor cell movement. Cell. 2008;135(3):510-23. PubMed PMID: 18984162.

15. Ahn J, Sanz-Moreno V, Marshall CJ. The metastasis gene NEDD9 product acts through integrin beta3 and Src to promote mesenchymal motility and inhibit amoeboid motility. J Cell Sci. 2012;125(Pt 7):1814-26. doi: 10.1242/jcs.101444. PubMed PMID: 22328516.

16. Ammer AG, Weed SA. Cortactin branches out: roles in regulating protrusive actin dynamics. Cell Motil Cytoskeleton. 2008;65(9):687-707. doi: 10.1002/cm.20296. PubMed PMID: 18615630; PMCID: PMC2561250. 
17. Ice RJ, McLaughlin SL, Livengood RH, Culp MV, Eddy ER, Ivanov AV, Pugacheva EN. NEDD9 depletion destabilizes Aurora A kinase and heightens the efficacy of Aurora A inhibitors: implications for treatment of metastatic solid tumors. Cancer Res. 2013;73(10):3168-80. doi: 10.1158/00085472.CAN-12-4008. PubMed PMID: 23539442; PMCID: 3667743.

18. Pugacheva EN, Jablonski SA, Hartman TR, Henske EP, Golemis EA. HEF1-dependent Aurora A activation induces disassembly of the primary cilium. Cell. 2007;129(7):1351-63. PubMed PMID: 17604723.

19. Kozyreva VK, McLaughlin SL, Livengood RH, Calkins RA, Kelley LC, Rajulapati A, Ice RJ, Smolkin MB, Weed SA, Pugacheva EN. NEDD9 regulates actin dynamics through cortactin deacetylation in an AURKA/HDAC6-dependent manner. Mol Cancer Res. 2014;12(5):681-93. doi: 10.1158/1541-7786.MCR-13-0654. PubMed PMID: 24574519; PMCID: 4020952.

20. Wolf K, Te Lindert M, Krause M, Alexander S, Te Riet J, Willis AL, Hoffman RM, Figdor CG, Weiss SJ, Friedl P. Physical limits of cell migration: control by ECM space and nuclear deformation and tuning by proteolysis and traction force. J Cell Biol. 2013;201(7):1069-84. doi: 10.1083/jcb.201210152. PubMed PMID: 23798731; PMCID: 3691458.

21. Friedl $\mathrm{P}$, Wolf $\mathrm{K}$, Lammerding J. Nuclear mechanics during cell migration. Curr Opin Cell Biol. 2011;23(1):55-64. doi: 10.1016/j.ceb.2010.10.015. PubMed PMID: 21109415; PMCID: 3073574.

22. Seo S, Ichikawa M, Kurokawa M. Structure and function of cas-L and integrin-mediated signaling. Crit Rev Immunol. 2006;26(5):391-406. Epub 2007/03/08. doi: 023606d26a204d18,78c1314826d867c1 [pii]. PubMed PMID: 17341185.

23. Aquino JB, Lallemend F, Marmigere F, Adameyko, II, Golemis EA, Ernfors P. The retinoic acid inducible Cas-family signaling protein Nedd9 regulates neural crest cell migration by modulating adhesion and actin dynamics. Neuroscience. 2009;162(4):1106-19. doi: 10.1016/j.neuroscience.2009.05.035. PubMed PMID: 19464348; PMCID: PMC2797478. 
24. Loskutov YV, Kozyulina PY, Kozyreva VK, Ice RJ, Jones BC, Roston TJ, Smolkin MB, Ivanov AV, Wysolmerski RB, Pugacheva EN. NEDD9/Arf6-dependent endocytic trafficking of matrix metalloproteinase 14: a novel mechanism for blocking mesenchymal cell invasion and metastasis of breast cancer. Oncogene. 2014. doi: 10.1038/onc.2014.297. PubMed PMID: 25241893.

25. McLaughlin SL, Ice RJ, Rajulapati A, Kozyulina PY, Livengood RH, Kozyreva VK, Loskutov YV, Culp MV, Weed SA, Ivanov AV, Pugacheva EN. NEDD9 depletion leads to MMP14 inactivation by TIMP2 and prevents invasion and metastasis. Mol Cancer Res. 2014;12(1):69-81. doi: 10.1158/15417786.MCR-13-0300. PubMed PMID: 24202705; PMCID: 3946989.

26. Yamazaki D, Kurisu S, Takenawa T. Involvement of Rac and Rho signaling in cancer cell motility in 3D substrates. Oncogene. 2009;28(13):1570-83. doi: 10.1038/onc.2009.2. PubMed PMID: 19234490.

27. Weaver AM, Karginov AV, Kinley AW, Weed SA, Li Y, Parsons JT, Cooper JA. Cortactin promotes and stabilizes Arp2/3-induced actin filament network formation. Curr Biol. 2001;11(5):3704. PubMed PMID: 11267876.

28. Pugacheva EN, Golemis EA. The focal adhesion scaffolding protein HEF1 regulates activation of the Aurora-A and Nek2 kinases at the centrosome. Nat Cell Biol. 2005;7(10):937-46. PubMed PMID: 16184168.

29. Castello-Cros R, Cukierman E. Stromagenesis during tumorigenesis: characterization of tumorassociated fibroblasts and stroma-derived 3D matrices. Methods Mol Biol. 2009;522:275-305. doi: 10.1007/978-1-59745-413-1_19. PubMed PMID: 19247611; PMCID: PMC2670062.

30. Wozniak MA, Keely PJ. Use of three-dimensional collagen gels to study mechanotransduction in T47D breast epithelial cells. Biol Proced Online. 2005;7:144-61. doi: 10.1251/bpo112. PubMed PMID: 16299584; PMCID: 1285185.

31. Kozyreva VK, Kiseleva AA, Ice RJ, Jones BC, Loskutov YV, Matalkah F, Smolkin MB, Marinak K, Livengood RH, Salkeni MA, Wen S, Hazard HW, Layne GP, Walsh CM, Cantrell PS, Kilby GW, 
Mahavadi S, Shah N, Pugacheva EN. Combination of Eribulin and Aurora A Inhibitor MLN8237 Prevents Metastatic Colonization and Induces Cytotoxic Autophagy in Breast Cancer. Molecular cancer therapeutics. 2016;15(8):1809-22. doi: 10.1158/1535-7163.MCT-15-0688. PubMed PMID: 27235164; PMCID: 4975626.

32. Kozyulina PY, Loskutov YV, Kozyreva VK, Rajulapati A, Ice RJ, Jones BC, Pugacheva EN. Prometastatic NEDD9 Regulates Individual Cell Migration via Caveolin-1-Dependent Trafficking of Integrins. Mol Cancer Res. 2015;13(3):423-38. doi: 10.1158/1541-7786.MCR-14-0353. PubMed PMID: 25319010; PMCID: PMC4369181.

33. Artym VV, Matsumoto K. Imaging cells in three-dimensional collagen matrix. Curr Protoc Cell Biol. 2010;Chapter 10:Unit 108 1-20. doi: 10.1002/0471143030.cb1018s48. PubMed PMID: 20853341; PMCID: PMC2988473.

34. Gaggioli C, Sahai E. Melanoma invasion - current knowledge and future directions. Pigment cell research / sponsored by the European Society for Pigment Cell Research and the International Pigment Cell Society. 2007;20(3):161-72. doi: 10.1111/j.1600-0749.2007.00378.x. PubMed PMID: 17516924.

35. Wyckoff JB, Pinner SE, Gschmeissner S, Condeelis JS, Sahai E. ROCK- and myosindependent matrix deformation enables protease-independent tumor-cell invasion in vivo. Curr Biol. 2006;16(15):1515-23. doi: 10.1016/j.cub.2006.05.065. PubMed PMID: 16890527.

36. Carragher NO, Walker SM, Scott Carragher LA, Harris F, Sawyer TK, Brunton VG, Ozanne BW, Frame MC. Calpain 2 and Src dependence distinguishes mesenchymal and amoeboid modes of tumour cell invasion: a link to integrin function. Oncogene. 2006;25(42):5726-40. doi: 10.1038/sj.onc.1209582. PubMed PMID: 16652152.

37. Hager MH, Morley S, Bielenberg DR, Gao S, Morello M, Holcomb IN, Liu W, Mouneimne G, Demichelis F, Kim J, Solomon KR, Adam RM, Isaacs WB, Higgs HN, Vessella RL, Di Vizio D, Freeman MR. DIAPH3 governs the cellular transition to the amoeboid tumour phenotype. EMBO Mol Med. 
2012;4(8):743-60. doi: 10.1002/emmm.201200242. PubMed PMID: 22593025; PMCID: PMC3494074.

38. Cukierman E, Pankov R, Stevens DR, Yamada KM. Taking cell-matrix adhesions to the third dimension. Science. 2001;294(5547):1708-12. doi: 10.1126/science.1064829. PubMed PMID: 11721053.

39. Wozniak MA, Modzelewska K, Kwong L, Keely PJ. Focal adhesion regulation of cell behavior. Biochim Biophys Acta. 2004;1692(2-3):103-19. doi: 10.1016/j.bbamcr.2004.04.007. PubMed PMID: 15246682.

40. Huttenlocher A, Horwitz AR. Integrins in cell migration. Cold Spring Harb Perspect Biol. 2011;3(9):a005074. doi: 10.1101/cshperspect.a005074. PubMed PMID: 21885598; PMCID: PMC3181029.

41. Schlegel N, Burger S, Golenhofen N, Walter U, Drenckhahn D, Waschke J. The role of VASP in regulation of CAMP- and Rac 1-mediated endothelial barrier stabilization. American journal of physiology. 2008;294(1):C178-88. doi: 10.1152/ajpcell.00273.2007. PubMed PMID: 17989211.

42. Montalvo-Ortiz BL, Castillo-Pichardo L, Hernandez E, Humphries-Bickley T, De la MotaPeynado A, Cubano LA, Vlaar CP, Dharmawardhane S. Characterization of EHop-016, novel small molecule inhibitor of Rac GTPase. The Journal of biological chemistry. 2012;287(16):13228-38. doi: 10.1074/jbc.M111.334524. PubMed PMID: 22383527; PMCID: 3339933.

43. Teckchandani A, Cooper JA. The ubiquitin-proteasome system regulates focal adhesions at the leading edge of migrating cells. eLife. 2016;5. doi: 10.7554/eLife.17440. PubMed PMID: 27656905.

44. Carisey A, Tsang R, Greiner AM, Nijenhuis N, Heath N, Nazgiewicz A, Kemkemer R, Derby B, Spatz J, Ballestrem C. Vinculin regulates the recruitment and release of core focal adhesion proteins in a force-dependent manner. Curr Biol. 2013;23(4):271-81. doi: 10.1016/j.cub.2013.01.009. PubMed PMID: 23375895; PMCID: 3580286. 
45. O'Neill GM, Golemis EA. Proteolysis of the docking protein HEF1 and implications for focal adhesion dynamics. Mol Cell Biol. 2001;21(15):5094-108. PubMed PMID: 11438665.

46. Stehbens SJ, Paszek M, Pemble H, Ettinger A, Gierke S, Wittmann T. CLASPs link focaladhesion-associated microtubule capture to localized exocytosis and adhesion site turnover. Nature cell biology. 2014;16(6):561-73. doi: 10.1038/ncb2975. PubMed PMID: 24859005; PMCID: 4108447. 47. Zhong J, Baquiran JB, Bonakdar N, Lees J, Ching YW, Pugacheva E, Fabry B, O'Neill GM. NEDD9 stabilizes focal adhesions, increases binding to the extra-cellular matrix and differentially effects 2D versus 3D cell migration. PLoS One.7(4):e35058. PubMed PMID: 22509381.

48. Zou Z, Yuan Z, Zhang Q, Long Z, Chen J, Tang Z, Zhu Y, Chen S, Xu J, Yan M, Wang J, Liu Q. Aurora kinase A inhibition-induced autophagy triggers drug resistance in breast cancer cells. Autophagy. 2012;8(12):1798-810. doi: 10.4161/auto.22110. PubMed PMID: 23026799; PMCID: 3541289.

49. Wollrab V, Thiagarajan R, Wald A, Kruse K, Riveline D. Still and rotating myosin clusters determine cytokinetic ring constriction. Nature communications. 2016;7:11860. doi: 10.1038/ncomms11860. PubMed PMID: 27363521; PMCID: 4932180.

50. Razidlo GL, Magnine C, Sletten AC, Hurley RM, Almada LL, Fernandez-Zapico ME, Ji B, McNiven MA. Targeting Pancreatic Cancer Metastasis by Inhibition of Vav1, a Driver of Tumor Cell Invasion. Cancer research. 2015;75(14):2907-15. doi: 10.1158/0008-5472.CAN-14-3103. PubMed PMID: 25977335; PMCID: 4506209. 


\section{Figure Legends}

Fig. 1. TNBC cell morphology changes upon NEDD9 and ROCK inhibition

(A) Western blot analysis of NEDD9 expression in MDA-MB-231, HCC1143, and Hs578T treated with multiple siRNAs. (B) Brightfield images of MDA-MB-231, HCC1143, and Hs578T cells treated with siCon or siNEDD9 in 3D collagen I and (C) cell elongation quantified as cell length/width (40 cells/group). (D) Brightfield images of BT549, HCC1395, and SUM159 cells expressing siCon, siNEDD9, or CA-RhoA, (E) cell elongation quantified as cell length/width (100 cells/group), and (F) western blots of NEDD9 knockdown and CA-RhoA expression. (G) Brightfield images of TNBC cells, vehicle or $\mathrm{Y}-27632$ treatment and $(\mathrm{H})$ cell elongation quantified as cell length/width (40 cells/group). ns, not significant; * $p<0.05$, student's $t$-test vs control.

Fig. 2. NEDD9 depletion increases phosphorylation of MLC2 and decreases phosphorylation of FAK and paxillin

(A) MDA-MB-231 siCon and siNEDD9 cells in collagen I stained for pMLC2, actin, and Hoechst DNA dye. Scale bar, $20 \mu \mathrm{m}$. (B) Box and whisker plot of pMLC2 relative fluorescence intensity (RFI), $n=3$, 20-30 cells/group. Intensity was normalized to the cell area. (C) Western blot and (D) quantification of MLC2 phosphorylation, $n=3$. (E) Collagen gel contraction assay of MDA-MB-231 CRISPR sgCon/sgNEDD9 cells over 24 hours and $(F)$ quantification of collagen gel area, $n=3$. (G) MDA-MB231 siCon and siNEDD9 cells in collagen I stained for $\mathrm{pFAK}^{\mathrm{Y} 397}$ or pPaxillin ${ }^{\mathrm{Y} 31}$ and Hoechst DNA dye. Scale bar, $20 \mu \mathrm{m}$. (H) Box and whisker plot of pFAK ${ }^{\Upsilon 397}$ fluorescence and (I) pPaxillin ${ }^{\Upsilon 31}$ fluorescence, $n=3$, at least 20 cells/group. (J) Quantification of \# of focal adhesions per cell, $n=3$, at least 20 cells/group. (K) Western blot and quantification of (L) FAK and (M) paxillin phosphorylation. $n=3$. ${ }^{*} p<0.05$, student's $t$-test vs control.

Fig. 3. NEDD9 regulates AURKA-driven phosphorylation of CTTN and stability of actin filaments

(A) Radioactive in vitro kinase assay of recombinant AURKA and full length WT CTTN proteins using 
radiolabeled P32-ATP, $n=3$. WB shows total protein (top and middle) while autoradiograph shows P32-phosphorylated protein (bottom). (B) Radioactive in vitro kinase assay of recombinant AURKA and N-term (1-350 aa) and C-term (350-546 aa) CTTN proteins using radiolabeled P32-ATP, $n=3$. WB shows total protein (top and middle) while autoradiograph shows P32-phosphorylated protein (bottom, 24 hour exposure). (C) Pyrene-actin polymerization assay of AURKA and CTTN, $n=4$. Curves were fit with Boltzmann sigmoidal analysis, ${ }^{*} p<0.05$. (D) Kymographs of cell membrane of MDA-MB-231 cells treated with Vehicle or MLN8237 and quantifications of (E) protrusion velocity and (F) maximum membrane extension. n.d., not detected.

\section{Fig. 4. NEDD9 drives Rac1 activity through interaction with GEF VAV2}

(A) Western blot of active-Rac1 pulldown (PD) from MDA-MB-231 siCon/siNEDD9 cells in 3D Matrigel using GST-PBD conjugated beads. Lane 1: GST-empty beads control. WCL, whole cell lysate. (B) Quantification of Rac1 activity in 3D collagen and Matrigel (active/total Rac1) by WB. (C) Quantification of RhoA activity in 3D collagen and Matrigel by G-LISA. (D) Co-immunoprecipitation of HA-VAV2 and RFP-NEDD9 through IP of each protein. IgG, mouse IgG control. (E) Western blot of active-Rac1 pulldown from MDA-MB-231 siCon/siVAV2 cells and (F) quantification of Rac1 activity. (G) Western blot of active-Rac1 pulldown from GFP-NEDD9 overexpressing MDA-MB-231 siCon/siVAV2 cells. Lane 1: GST-empty beads control. WCL, whole cell lysate. Exog, exogenous. Endog, endogenous. For all experiments: $n=3,{ }^{\star} p<0.05$, student's $t$-test vs control.

Fig. 5. Simultaneous targeting of NEDD9 and ROCK/RhoA hinders breast cancer cell motilitylinvasion in vitro

(A) Brightfield outlined cell morphology images ( $\sim 12$ hours), (B) individual cell tracking movement plots toward FBS chemoattractant (left), box and whisker plots of (C) cell body (CB) and leading edge (LE) speed, (D) cell body directionality, and (E) cell elongation of MDA-MB-231 cells with siCon/siNEDD9 + Vehicle/Y-27632 treatment in 3D collagen Ibidi chemotactic invasion movies. Scale bar, $20 \mu \mathrm{m} . n=$ 3, 30-40 cells per group. ns, not significant; ${ }^{\star} p<0.05$, one-way ANOVA. (F) GFP immunofluorescence 
images and box and whisker plots of $(\mathrm{G})$ cell body speed and $(\mathrm{H})$ cell body directionality of MDA-MB231 pGIPZ-GFP shControl and shNEDD9 cells after 24 hours being densely seeded in a 3D Matrigel sandwich assay. Scale bar: $20 \mu \mathrm{m} . n=3$, at least 60 cells per group. ${ }^{\star} p<0.05$, student's $t$-test vs control. (I) 3D projection boxes and (J) collective invasion quantification of the amount of MDA-MB231 pGIPZ-GFP shControl/shNEDD9 cells reaching $100 \mu \mathrm{m}$ invasion distance after 72 hours being densely seeded in a 3D Matrigel sandwich assay. ${ }^{*} p<0.05$, student's $t$-test vs control. (K) Western blot of shNEDD9 knockdown in collective invasion assay.

Fig. 6. Simultaneous targeting of NEDD9 and ROCK hinders breast cancer cell invasion and metastasis in vivo

(A) MDA-MB-231-luc2 TZ RFP-shCon and RFP-shNEDD9 cells injected into the mammary fat pad of NSG mice were grown for $\sim 3.5$ weeks before starting treatment (time 0 ) for 3 weeks with $10 \mathrm{mg} / \mathrm{kg}$ Y27632 and shRNA induction. (B) Weekly images of tumor cells in vivo via bioluminescence signal which was (C) quantified at the primary tumor site. (D) Western blot and (E) quantification of NEDD9 knockdown in final primary tumors. (F) Quantification of number of RFP-positive circulating tumor cells in mouse blood by FACS analysis. (G) Quantification of number of visible metastases per area of lung tissue. $(\mathrm{H})$ Proposed schematic of mesenchymal and amoeboid pathways in breast cancer. $n=5$ mice/group. ${ }^{*} p<0.05$, one-way ANOVA. 


\section{Figures}

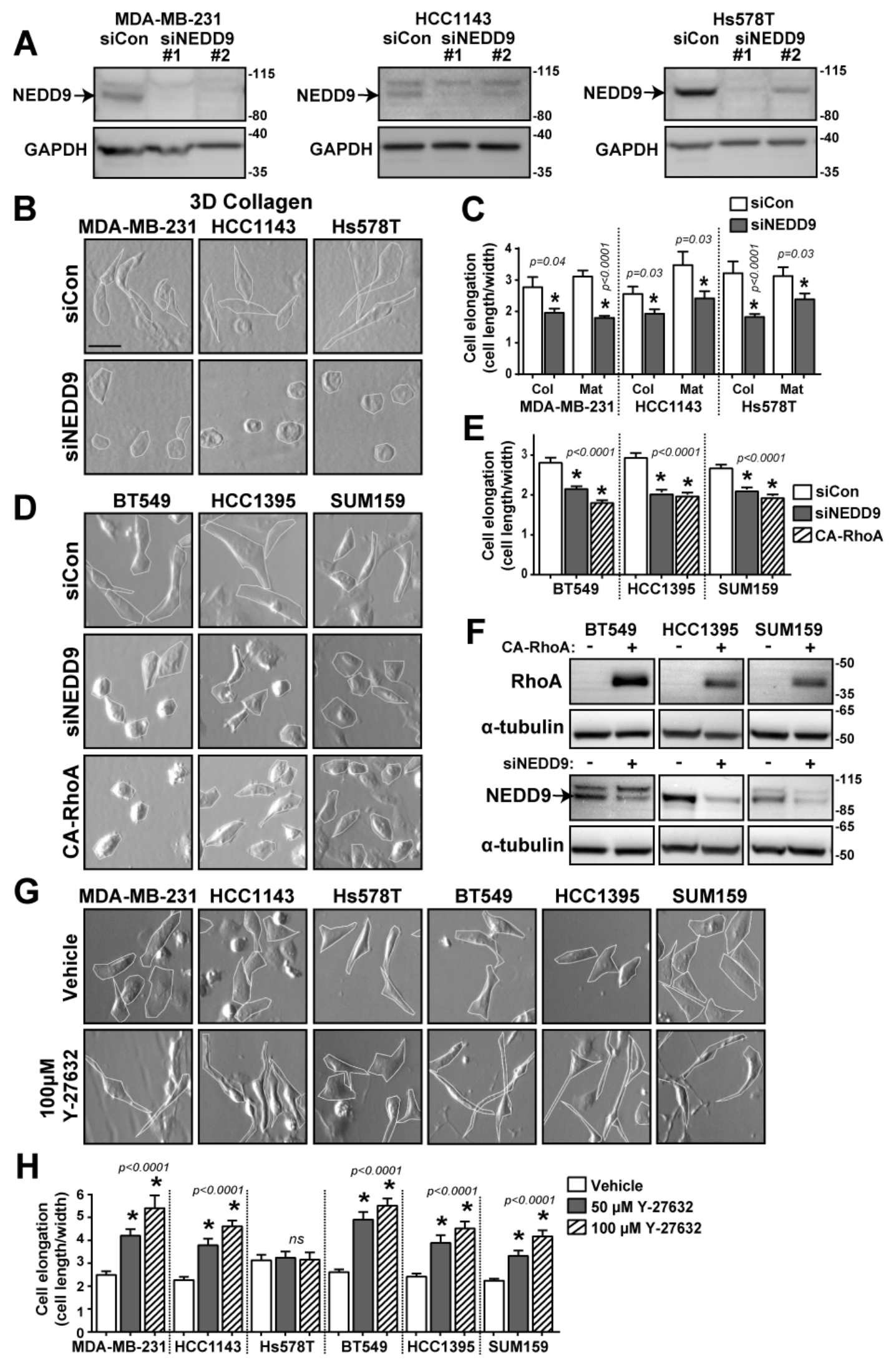

Figure 1. 

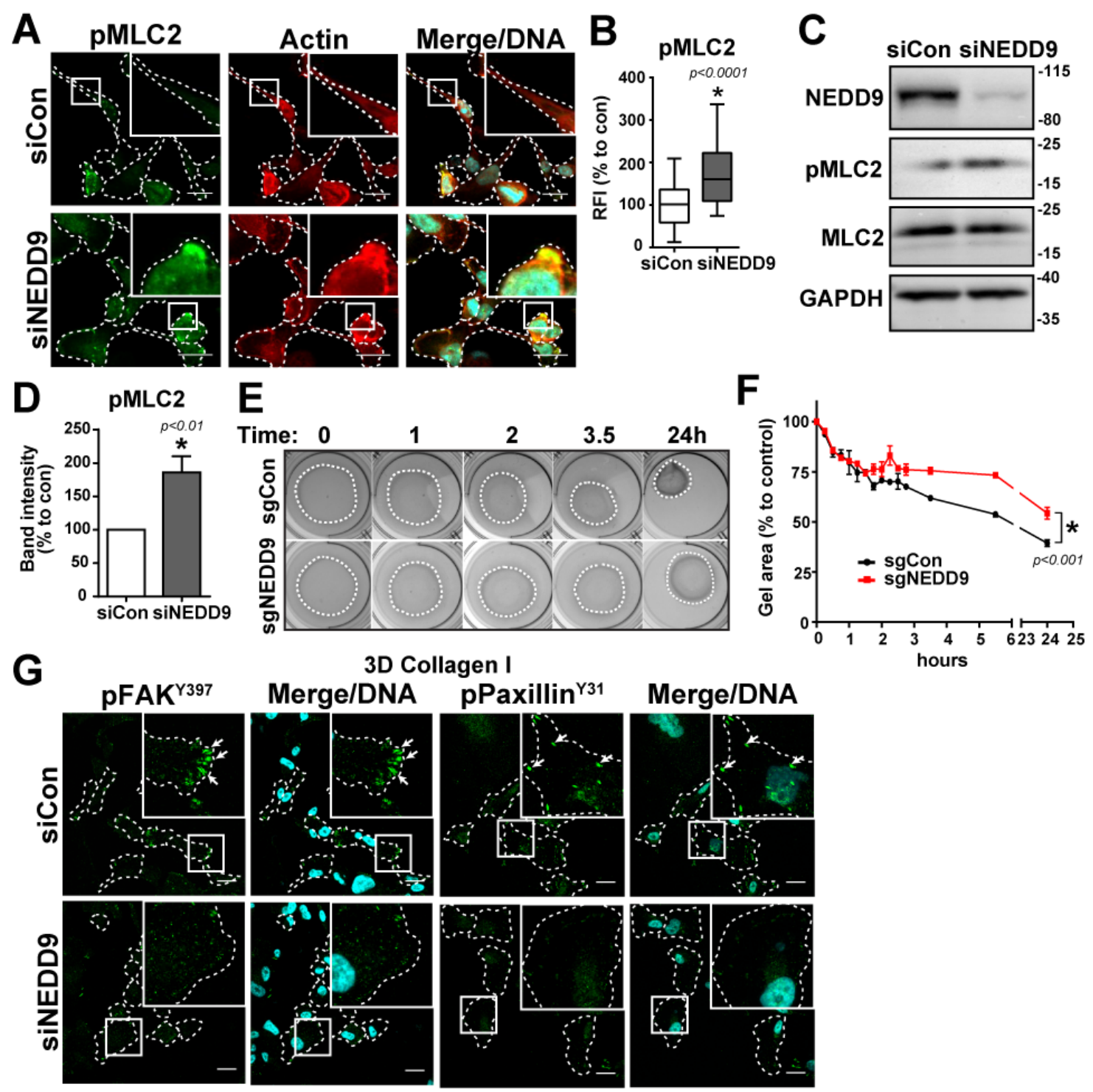

Merge/DNA
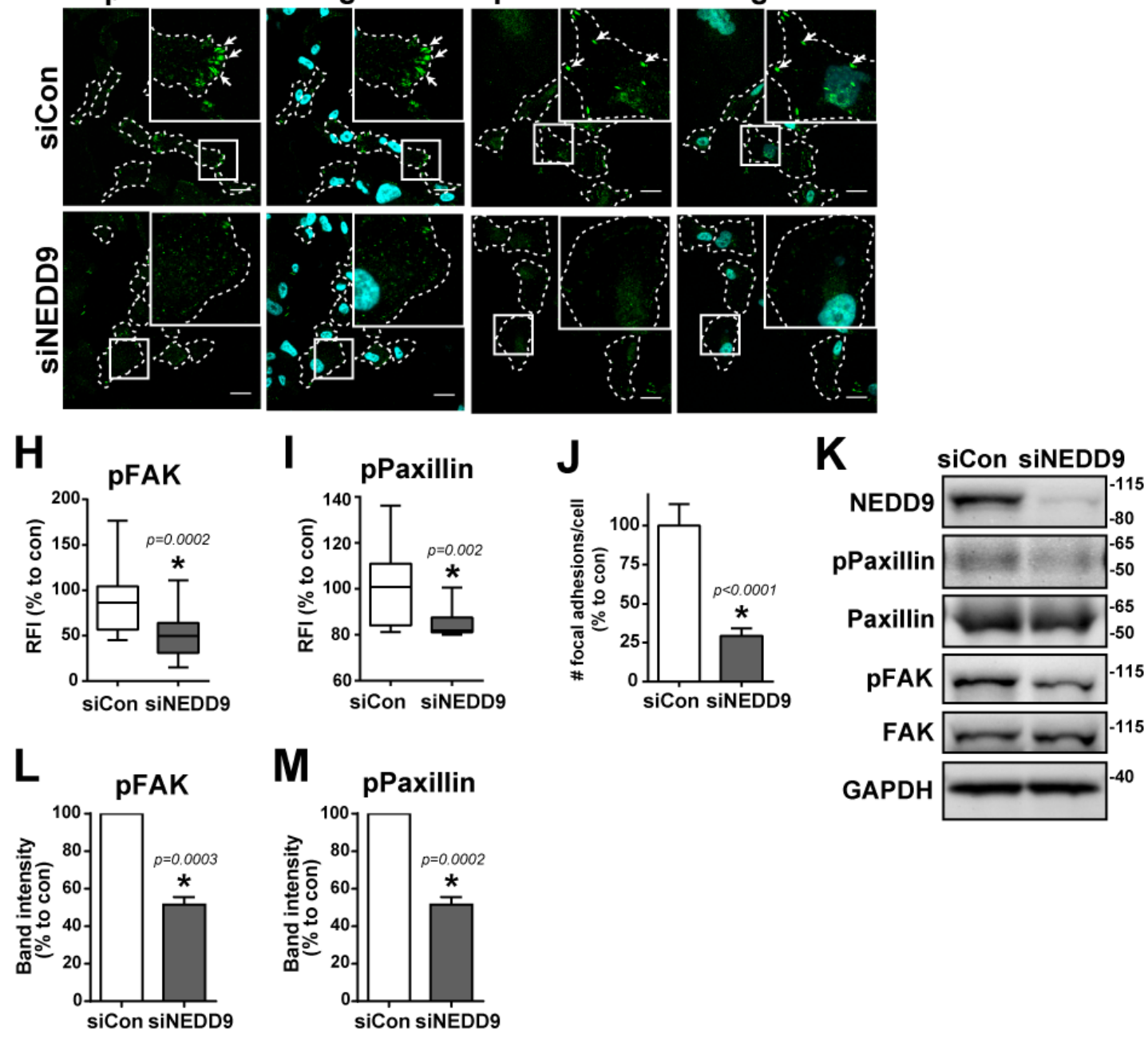

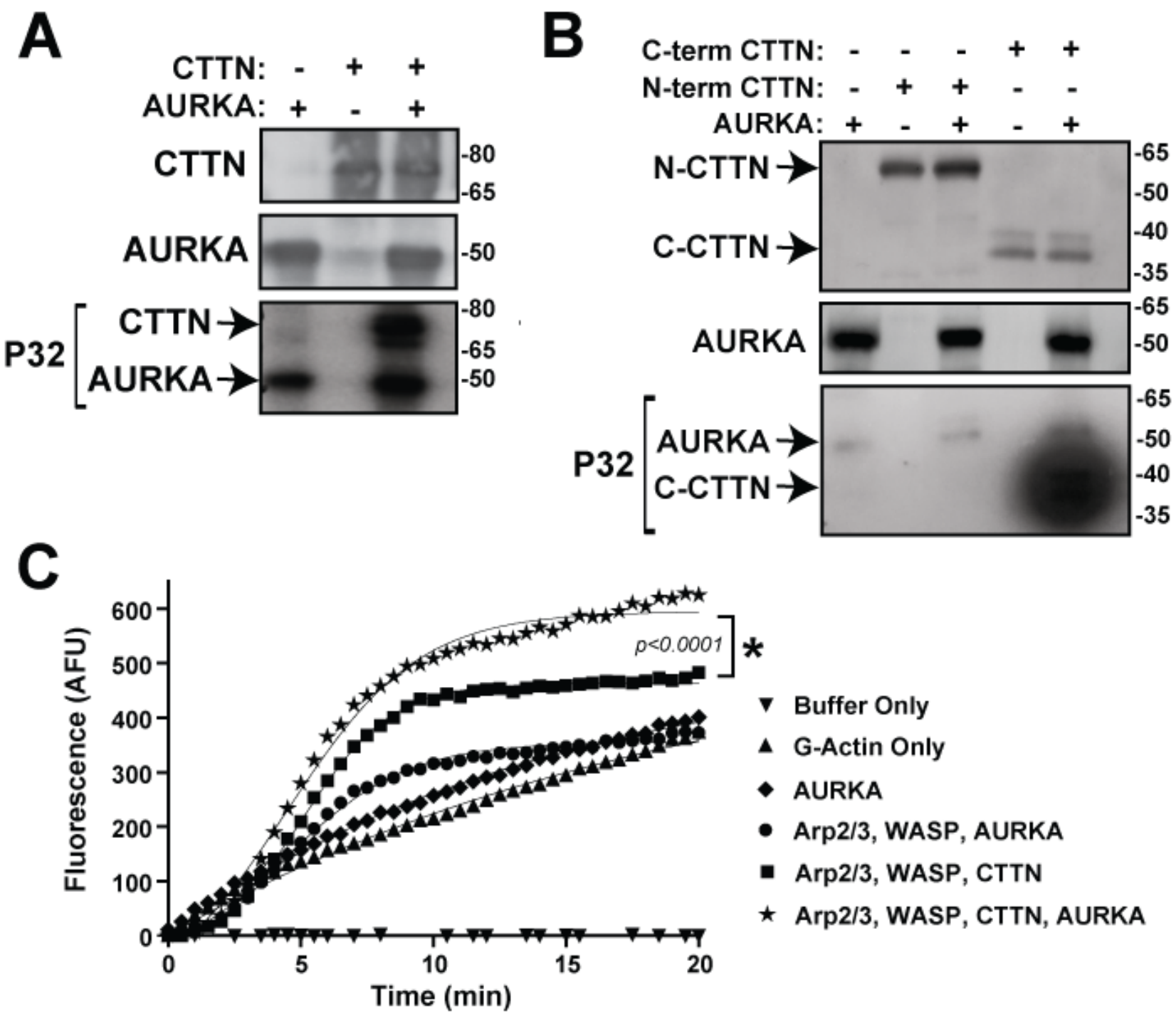

v Buffer Only

- G-Actin Only

- AURKA

- Arp2/3, WASP, AURKA

- Arp2/3, WASP, CTTN

$\star$ Arp2/3, WASP, CTTN, AURKA
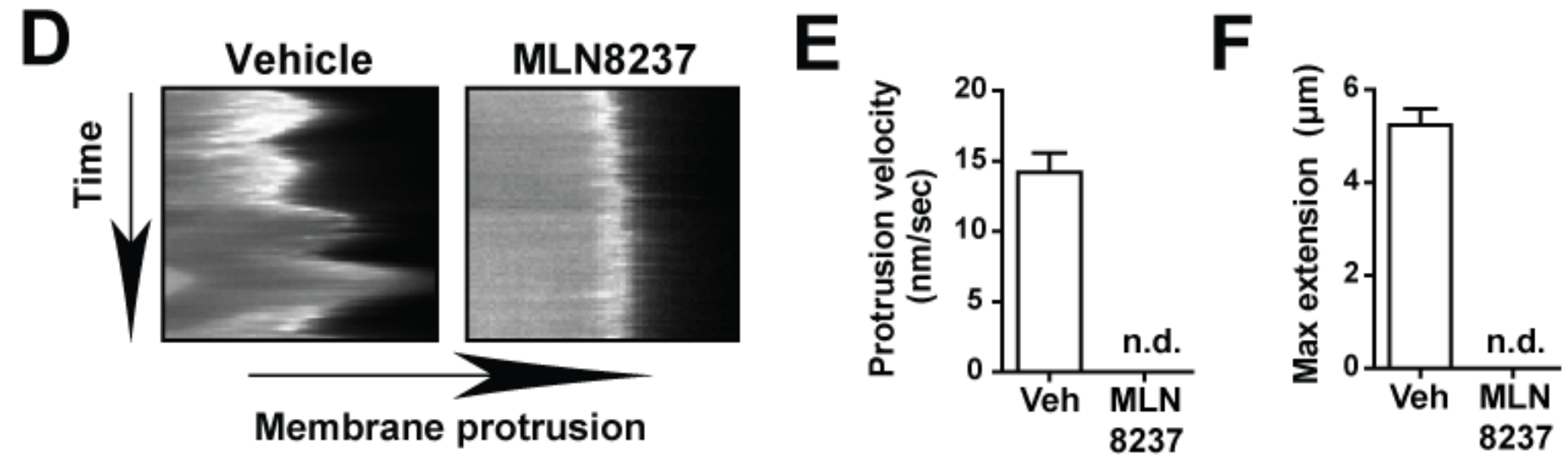

Figure 3. 
A
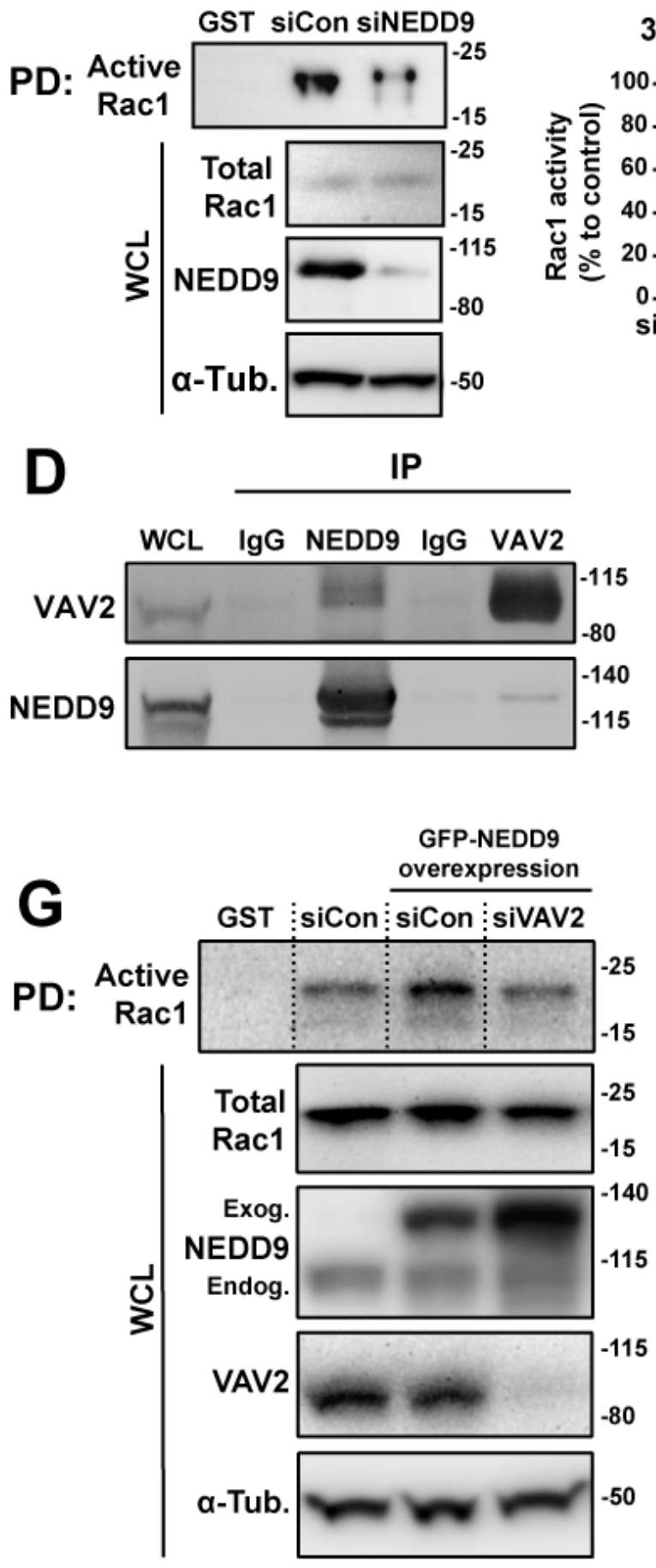

PD: Active Rac1

3D Collagen 3D Matrigel
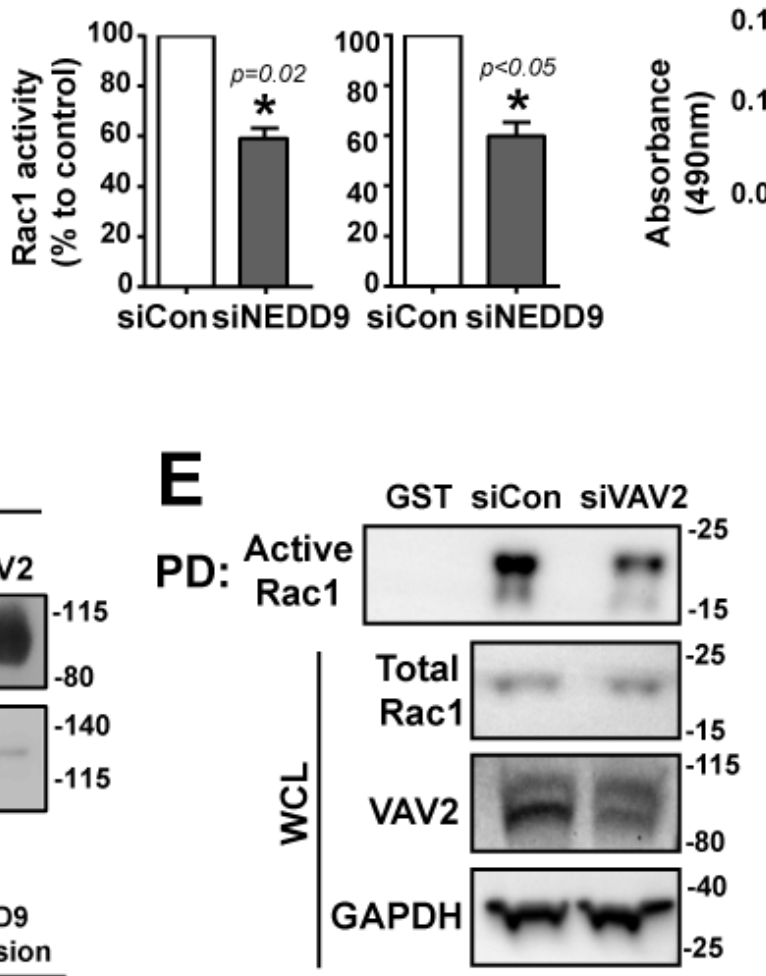

G-LISA: Active RhoA 3D Collagen 3D Matrigel

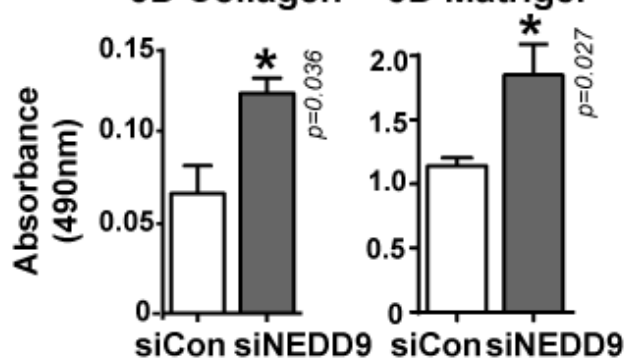

E

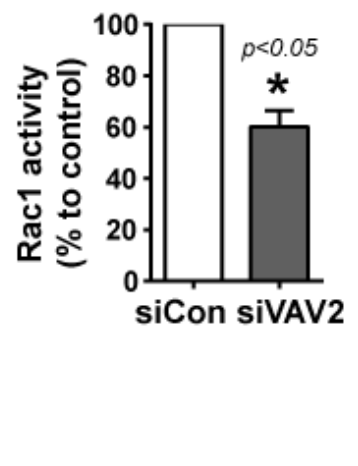

Figure 4. 
A

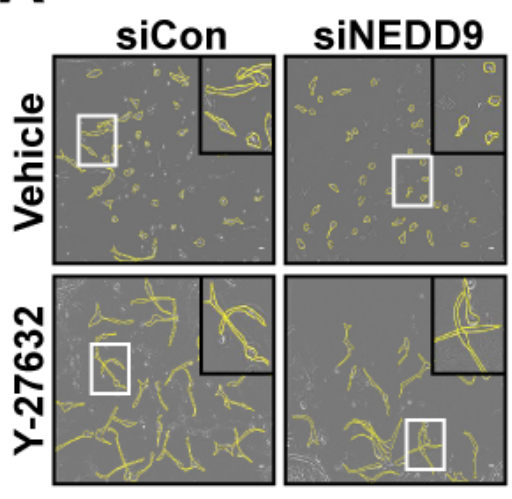

C

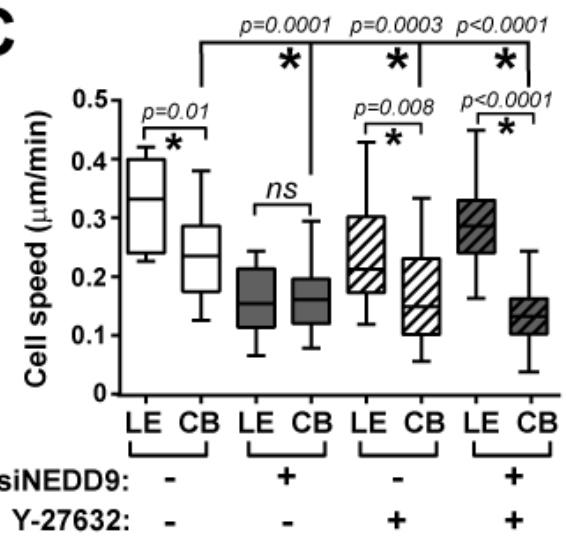

B

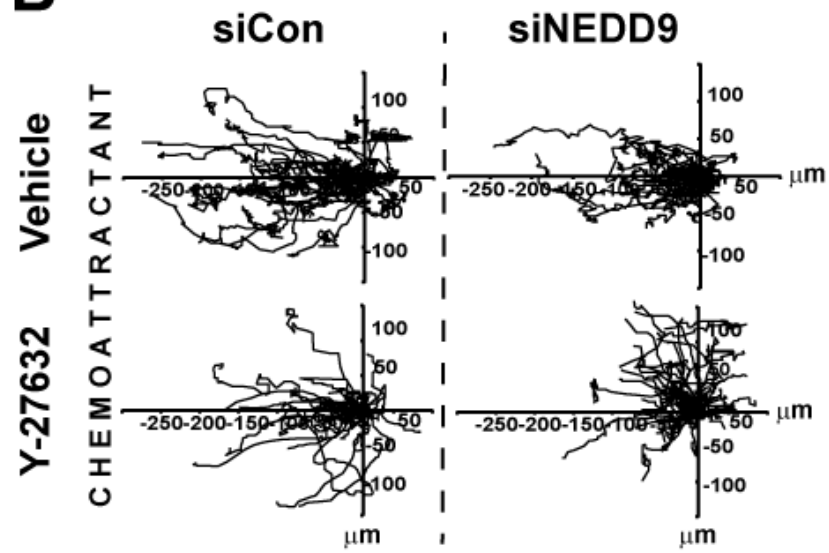

D

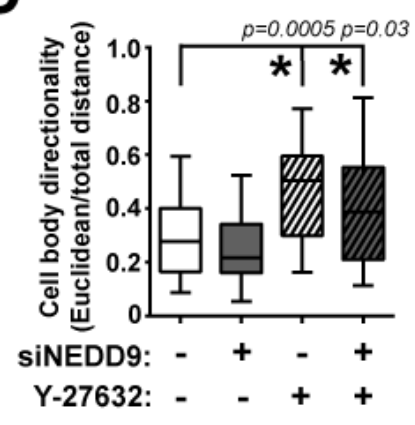

E

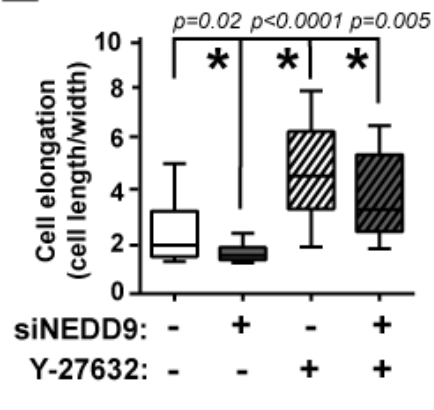

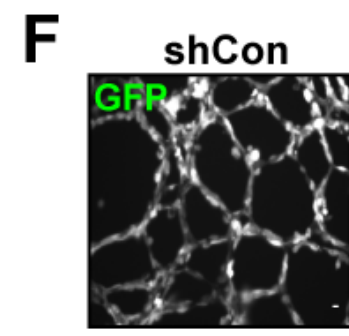
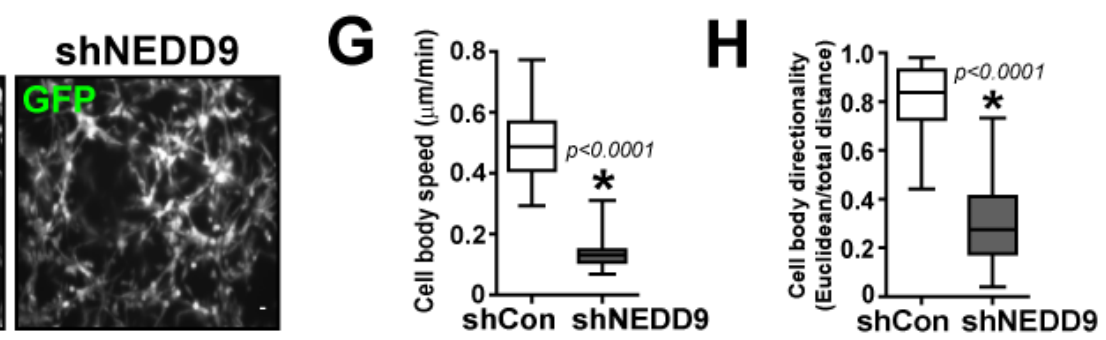

I
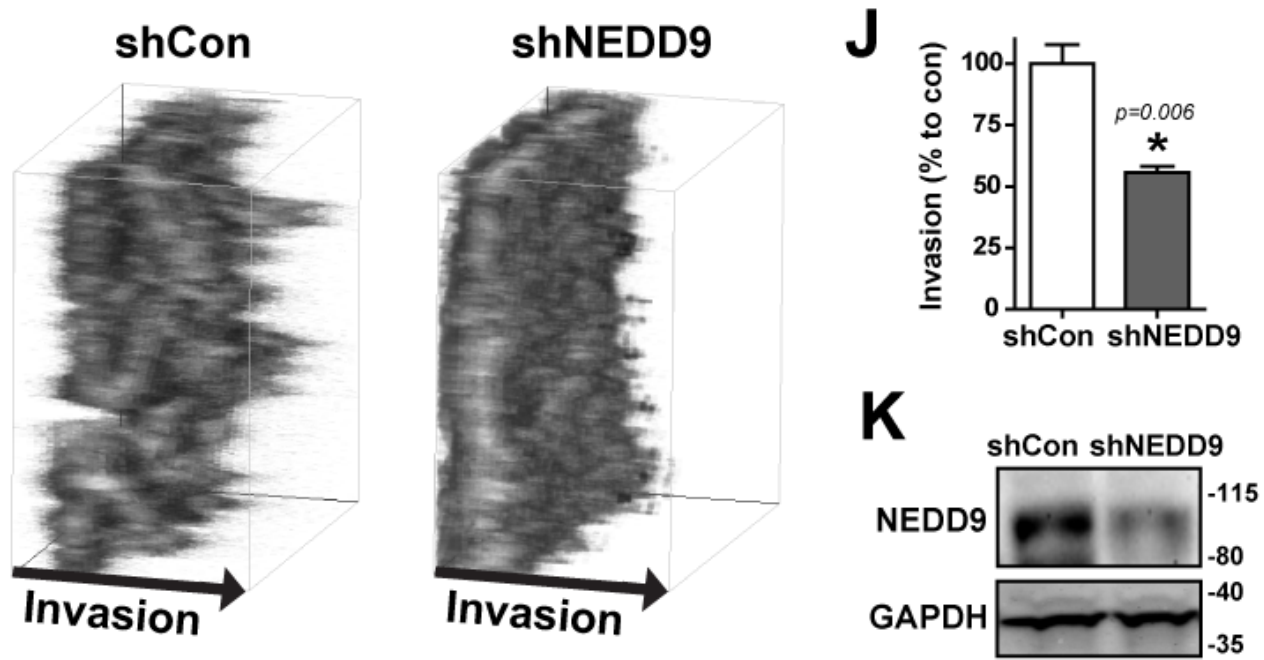

Figure 5. 

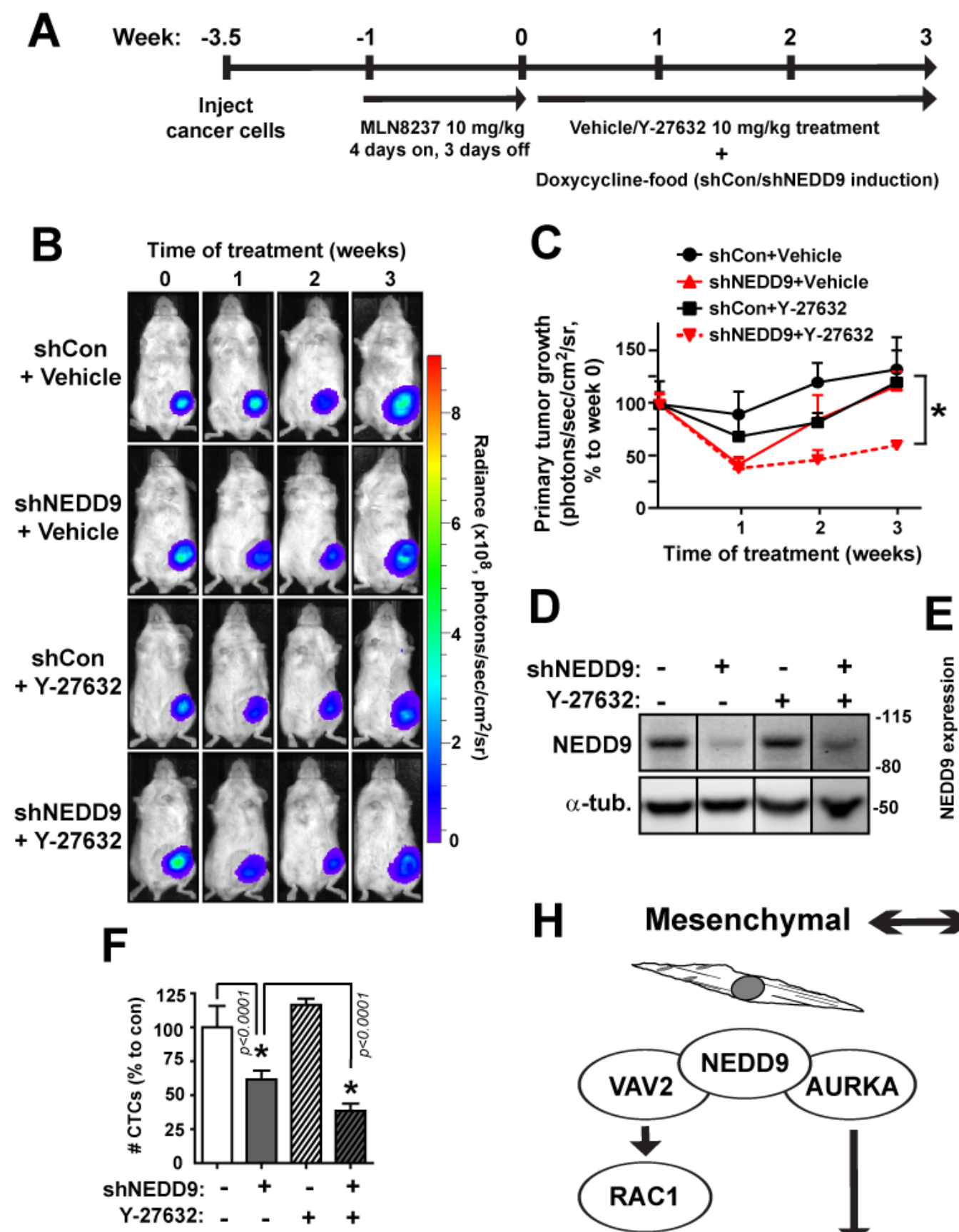

G
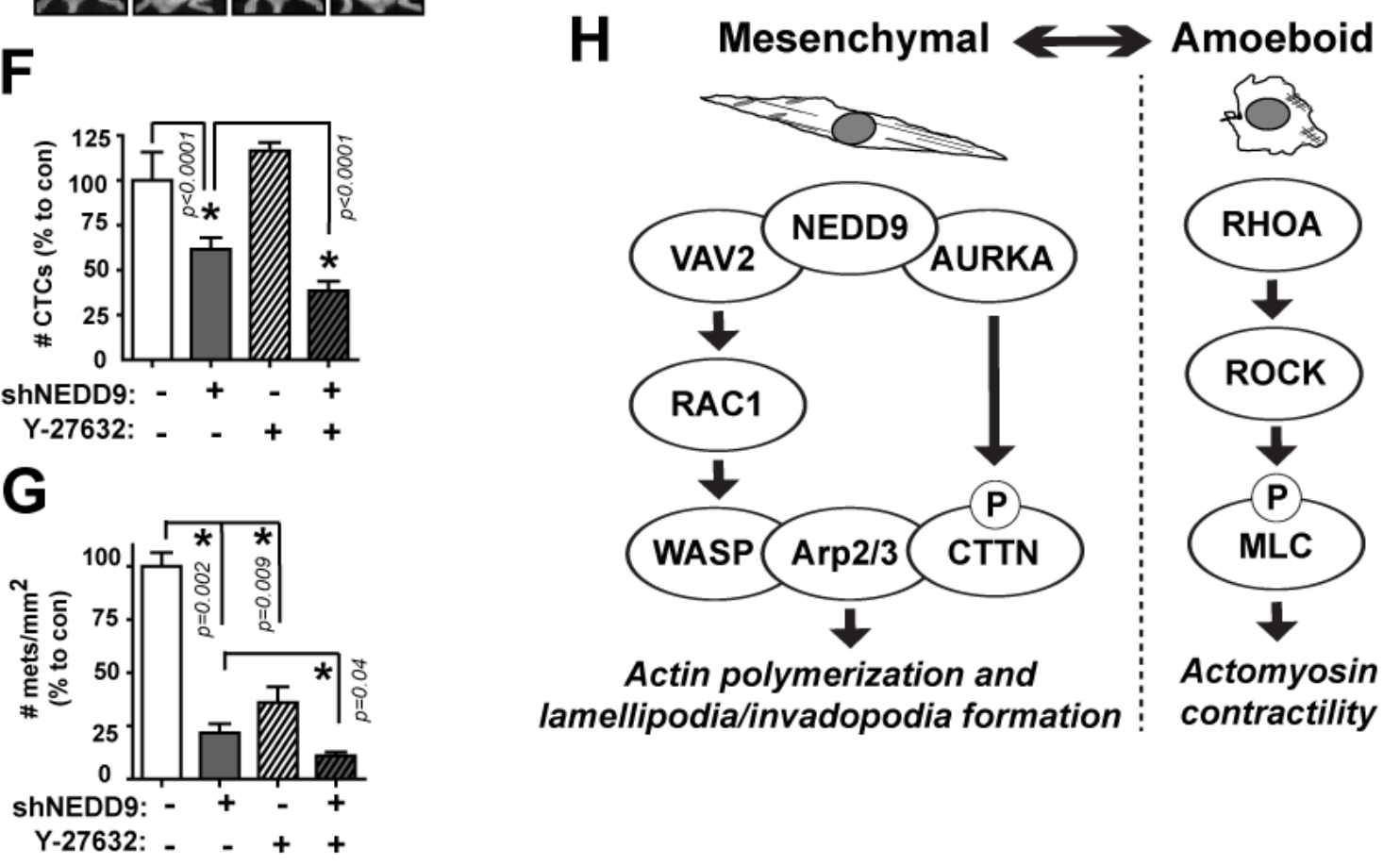

Figure 6. 


\section{Supplemental Figures}
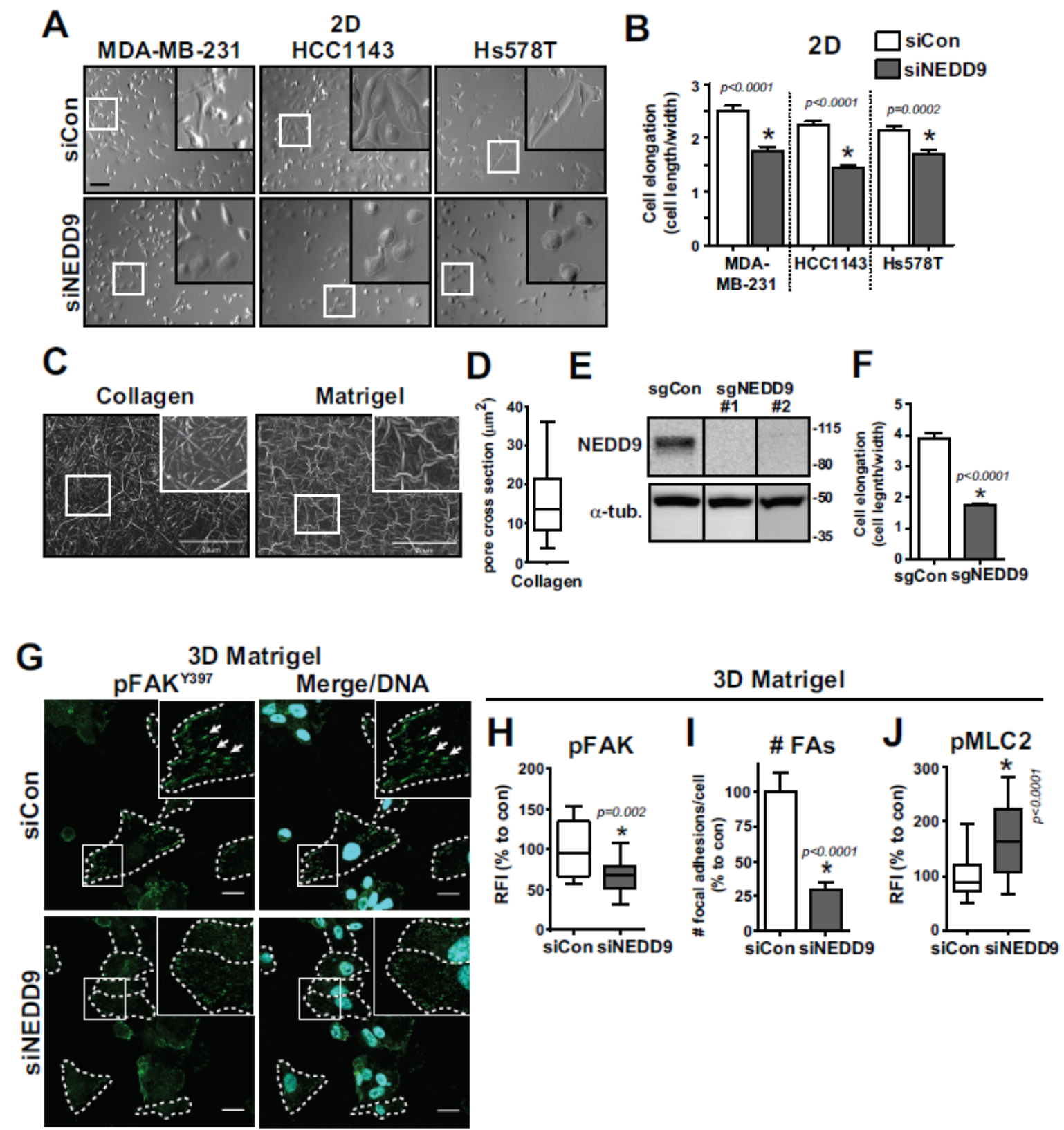

Fig. S1. NEDD9 depletion causes a switch to amoeboid morphology

(A) Brightfield images of outlined siControl and SMARTpool siNEDD9 MDA-MB-231, HCC1143, and Hs578T cells in 2D and (B) cell elongation quantified as cell length/width (at least 60-70 cells/group). (C) Scanning electron microscopy images of bovine skin collagen I and Matrigel matrices. (D) Box and whisker plot of collagen pore cross section area $(n=40$ pores). (E) Western blot of NEDD9 knockdown with two CRISPR sgRNAs in MDA-MB-231 cells. (F) Quantification of MDA-MB-231 cell elongation with SMARTpool CRISPR sgNEDD9 knockdown (at least 120 cells/group). (G) MDA-MB231 siCon and siNEDD9 cells in Matrigel stained for pFAK ${ }^{1397}$ and DNA dye. $(\mathrm{H})$ Box and whisker plot of pFAK ${ }^{\mathrm{r} 397}$ fluorescence, (I) quantification of \# of focal adhesions per cell and (J) box and whisker plot of pMLC2 fluorescence intensity in Matrigel, $n=3$, at least 30 cells/group. Scale bars, $20 \mu \mathrm{m}$. For all experiments: ${ }^{*} p<0.05$, student's $t$-test vs control. 


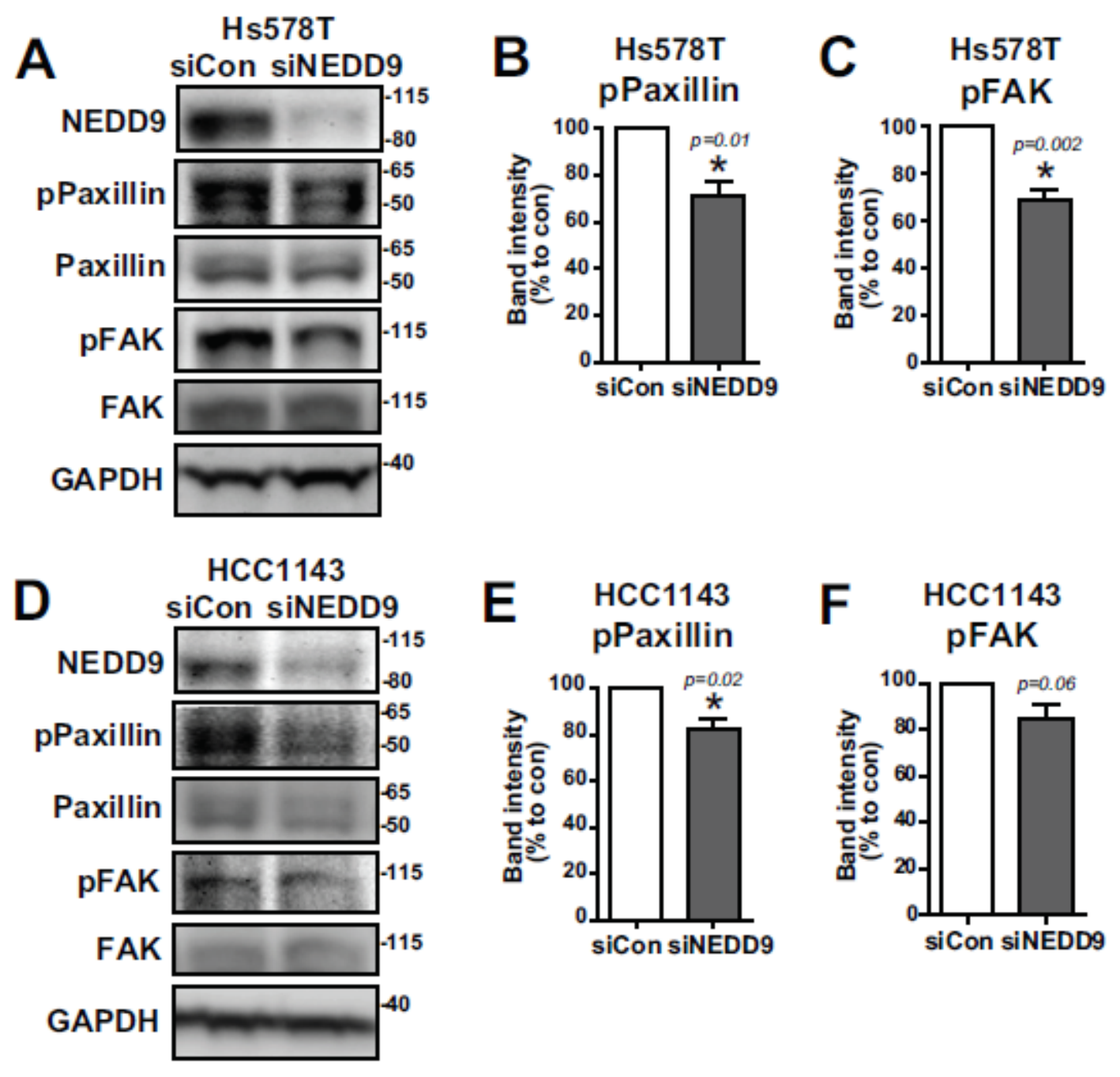

Fig. S2. NEDD9 depletion decreases phosphorylation of focal adhesion proteins in other BC cell lines

(A) Western blot and quantification of (B) $\mathrm{pFAK}^{\mathrm{r} 397}$ and (C) pPaxillin ${ }^{\gamma 31}$ phosphorylation in Hs578T breast cancer cells. (D) Western blot and quantification of (E) pFAK ${ }^{1397}$ and (F) pPaxillin ${ }^{131}$ phosphorylation in HCC1143 breast cancer cells. $n=3$. ${ }^{\star} p<0.05$, student's $t$-test vs control. 


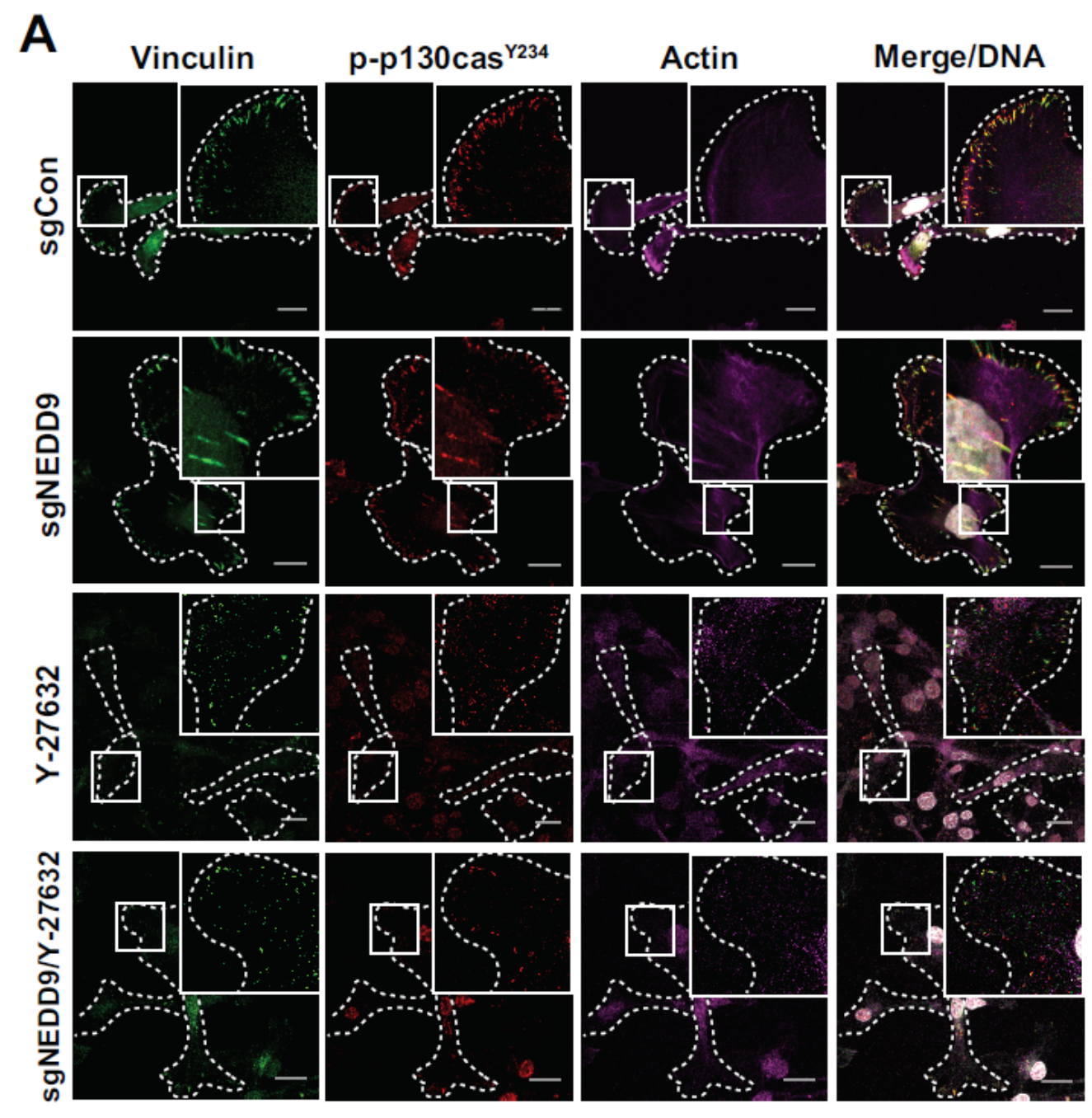

B
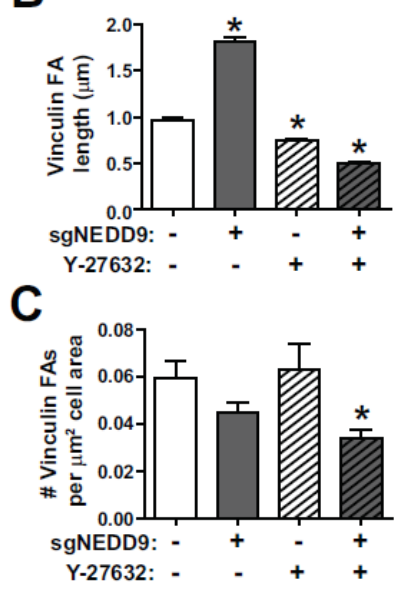

D

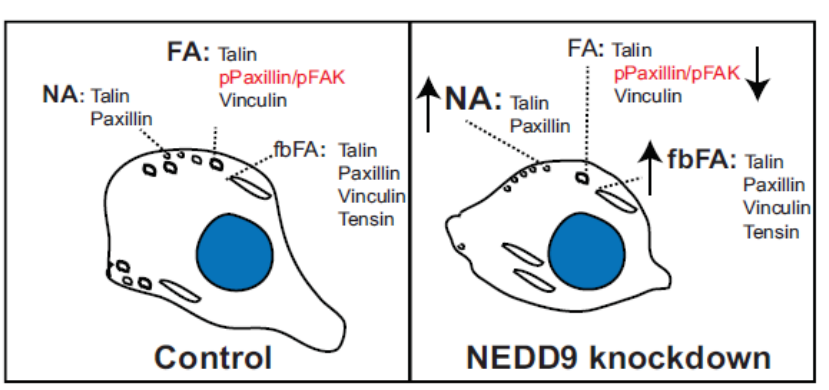

Fig. S3. NEDD9 depletion affects vinculin-containing focal adhesion dynamics

(A) MDA-MB-231 sgCon and sgNEDD9 cells +/- Y-27632 treatment stained for vinculin with additional stains for phospho-p130cas ${ }^{r 234}$, actin, and Hoechst DNA dye. Scale bars, $20 \mu \mathrm{m}$. (B) Quantification of vinculin-positive focal adhesion length. (C) Quantification of \# of vinculin-positive focal adhesions. ${ }^{*} p<0.05$, one-way ANOVA. (D) Schematic of focal adhesion maturation under NEDD9 knockdown. NA, nascent adhesion; FA, focal adhesion; fbFA, fibrillar focal adhesion. 

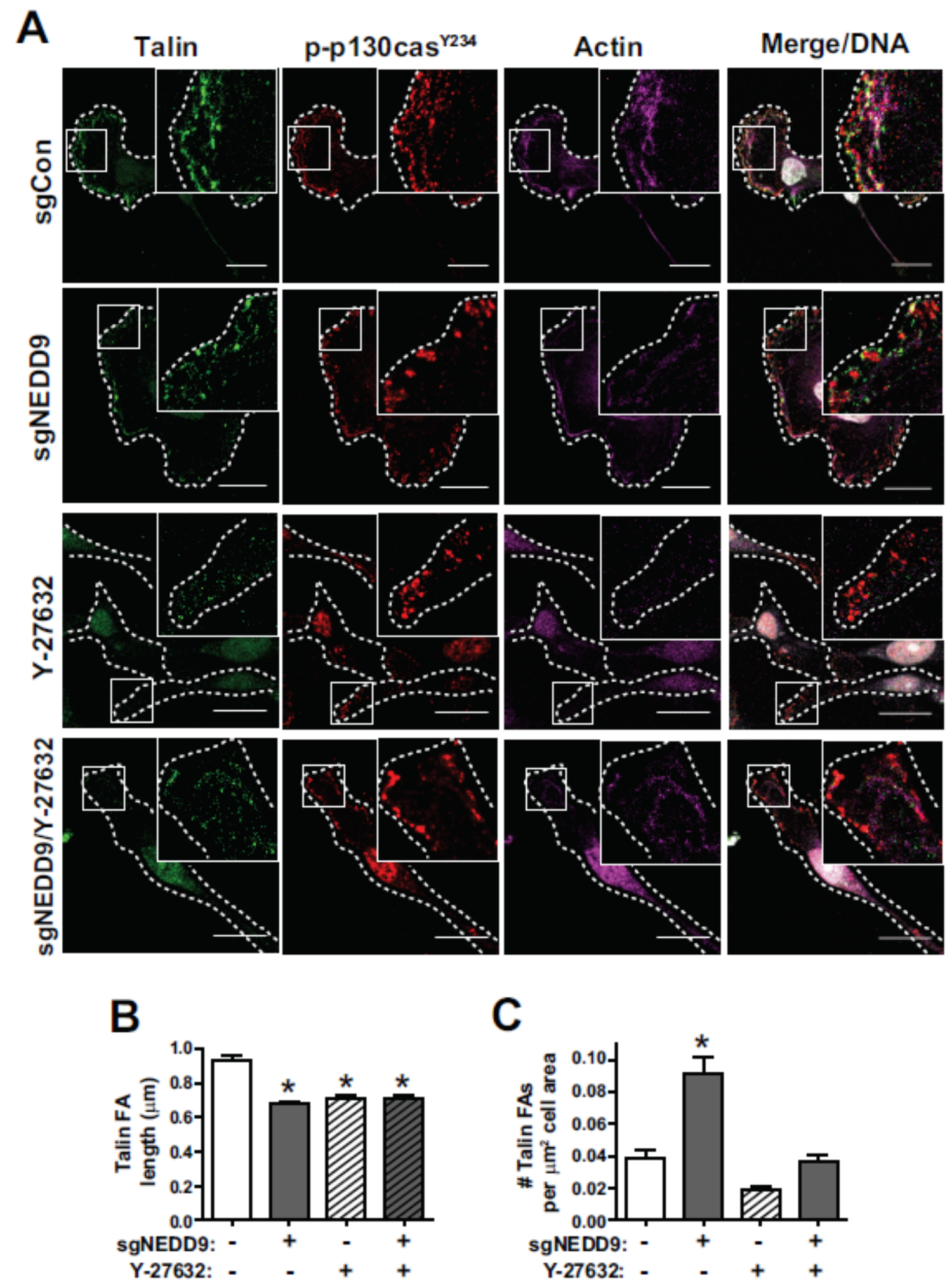

Fig. S4. NEDD9 depletion affects talin-containing focal adhesion dynamics

(A) MDA-MB-231 sgCon and sgNEDD9 cells +/- Y-27632 treatment stained for talin with additional stains for phospho-p130 cas $^{\gamma 234}$, actin, and Hoechst DNA dye. Scale bars, $20 \mu \mathrm{m}$. (B) Quantification of talin-positive focal adhesion length. (C) Quantification of \# of talin-positive focal adhesions. ${ }^{*} p<0.05$, one-way ANOVA. 


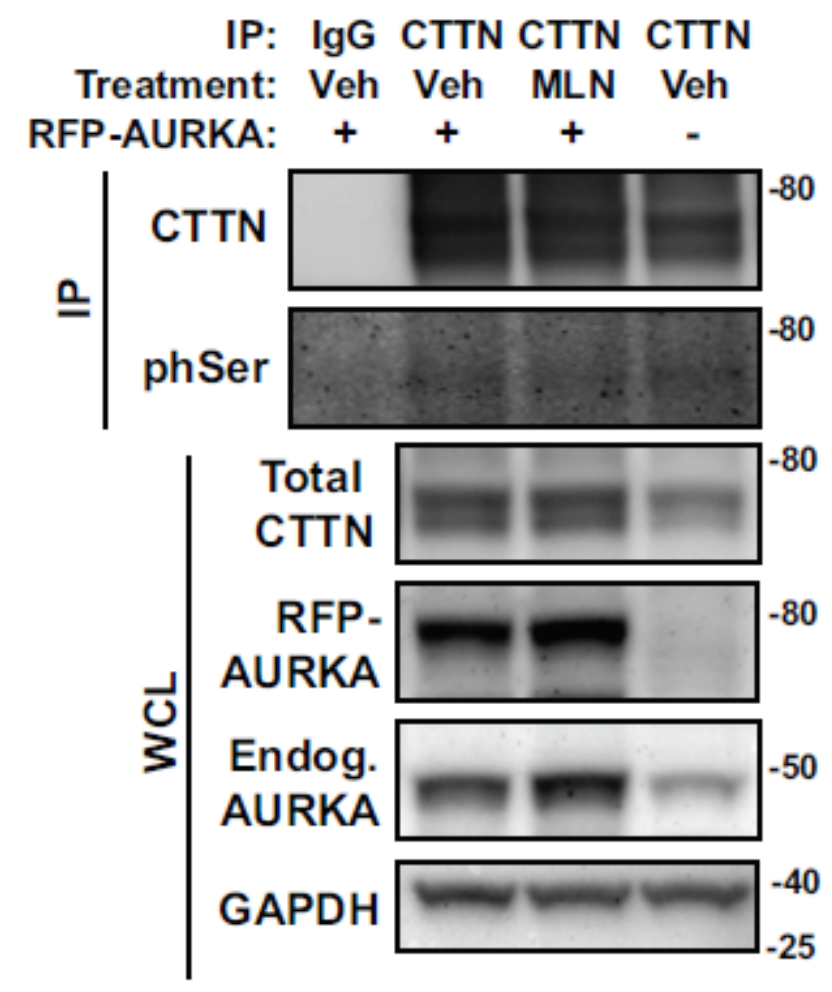

Fig. S5. AURKA phosphorylates CTTN in breast cancer cells

Immunoprecipation (IP) of CTTN with mouse monoclonal antibody (4F11) from MDA-MB-231 cells overexpressing RFP-AURKA and treated overnight with Vehicle or $100 \mathrm{nM}$ AURKA-inhibitor MLN8237. Western blotted with pan-phospho-serine antibody. IgG, mouse IgG control. WCL, whole cell lysate. Endog, endogenous. 

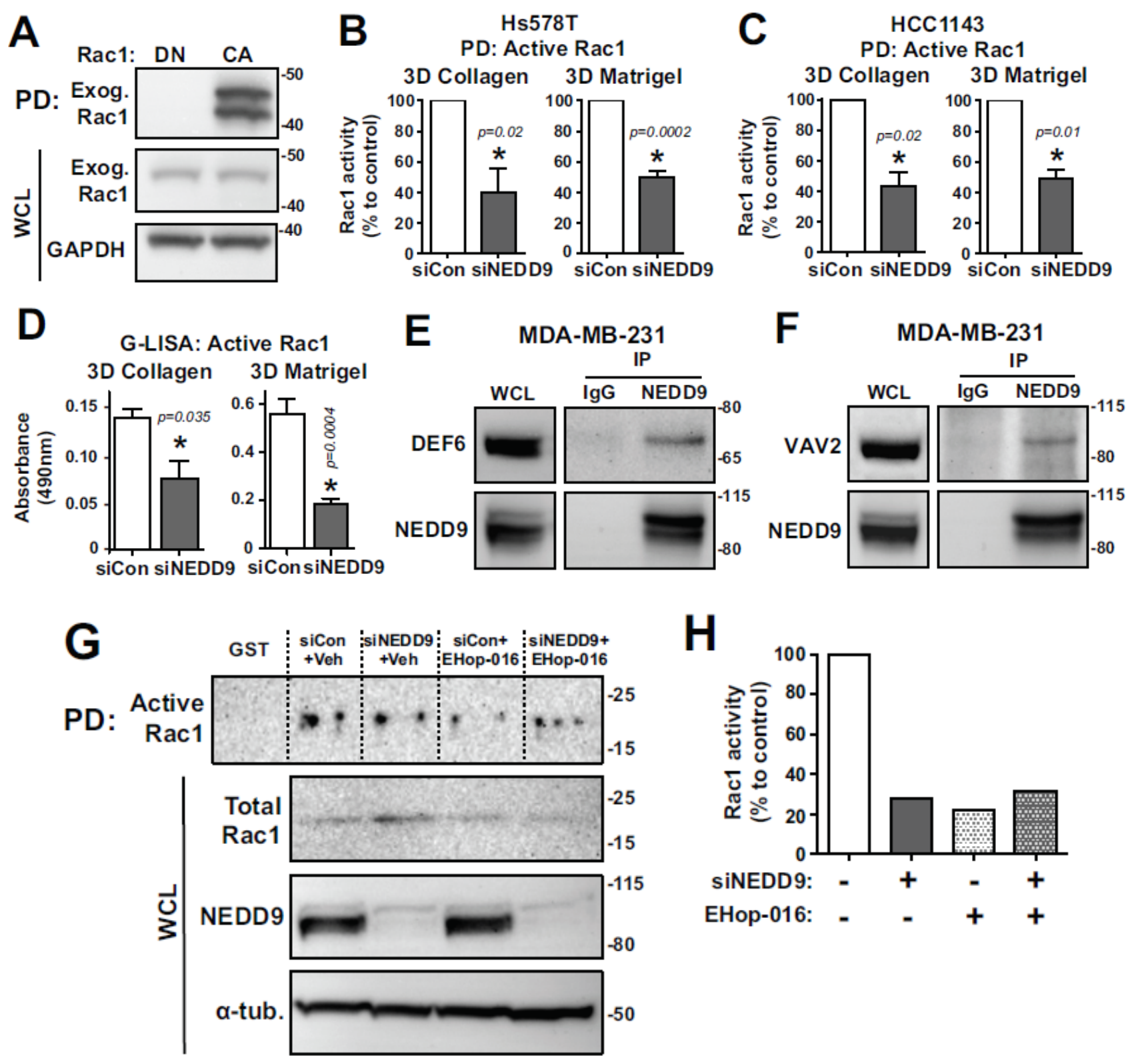

Fig. S6. NEDD9 depletion decreases Rac1 activity in other breast cancer cell lines

(A) Western blot of active-Rac1 pulldown from exogenous GST-tagged constitutively active or dominant negative Rac1-expressing MDA-MB-231 cells to show the activity specificity of GST-PBD beads. (B) Quantifications of Rac1 activity in 3D collagen and Matrigel (active/total Rac1) in pulldowns from Hs578T and (C) HCC1143 cells, $n=3$, ${ }^{*} p<0.05$, student's $t$-test vs control. (D) Quantification of Rac1 activity in 3D collagen and Matrigel by G-LISA, ${ }^{*} p<0.05$, student's $t$-test vs control. (E) Endogenous VAV2 and (F) DEF6 IPs from MDA-MB-231 cells via NEDD9 pulldown, $n=$ 3. IgG, mouse IgG control. (G) Western blot of active-Rac1 pulldown from MDA-MB-231 siCon/siNEDD9 cells + Vehicle/EHop-016 with $(\mathrm{H})$ quantification of Rac1 activity (active/total Rac1). Lane 1: GST-empty beads control. WCL, whole cell lysate. 


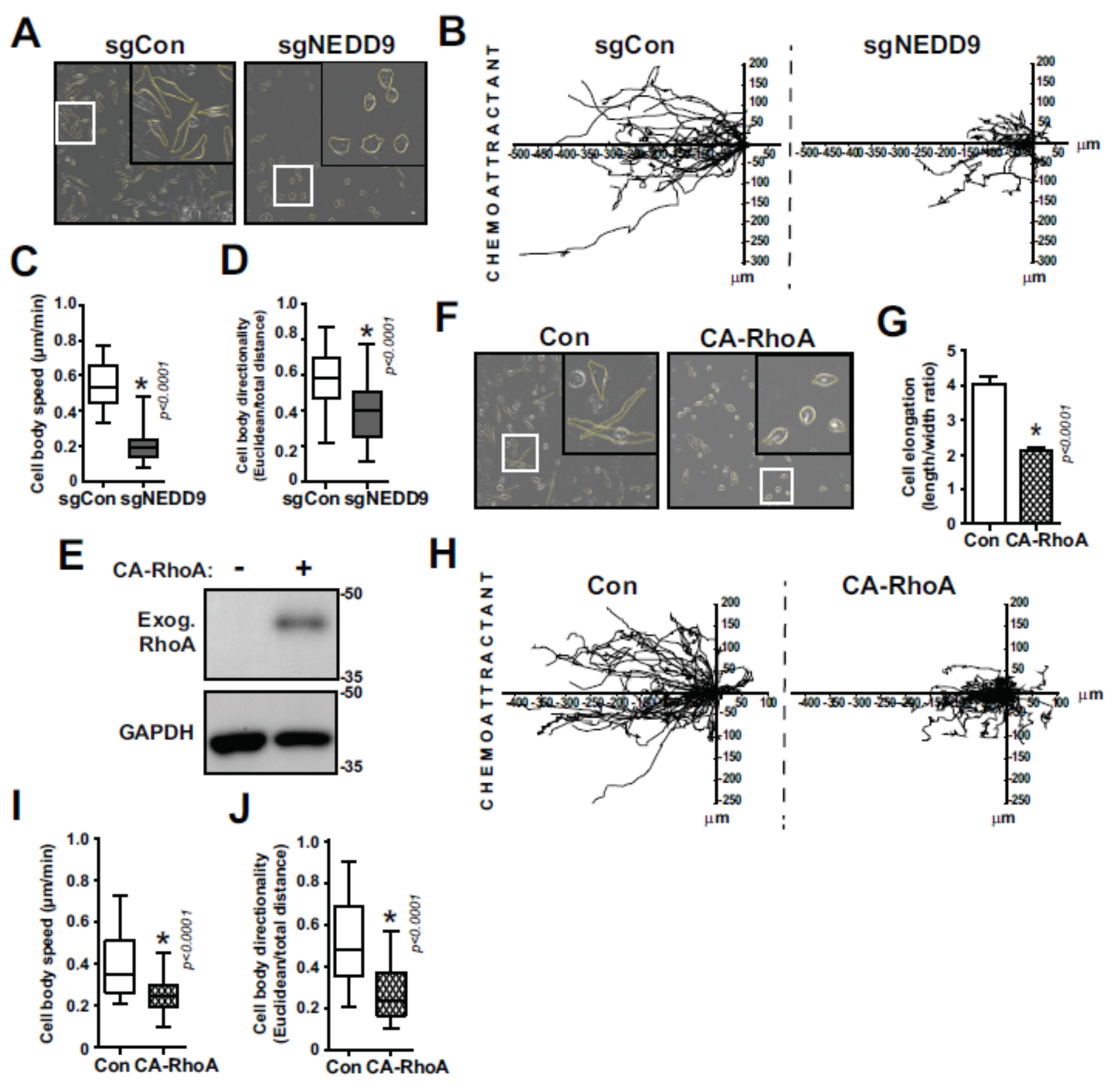

Fig. S7. Depletion of NEDD9 via CRISPR-Cas9 system and overexpression of CA-RhoA decreases cell invasion and increases round amoeboid phenotype

(A) Brightfield outlined cell morphology images ( 12 hours), (B) individual cell tracking movement plots toward FBS chemoattractant (left), and box and whisker plots of (C) cell body speed and (D) cell body directionality of MDA-MB-231 sgCon/sgNEDD9 cells in 3D collagen lbidi chemotactic invasion movies, 30-40 cells/group. (E) Western blot of exogenous CA-RhoA overexpression in MDA-MB-231 cells. (F) Brightfield outlined cell morphology images ( 12 hours), (G) box and whisker plot of cell elongation, $(\mathrm{H})$ individual cell tracking movement plots toward FBS chemoattractant (left), and box and whisker plots of (I) cell body (CB) speed and (J) cell body directionality of MDA-MB-231 control and CA-RhoA overexpressing cells in 3D collagen Ibidi chemotactic invasion movies, 30-40 cells/group. Scale bars, $20 \mu \mathrm{m}$. For all experiments: $n=3$, ${ }^{\star} p<0.05$, student's $t$-test vs control. 

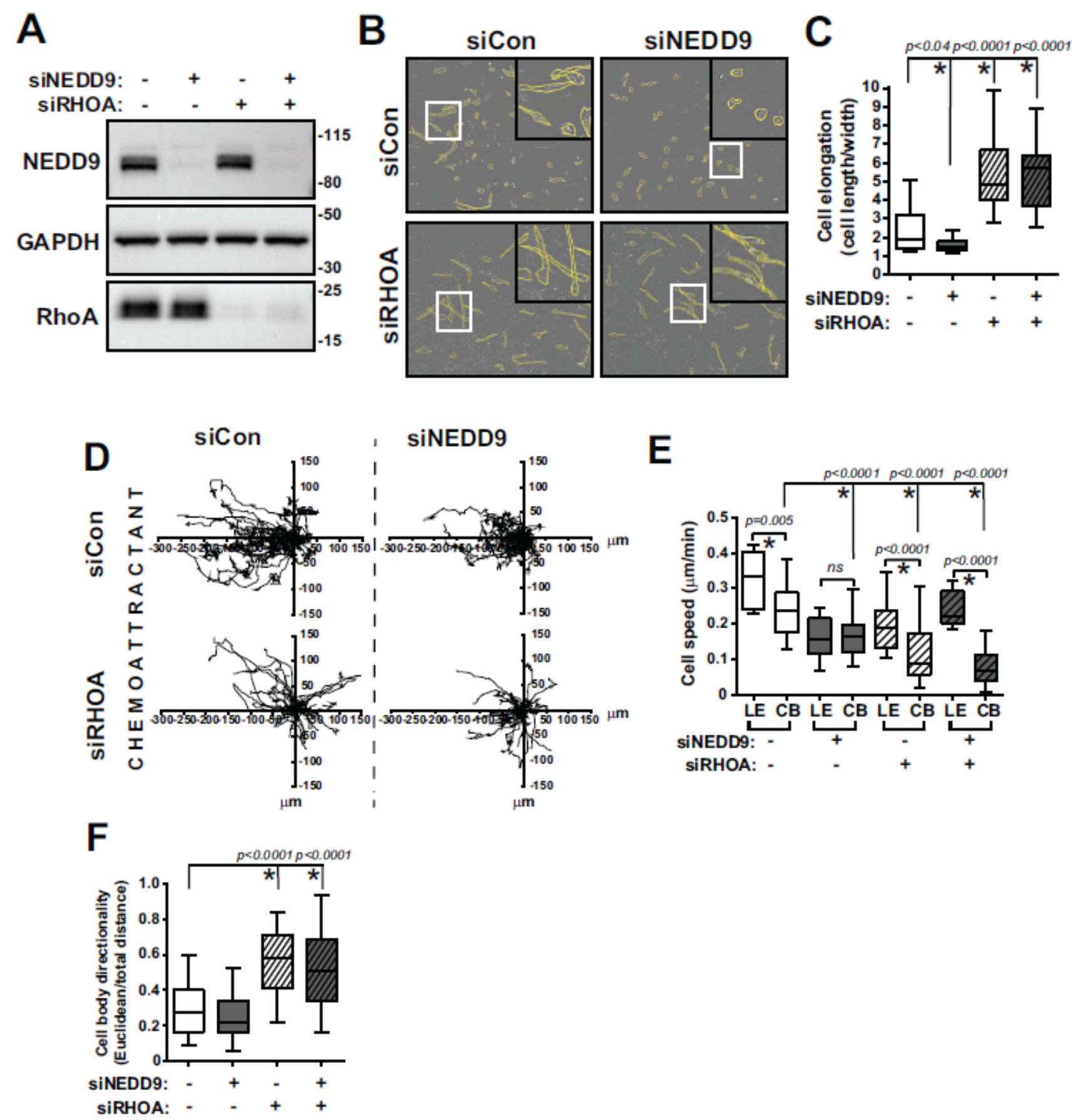

Fig. S8. Simultaneous inhibition of mesenchymal and amoeboid pathways through NEDD9 and RhoA knockdown hinders cell invasion in vitro

(A) Western blot of NEDD9 and RhoA knockdown in MDA-MB-231 cells. (B) Brightfield outlined cell morphology images ( $\sim 2$ hours), (C) box and whisker plot of cell elongation, (D) individual cell tracking movement plots toward FBS chemoattractant (left), and box and whisker plots of (E) cell body (CB) speed and (F) cell body directionality of MDA-MB-231 cells with siCon, siNEDD9, or siRhoA in 3D collagen Ibidi chemotactic invasion movies, $n=3,30-40$ cells/group. Scale bars, 20 $\mu \mathrm{m}$. ns, not significant; ${ }^{*} p<0.05$, one-way ANOVA. 


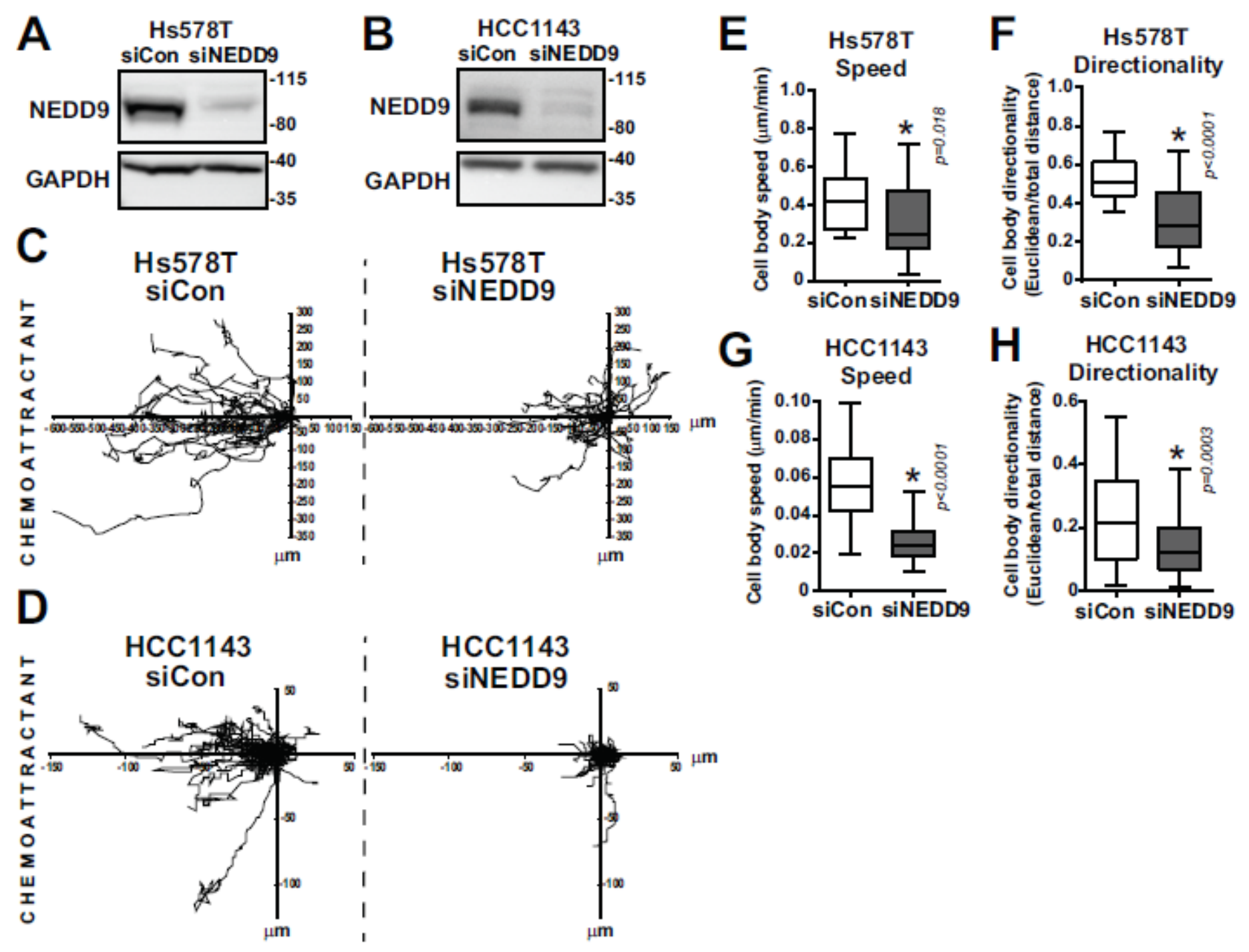

Fig. S9. Depletion of NEDD9 hinders invasion of other breast cancer cell lines in vitro

(A) Western blot of SMARTpool siNEDD9 treatment in Hs578T and (B) HCC1143 cells. (C-H) Individual cell tracking movement plots toward FBS chemoattractant (C-D, left) and box and whisker plots of cell body speed and cell body directionality of (C, E-F) Hs578T and (D, G-H) HCC1143 siCon/siNEDD9 cells in 3D collagen Ibidi chemotactic invasion movies, $n=3,30-40$ cells/group. ${ }^{*} p<0.05$, student's $t$-test vs control. 

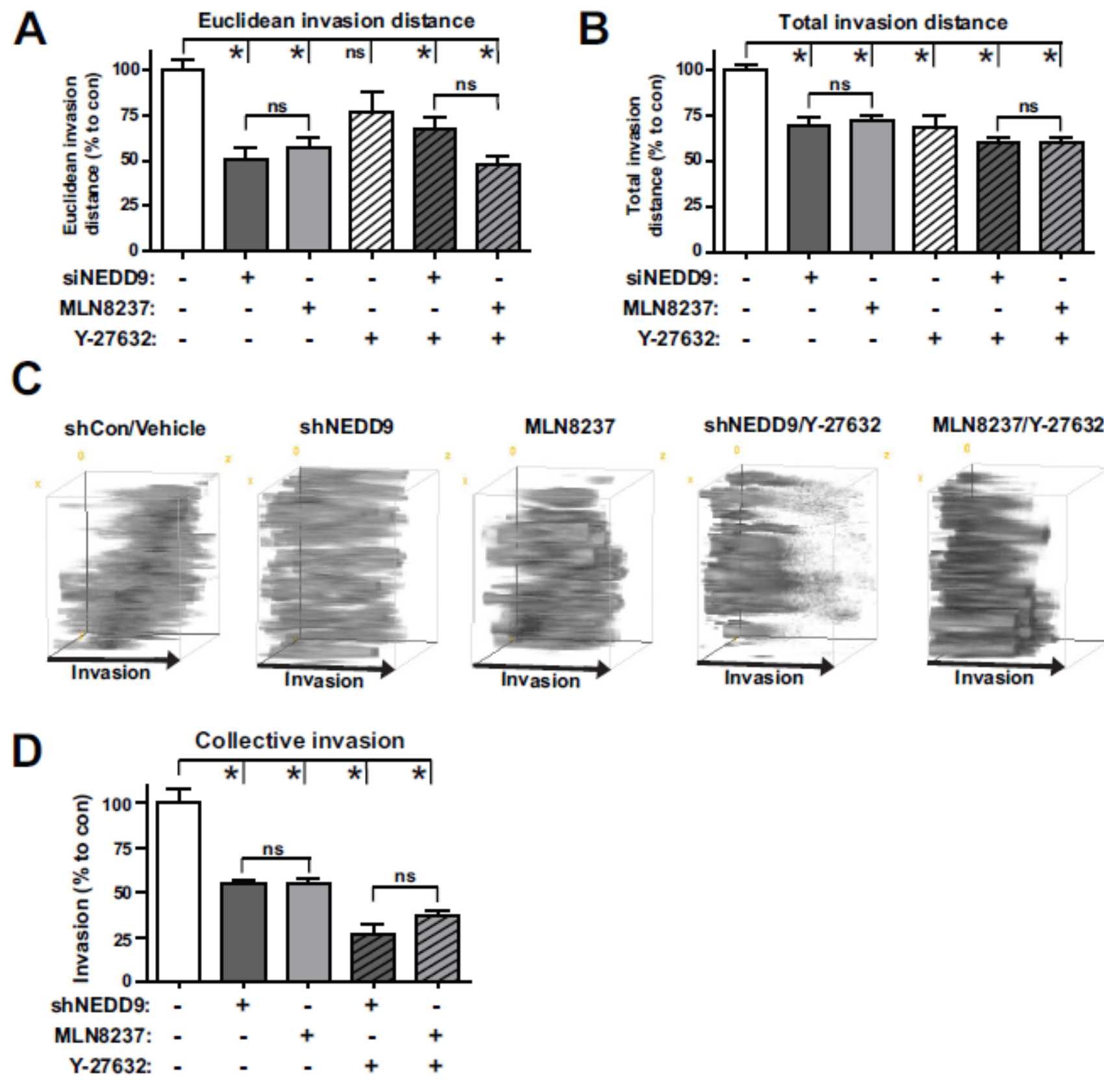

MLN8237/Y-27632

Fig. S10. AURKA inhibition hinders breast cancer cell invasion

(A) Quantification of Euclidean distance and (B) total distance invaded by MDA-MB-231 siCon/siNEDD9 cells (+/- MLN8237 and Y-27632 treatment) in 3D collagen Ibidi chemotactic individual cell invasion assays, at least 60 cells/group. ${ }^{*} p<0.05$, one-way ANOVA. (C) 3D projection boxes and (D) collective invasion quantification of the amount of MDA-MB-231 pGIPZ-GFP shControl/shNEDD9 cells (+/- MLN8237 and Y-27632 treatment) reaching $100 \mu \mathrm{m}$ invasion distance after 72 hours being densely seeded in a $3 \mathrm{D}$ matrigel sandwich assay. $n=3,{ }^{*} p<0.05$, one-way ANOVA. ns, not significant. 


\begin{tabular}{|c|c|c|}
\hline Rac1 GEF & GEF pulls NEDD9? & NEDD9 pulls GEF? \\
\hline Dock4 & No & No \\
\hline Dock180 & No & No \\
\hline VAV2 & Yes & Yes \\
\hline Tiam1 & Untested & No \\
\hline GEF-H1 & No & No \\
\hline ECT2 & No & Yes \\
\hline ARHGEF4 & No & Yes \\
\hline DEF6 & No & Yes \\
\hline ARHGEF2 & No & No \\
\hline Dbl & No & Yes \\
\hline
\end{tabular}

Table S1. Co-immunoprecipitation results of NEDD9 with multiple GEF proteins

Results from co-immunoprecipitations of exogenous NEDD9 and multiple different al Rac1 GEFs in 293T cells. Multiple GEFs were found to pull down with NEDD9 protein, but only VAV2 was found to also reciprocally co-IP NEDD9 when pulling down the GEF protein itself. 


\section{Video Legends}

Video S1. Ibidi chemotactic invasion of MDA-MB-231 cells with NEDD9 depletion and ROCK inhibition

Movie of individual MDA-MB-231 siCon/siNEDD9 cells treated with Vehicle or Y-27632 in 3D collagen manually tracked over the course of 23 hours. A serum chemoattractant-containing reservoir was present on the left side of the frame.

Video S2. Ibidi chemotactic invasion of MDA-MB-231 cells with CRISPR sgNEDD9 depletion Movie of individual MDA-MB-231 sgCon/sgNEDD9 cells in 3D collagen manually tracked over the course of 23 hours. A serum chemoattractant-containing reservoir was present on the left side of the frame.

Video S3. Ibidi chemotactic invasion of MDA-MB-231 cells with CA-RhoA overexpression Movie of individual CA-RhoA expressing MDA-MB-231 cells in 3D collagen manually tracked over the course of 23 hours. A serum chemoattractant-containing reservoir was present on the left side of the frame.

Video S4. Ibidi chemotactic invasion of MDA-MB-231 cells with NEDD9 and RhoA depletion Movie of individual MDA-MB-231 siCon/siNEDD9/siRHOA cells in 3D collagen manually tracked over the course of 23 hours. A serum chemoattractant-containing reservoir was present on the left side of the frame.

Video S5. Ibidi chemotactic invasion of Hs578T cells with NEDD9 depletion Movie of individual Hs578T siCon/siNEDD9 cells in 3D collagen manually tracked over the course of 23 hours. A serum chemoattractant-containing reservoir was present on the left side of the frame.

Video S6. Ibidi chemotactic invasion of HCC1143 cells with NEDD9 depletion Movie of individual HCC1143 siCon/siNEDD9 cells in 3D collagen manually tracked over the course of 46 hours. A serum chemoattractant-containing reservoir was present on the left side of the frame. 
Video S7. Ibidi chemotactic invasion of MDA-MB-231 cells with AURKA and ROCK inhibition Movie of individual MDA-MB-231 cells treated with MLN8237 or Y-27632 in 3D collagen manually tracked over the course of 23 hours. A serum chemoattractant-containing reservoir was present on the left side of the frame.

Video S8. Collective invasion of MDA-MB-231 cells with NEDD9 depletion

Movie of collective invasion of densely seeded MDA-MB-231 pGIPZ-GFP shCon/shNEDD9 cells in 3D Matrigel manually tracked over the course of 24 hours. 


\section{Supplemental Materials and Methods}

\section{RNAs and plasmids}

pGIPZ and pTRIPZ-shControl/NEDD9 shRNAs (ThermoFisher Scientific), Control siRNA (Bioneer and Origene), NEDD9 siRNA (2-siRNA SMARTpool of 1: Dharmacon \#D-019466-22 and 2: \#D-019466-23), RhoA siRNA (3-siRNA SMARTpool: Origene \#SR300278A, SR300278B, and SR300278C), and VAV2 siRNA (3-siRNA SMARTpool: Origene \#SR305062A, SR305062B, and SR305062C) were used based on manufacturers' recommendations. lentiCRISPRv2 plasmid was a gift from Feng Zhang (Addgene plasmid \#52961) (1). NEDD9 sgRNA (sequence \#1: GTACCCATCCAGATACCAAA, \#2: TGTGGAGGATGAGTTCCGGG) was designed using Broad Institute sgRNA Designer online tool and subcloned into lentiCRISPRv2 as described (2). pEGFP-C3Rac1-T17N dominant negative (DN), pEYFP-C1-Rac1-Q61L constitutively active (CA), and pEGFPC3-RhoA-Q63L (CA) plasmids were a gift from Dr. Michael Schaller (West Virginia University). pGSTparallel2-CTTN-WT, pGST-parallel2-CTTN-Nterm-1-350, and pGST-parallel2-CTTN-Cterm-350-546 were a gift from Dr. Scott Weed (West Virginia University). pDEST/LifeAct-mCherry-N1 was a gift from Robin Shaw (Addgene plasmid \#40908) (3). pGEX-6P-1 (Amersham) and pGEXTK-Pak1 70-117 (gift from Jonathan Chernoff, Addgene plasmid \#12217) plasmids were used to produce GST-control and GST-Pak1 binding domain (PBD) proteins respectively for pulldowns. pcDNA3-FLAG-NEDD9 and pcDNA3.1-mRFP-NEDD9 were previously reported (4). pC.HA Vav2 was a gift from Joan Brugge (Addgene plasmid \# 14554) (5). YF-Tiam1 was a gift from Tobias Meyer (Addgene plasmid \# 20154) (6). ARHGEF2 (GE Healthcare), DEF6 (PlasmID), ARHGEF4 (PlasmID), and Dbl (gift from Dr. Xosé Bustelo, University of Salamanca-CSIC) were subcloned into pcDNA3.1-6HA vector. pCEV32F3ECT2 plasmid was a gift from Dr. Toru Miki (Nagaoka University of Technology). pCMV5-HA3-GEFH1 plasmid was a gift from Dr. Celine de Mardirossian (The Scripps Research Institute). The indicated above plasmids or RNAs were introduced via nucleofection (Amaxa) according to manufacturer's recommendation or virus infection (293T packaging cells, LifeTechnologies) as previously described 
(7).

\section{Matrix pore size analysis}

Confocal reflection microscopy: The lattice of $1.5 \mathrm{mg} / \mathrm{ml}$ 3D bovine skin collagen I (Advanced BioMatrix) was imaged using confocal reflection microscopy (Zeiss-LSM510, 63X objective with $2 \mu \mathrm{m}$ steps) as previously described (8). The images were rendered as a 3D projection using ImageJ software (NIH) (9) and pore size was quantified by manually outlining visible holes in the lattice to calculate cross sections.

Scanning electron microscopy: $1.5 \mathrm{mg} / \mathrm{ml}$ collagen and $4 \mathrm{mg} / \mathrm{ml}$ Matrigel (Corning) were fixed with glutaraldehyde and dehydrated with increasing ethanol. Matrices were then dried and sputtered for 120 seconds with a Denton Desk V Sputter. Samples were imaged using a Hitachi S-4700F scanning electron microscope.

\section{Western blotting}

Samples were prepared in Laemmli buffer, resolved in Bolt 4-12\% Bis-Tris/Novex acrylamide gel (LifeTechnologies), transferred onto $0.45 \mu \mathrm{m}$ PVDF membrane (Millipore), and blocked with 5\% milk or bovine serum albumin in PBS or TBS with 0.05\% Tween-20 (Fisher). Antibodies used included:

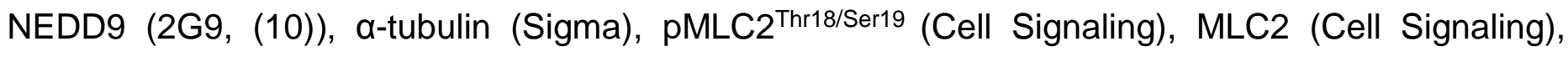
pPaxillin ${ }^{\Upsilon 31}$ (Biosource), paxillin (Calbiochem), pFAK ${ }^{\Upsilon 397}$ (Calbiochem), FAK (Calbiochem), AURKA (AurA-N, custom (4)), CTTN (4F11, gift from Dr. Scott Weed, West Virginia University), CTTN (H-191, Santa Cruz), pan-phospho-serine (Zymed), Rac1 (Cytoskeleton), RhoA (Cell Signaling), GAPDH (Millipore), VAV2 (Santa Cruz), DEF6 (Santa Cruz), HA-tag (Cell Signaling), Flag-tag (Cell Signaling), and HRP-conjugated anti-rabbit/anti-mouse (Jackson ImmunoResearch). Protein bands were detected with HyGLO chemiluminescent HRP detection reagent (Denville), imaged (Syngene G:Box), and quantified using GeneTools 4.01 software from Syngene as previously described (7).

\section{Immunofluorescence}

In addition to antibodies already described for WB, additional antibodies/stains used for IF 
included Rhodamine-Phalloidin (Cytoskeleton), Vinculin (Santa Cruz), Talin (Santa Cruz), Tensin (gift from Dr. Michael Schaller, West Virginia University), p-p130cas ${ }^{\Upsilon 234}$ (Open Biosystems), Alexa Fluor 647-phalloidin (Invitrogen), anti-rabbit or anti-mouse Alexa Fluor 488/555/647-IgG (Jackson ImmunoResearch), and Hoechst-33342 DNA dye (LifeTechnologies). Coverslips were mounted using ProLong anti-fade reagent (LifeTechnologies) and imaged using a Zeiss-LSM510 microscope and $63 \mathrm{X}$ objective and rendered as 3D projections using ImageJ software. Relative fluorescence intensity $(\mathrm{RFI})$ was measured as the mean gray value per cell area in ImageJ. Focal adhesion length was measured and the number of adhesions was counted per cell and normalized to the total cell area.

\section{Immunoprecipitation and western blot of cortactin phosphorylation in cells}

AURKA overexpression was induced with doxycycline overnight in MDA-MB-231 pLUTZmRFP-AURKA cells and then treated for 24 hours with 100nM MLN8237. Cells were lysed with PTY lysis buffer and processed as previously described (10). Lysates were precleared with protein-A/Gsepharose (GE Healthcare) for 1 hour at $4^{\circ} \mathrm{C}$. Mouse IgG control or anti-CTTN (4F11) antibodies were added to precleared lysates overnight rotating at $4^{\circ} \mathrm{C}$. Protein-A/G-sepharose beads preblocked with bovine serum albumin were added to the rotating tubes for 2 hours. Beads were allowed to settle for 15 minutes on ice, then washed three times with PTY buffer. Beads were resuspended in Laemmli buffer and boiled at $100^{\circ} \mathrm{C}$ to elute proteins for gel electrophoresis and western blotting. Pan-phosphoserine antibody (Zymed) was used to stain for cortactin phosphorylation on the WB and total cortactin was stained with another cortactin specific antibody (H-191, Santa Cruz).

\section{Quantification of cell invasion movies}

Cell elongation was measured as a function of cell length to cell width at the midpoint of the movies to give cells adequate time to adapt to their surroundings and capture their morphology during invasion. Cell body and leading edge speeds were calculated by manually tracking physical movement of either the main cell body or the protruding/retracting leading edge using MTrackJ plugin for ImageJ (11). Cell body directionality was measured from the tracking data as a function of Euclidean distance 
from the initial starting point over the total distance traveled. Individual cell movement tracking plots were made using help from Ibidi Chemotaxis and Migration Tool software. 


\section{Supplemental References}

1. Sanjana NE, Shalem O, Zhang F. Improved vectors and genome-wide libraries for CRISPR screening. Nat Methods. 2014;11(8):783-4. doi: 10.1038/nmeth.3047. PubMed PMID: 25075903; PMCID: PMC4486245.

2. Shalem O, Sanjana NE, Hartenian E, Shi X, Scott DA, Mikkelsen TS, Heckl D, Ebert BL, Root DE, Doench JG, Zhang F. Genome-scale CRISPR-Cas9 knockout screening in human cells. Science. 2014;343(6166):84-7. doi: 10.1126/science.1247005. PubMed PMID: 24336571; PMCID: PMC4089965.

3. Smyth JW, Vogan JM, Buch PJ, Zhang SS, Fong TS, Hong TT, Shaw RM. Actin cytoskeleton rest stops regulate anterograde traffic of connexin 43 vesicles to the plasma membrane. Circ Res. 2012;110(7):978-89. doi: 10.1161/CIRCRESAHA.111.257964. PubMed PMID: 22328533; PMCID: PMC3621031.

4. Kozyreva VK, McLaughlin SL, Livengood RH, Calkins RA, Kelley LC, Rajulapati A, Ice RJ, Smolkin MB, Weed SA, Pugacheva EN. NEDD9 regulates actin dynamics through cortactin deacetylation in an AURKA/HDAC6-dependent manner. Mol Cancer Res. 2014;12(5):681-93. doi: 10.1158/1541-7786.MCR-13-0654. PubMed PMID: 24574519; PMCID: 4020952.

5. Moores SL, Selfors LM, Fredericks J, Breit T, Fujikawa K, Alt FW, Brugge JS, Swat W. Vav family proteins couple to diverse cell surface receptors. Mol Cell Biol. 2000;20(17):6364-73. PubMed PMID: 10938113; PMCID: PMC86111.

6. Inoue T, Heo WD, Grimley JS, Wandless TJ, Meyer T. An inducible translocation strategy to rapidly activate and inhibit small GTPase signaling pathways. Nat Methods. 2005;2(6):415-8. doi: 10.1038/nmeth763. PubMed PMID: 15908919; PMCID: PMC3579513.

7. Loskutov YV, Kozyulina PY, Kozyreva VK, Ice RJ, Jones BC, Roston TJ, Smolkin MB, Ivanov AV, Wysolmerski RB, Pugacheva EN. NEDD9/Arf6-dependent endocytic trafficking of matrix 
metalloproteinase 14: a novel mechanism for blocking mesenchymal cell invasion and metastasis of breast cancer. Oncogene. 2014. doi: 10.1038/onc.2014.297. PubMed PMID: 25241893.

8. Wolf K, Te Lindert M, Krause M, Alexander S, Te Riet J, Willis AL, Hoffman RM, Figdor CG, Weiss SJ, Friedl P. Physical limits of cell migration: control by ECM space and nuclear deformation and tuning by proteolysis and traction force. J Cell Biol. 2013;201(7):1069-84. doi: 10.1083/jcb.201210152. PubMed PMID: 23798731; PMCID: 3691458.

9. Artym VV, Matsumoto K. Imaging cells in three-dimensional collagen matrix. Curr Protoc Cell Biol. 2010;Chapter 10:Unit 108 1-20. doi: 10.1002/0471143030.cb1018s48. PubMed PMID: 20853341; PMCID: PMC2988473.

10. Pugacheva EN, Golemis EA. The focal adhesion scaffolding protein HEF1 regulates activation of the Aurora-A and Nek2 kinases at the centrosome. Nat Cell Biol. 2005;7(10):937-46. PubMed PMID: 16184168.

11. Meijering E, Dzyubachyk O, Smal I. Methods for cell and particle tracking. Methods Enzymol. 2012;504:183-200. doi: 10.1016/B978-0-12-391857-4.00009-4. PubMed PMID: 22264535. 


\section{CHAPTER 3: SUMMARY}

The work detailed in this dissertation uncovers significant insights into the mechanisms and therapeutic viability of inhibiting NEDD9-driven mesenchymal migration and invasion in combination with amoeboid pathway targeting. Triple negative breast cancer has remained an extremely prevalent and deadly cancer with minimal treatment options available for patients, especially for those patients who are metastatic. Metastasis from the primary tumor site is the most life threatening aspect of TNBC, making the inhibition of cancer cell movement an ideal treatment strategy in order to stop its spread to distant organs.

In this project, we report a novel relationship between NEDD9 and the Rac1 GEF VAV2 in breast cancer, where NEDD9 expression contributes to Rac1 activation in a VAV2-dependent manner. This VAV2-Rac1 signaling cascade in combination with another NEDD9-driven signaling network through AURKA-HDAC6-CTTN, both of which contribute to actin polymerization dynamics and subsequent lamellipodia/invadopodia formation, makes NEDD9 a prime therapeutic target to downregulate mesenchymal movement. In addition, we report the novel finding that NEDD9 inhibition by itself seems to hinder aspects of both mesenchymal and amoeboid migration phenotypes. These cells lose many mesenchymal characteristics and gain an amoeboid-like phenotype - becoming more rounded, losing large mature focal adhesions and gaining nascent adhesions, and increasing phosphorylation of myosin light chain. Nevertheless, while appearing amoeboid, they are functionally reduced by not translating these amoeboid features into increased cell contractility in collagen gel assays. This may be linked to some disruption between the myosin motors and actin filaments or a deficiency in adhesion disassembly - future work on this topic will be interesting to pursue.

Furthermore, we report that inhibition of NEDD9 causes a severe decrease in breast cancer cell invasion, pulmonary metastases, and circulating tumor cells in the mouse blood stream, which can be exacerbated even further through simultaneous treatment with ROCK- 
targeting compounds. Similar results in invasion inhibition were obtained through targeting of AURKA and RhoA proteins. Combination of such treatments, which impede critical components of both mesenchymal and amoeboid pathways, yields cells with very long morphology that have thin needle-like leading edge protrusions and lagging cell rears, possibly due to reduced MMP activation in the front and a deficiency in rear cell contractility to bring the cell forward. These results highlight the potential for NEDD9 as a promising new therapeutic target, and additionally, highlights the dual pathway inhibition strategy as a viable and encouraging approach which merits further study for its possible application into clinical trials for human breast cancer patients. 